\title{
Phenolic Compounds Exerting Lipid-Regulatory, Anti-Inflammatory and Epigenetic Effects as Complementary Treatments in Cardiovascular Diseases
}

\author{
Laura Toma $^{1}$, Gabriela Maria Sanda ${ }^{1}$, Loredan Stefan Niculescu ${ }^{1}$, Mariana Deleanu ${ }^{1,2}$, \\ Anca Volumnia Sima ${ }^{1}$ and Camelia Sorina Stancu ${ }^{1, *}$ \\ 1 Lipidomics Department, Institute of Cellular Biology and Pathology "Nicolae Simionescu" of the Romanian \\ Academy, 8, B.P. Hasdeu Street, 050568 Bucharest, Romania; laura.toma@icbp.ro (L.T.); \\ gabriela.sanda@icbp.ro (G.M.S.); loredan.niculescu@icbp.ro (L.S.N.); mariana.deleanu@icbp.ro (M.D.); \\ anca.sima@icbp.ro (A.V.S.) \\ 2 Faculty of Biotechnology, University of Agronomical Sciences and Veterinary Medicine, 59, Marasti Blvd., \\ 011464 Bucharest, Romania \\ * Correspondence: camelia.stancu@icbp.ro
}

Received: 30 March 2020; Accepted: 17 April 2020; Published: 21 April 2020

check for updates

\begin{abstract}
Atherosclerosis is the main process behind cardiovascular diseases (CVD), maladies which continue to be responsible for up to $70 \%$ of death worldwide. Despite the ongoing development of new and potent drugs, their incomplete efficacy, partial intolerance and numerous side effects make the search for new alternatives worthwhile. The focus of the scientific world turned to the potential of natural active compounds to prevent and treat CVD. Essential for effective prevention or treatment based on phytochemicals is to know their mechanisms of action according to their bioavailability and dosage. The present review is focused on the latest data about phenolic compounds and aims to collect and correlate the reliable existing knowledge concerning their molecular mechanisms of action to counteract important risk factors that contribute to the initiation and development of atherosclerosis: dyslipidemia, and oxidative and inflammatory-stress. The selection of phenolic compounds was made to prove their multiple benefic effects and endorse them as CVD remedies, complementary to allopathic drugs. The review also highlights some aspects that still need clear scientific explanations and draws up some new molecular approaches to validate phenolic compounds for CVD complementary therapy in the near future.
\end{abstract}

Keywords: cardiovascular diseases; inflammation; lipid metabolism; non-coding RNA; oxidative stress; phenolic compounds

\section{Introduction}

Cardiovascular diseases (CVD) continue to be the leading cause of mortality and morbidity worldwide, despite the various therapies developed for their treatment, therapies that have an important global economic impact [1,2]. The main cause of CVD is atherosclerosis, a multifactorial disorder induced and augmented by risk factors such as dyslipidemia, oxidative and inflammatory stress, diabetes mellitus, hypertension, smoking, ageing and genetic mutations [3]. Many therapies designed to treat atherosclerosis either have failed completely or partially (cholesteryl ester transfer protein (CETP) inhibitors, antioxidants, vitamins), or were too expensive to be applied to the entire population at CVD risk (apoA-I Milano); others, though successful, induced considerable side-effects (statins) $[4,5]$. Thus, the quest for strategies to prevent or treat CVD is of high and continued interest. 
In the last decade the scientific researchers turned their attention to phytochemicals, as effective, safe and low-cost natural bioactive compounds for CVD treatment.

Dyslipidemia consists of increased blood concentrations of total cholesterol (TC), low density lipoproteins-cholesterol (LDL-C) and/or triglycerides (TG), and decreased high density lipoproteins-cholesterol (HDL-C) [6]. The lipid metabolism is complex and the candidate mechanisms that could generate dyslipidemia include: (i) excessive dietary lipid absorption in the small intestine; (ii) packing of exogenous lipids with cholesterol and fatty acids produced de novo in the liver and their secretion as very low density lipoproteins (VLDL); (iii) hydrolysis of TG from VLDL by lipases and their conversion into LDL, which are taken up by the peripheral tissues through LDL receptor (LDL-R) and scavenger receptors; (iv) diminished production of HDL by the liver and small intestine, thereby decreasing reverse cholesterol transport (RCT) from the peripheral tissues to the liver; (v) lowered excess cholesterol excretion from the liver into gallbladder or to the intestinal lumen through the ATP-binding cassette G5 and G8 transporters (ABCG5/G8) that facilitate trans-intestinal cholesterol efflux (TICE). Dyslipidemia is associated with the accumulation of LDL in the sub-endothelium of the artery wall. At this site, LDL undergoes oxidative modifications (oxLDL) that trigger inflammatory responses, and is taken up by the monocyte-derived macrophages infiltrated in the sub-endothelium which thus become lipid-loaded foam cells, the hallmark of atheroma development [7]. Until now, the most effective lipid-lowering treatment for hyperlipidemic patients was the statin therapy. But recent recommendations have extended it to the asymptomatic adults at low cardiovascular risk (Systematic COronary Risk Evaluation $<1 \%$ ) and with lower LDL-C levels $(<4.9 \mathrm{mmol} / \mathrm{L})$, according to their levels of predicted CVD risk [8]. This extension will be accompanied by a higher number of subjects manifesting side effects and the need for replacement of the statin therapy with new effective and better tolerated medication.

Under physiological conditions, reactive oxygen species (ROS) are generated in low concentrations and serve as mediators that regulate vascular function $[9,10]$. Increased generation of ROS, due to the increased production of free radicals or paucity of antioxidants, generates oxidative stress and causes peroxidation of cellular lipids and lipoproteins that contribute to CVD progression [11]. Oxidative stress affects the bioavailability of nitric oxide (NO), an important vascular relaxing factor. When the endothelial nitric oxide synthase (eNOS) is uncoupled, NO and the superoxide radicals react and generate the oxidizing peroxynitrite anions, thereby inducing endothelial dysfunction [12]. Mitochondria control cell energy production and the respiratory cycle, processes closely related to oxidative stress [13]. To counteract or prevent the detrimental effect of ROS, numerous antioxidant systems have been developed, such as glutathione, flavonoids, superoxide dismutase (SOD), catalase, glutathione peroxidase (GSH-Px) and hemeoxygenase-1 (HO-1) [14]. The nuclear erythroid 2-related transcription factor (Nrf2) is redox-sensitive and plays an important role in regulating the production of the antioxidant enzymes [15]. Under physiological conditions, the enzyme paraoxonase 1 (PON1) accounts for HDL antioxidant properties, while the pro-oxidant enzyme myeloperoxidase (MPO) becomes attached to HDL under hyperlipidemic conditions [16]. In the last few decades, the quality and function of HDL became a consistent indicator of CVD risk $[17,18]$. Under augmented oxidative stress, HDL becomes dysfunctional, presenting an increased number of MPO molecules that replace the PON1 molecules $[17,19]$. Thus, dysfunctional HDL can no longer protect LDL from oxidation, these alterations being the key risk factors for initiation and progression of the atherosclerotic plaques.

Exposure of endothelial cells (EC) to risk factors induces their activation which consists in the production of pro-inflammatory molecules such as selectins (E-selectin, P-selectin, L-selectin), and of adhesion molecules, such as intracellular adhesion molecule 1 (ICAM-1) and vascular cell adhesion 1 (VCAM-1) promoting monocyte adhesion and their transmigration into the sub-endothelium $[20,21]$. The macrophages produce pro-inflammatory cytokines, such as interleukin-1 $\beta$ (IL-1 $\beta$ ), IL-12 and tumor necrosis factor- $\alpha$ (TNF- $\alpha$ ), or chemokines, such as monocyte chemoattractant protein-1 (MCP-1) to attract more monocytes, thereby stimulating the inflammatory process [22]. A central role in the stimulation of the inflammatory stress in atherosclerosis is played by the nuclear factor kappa B 
(NF-kB) [23]. A strong inhibitor of NF- $\mathrm{kB}$ is sirtuin-1 (SIRT-1), and toll-like receptor 4 (TLR4) is an activator of NF-kB [21,24]. Another important pro-inflammatory intracellular protein complex is the nucleotide binding and domain-like receptor 3 (NLRP3) inflammasome, which stimulates the primary pro-inflammatory response determining the activation of the secondary inflammatory mediators, such as IL-6 or C reactive protein (CRP), thereby amplifying the inflammatory stress [25].

Since the completion of the Human Genome Project, it has become evident that several additional mechanisms related to epigenomic, transcriptomic, epitranscriptomic, proteomic and metabolomic regulations are crucial for determinations of the phenotypes of many human disorders, including CVD [26]. The emerging non-coding RNAs (ncRNAs) have major regulatory roles in gene expression, and thus could function as potential targets for personalized treatment of CVD patients [27-29]. They can be divided into small ncRNAs ( $<200 \mathrm{nt})$, such as microRNA (miRNAs), transfer RNAs and small nucleolar RNAs, and longer ncRNAs (lncRNA), that include ribosomal and natural antisense transcripts. Members of a class of small ( $22 \mathrm{nt}) \mathrm{ncRNA}$, single stranded in mature form miRNAs have been identified as potent post-transcriptional regulators of genes, including those involved in lipid metabolism [30]. MiRNAs control their target gene's expression by either imperfect base pairing to $3^{\prime}$ untranslated regions ( $3^{\prime}$ UTR) of mRNA [31] or by binding to other regions, including $5^{\prime}$ UTRs or protein-coding exons [32], thereby inducing the repression of their target mRNAs. Circulating miRNAs are found in the blood closely associated with proteins, lipoproteins and extracellular vesicles (EVs) [33]. The levels of circulating miRNAs vary and have specific profiles in diverse pathophysiological states [34,35], leading to the possibility of using these molecules as promising markers for diagnosis and prognosis [36,37]. Published studies demonstrate that plasma miRNAs may be used as markers in the diagnosis of myocardial infarction [38], while EVs and HDL-associated miRNAs levels can discriminate between stable and vulnerable coronary artery disease patients [39-41]. It was reported that circulating and hepatic miRNAs expression could be modulated by hypolipidemic dietary interventions, such as probiotics administration [42]. For all these reasons, miRNAs could be very useful targets in nutritional science and could be used to test the pathways modulated by dietary treatments in healthy and/or diseased populations [43].

Phytochemicals such as phenolic compounds have been extensively studied, and important data exist on their use in CVD patients. In the present review we aim to focus on the molecular mechanisms of action that prove the multiple benefic effects of the phenolic compounds and endorse them as CVD remedies, complementary to allopathic drugs. We explore the active compounds that effectively target dyslipidemia, and oxidative and inflammatory stress, the main risk factors in atherosclerosis evolution. Thus, we discuss below the representative compounds for which a consistent number of mechanisms of action have been described. They belong to the following groups: hydroxycinnamic acids (curcumin, caffeic acid), stilbenes (resveratrol), flavonols (quercetin), flavones (apigenin, luteolin), flavanones (naringenin, hesperetin), flavanols (catechins, gallocatechins), isoflavones (genistein), anthocyanins/anthocyanidines and guaiacols (gingerols, shogaols).

\section{Biologically Active Phenolic Compounds and Their Mechanisms of Action}

Phytochemicals are biologically active compounds from plants that can regulate physiological and pathological processes with benefic consequences for human health. Phenolic compounds are one of the largest groups of phytochemicals. Their bioavailability is decisive to exerting beneficial effects in vivo and is influenced by the molecular size and complexity of their chemical structure, including conjugation with other phenols, polymerization, glycosylation, acylation or hydroxylation [44].

\subsection{Hydroxycinnamic Acids Group}

Curcumin (diferuloylmethane) (Figure 1) is the most important bioactive compound from Curcuma longa, belonging to the Zingiberaceae family. The curcuminoids comprise several compounds, such as curcumin, desmethoxycurcumin and bis-demethoxy-curcumin. The source of curcumin is turmeric, a yellow-colored spice [45]. Pharmacokinetic studies revealed that curcumin is poorly soluble in 
water; has low absorption in the gut, rapid metabolism and systemic elimination, and consequently, has low bioavailability after oral administration. The clinical efficacy of curcumin could be improved by formulations that enhance its solubility and stability and diminish the first-pass metabolism. To that end, certain strategies have been elaborated, such as the development of curcumin-piperine complexes, curcumin nanoparticles, cyclodextrin inclusions, curcumin liposomes and curcumin phospholipids' complexes, part of these systems exhibiting a 100-fold increase of bioavailability relative to unformulated curcumin [46].

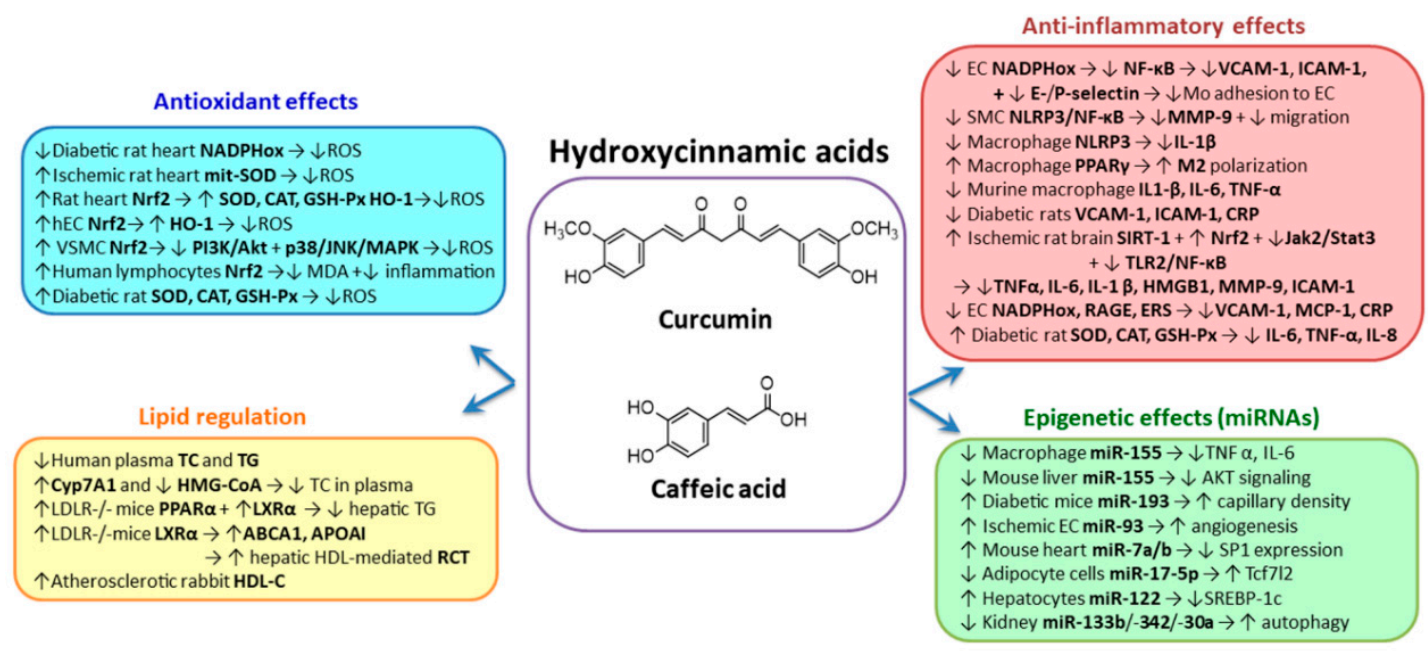

Figure 1. Chemical structure and protective effects exerted by curcumin and caffeic acid to improve cardiovascular diseases outcomes as demonstrated by experimental and clinical evidence.

In vitro and in vivo studies demonstrate curcumin's pleiotropic effects, due to its ability to interact with numerous molecular targets in different cell types. The anti-atherogenic potential of curcumin consists in its capacity to lower blood cholesterol and TG in healthy subjects ( $80 \mathrm{mg} /$ day for 4 weeks) [47]. It is reported that turmeric inhibits LDL oxidation in atherosclerotic rabbits and increases serum HDL-C levels in diabetic rats [48]. The hypolipidemic effect of curcumin is based on the inhibition of the intestinal cholesterol absorption and increased activity of cholesterol-7alpha-hydroxylase (CYP7A1), the rate-limiting enzyme in the synthesis of bile acids [48]. In addition, curcumin inhibits 3-hydroxy-3-methyl-glutaryl-coenzyme A (HMG-CoA) reductase. Administration of 0.02\% w/w curcumin for 18 weeks to $1 \mathrm{dlr}^{-/-}$mice fed a high-cholesterol diet induces an inhibition of the hepatic TG accumulation by upregulation of peroxisome proliferator-activated receptors alpha (PPAR $\alpha)$ and liver $X$ receptor alpha (LXR $\alpha)$ expression [49]. PPAR $\alpha$ is an important activator of fatty acid oxidation and inhibitor of hepatic fatty acid synthase (FAS) activity. $\mathrm{LXR} \alpha$ regulates the gene expression of the key enzyme involved in cholesterol conversion to bile acid (CYP7A1), and increases expression of liver apolipoprotein A-I (apoA-I) and ATP-binding cassette A1 (ABCA1), which facilitates the HDL-mediated RCT [50]. It is known that an increase of $1 \mathrm{mg} / \mathrm{dL}$ in HDL-C level reduces coronary heart disease risk by $2-3 \%$, and CVD mortality risk by $3.7-4.7 \%$ [51].

The antioxidant action of curcumin resides in the inhibition of ROS production by repressing the catalytic subunits p67phox, p47phox and p22phox of nicotinamide adenine dinucleotide phosphate (NADPH) oxidase [52,53]. In parallel, curcumin reduces ROS by upregulating the expression of endogenous antioxidant enzymes, such as SOD, catalase, GSH-Px and HO-1 [54,55]. Another interesting mechanism by which curcumin exerts antioxidant effects is the preservation of the mitochondrial redox potential [13] that has been evidenced in vivo in rat hearts subjected to ischemia-reperfusion. Curcumin pretreatment increases mitochondrial SOD activity and decreases mitochondrial $\mathrm{H}_{2} \mathrm{O}_{2}$ and malondialdehyde (MDA) levels [13]. HO-1 is an enzyme activated by oxidative stress which reduces inflammation by inhibiting the expression of endothelial adhesion molecules [56]. It was reported that 
curcumin can induce HO-1 in TNF- $\alpha$-treated EA.hy926 cells in a dose-dependent manner and through activation of the transcription factor Nrf2. It also decreases ICAM-1 expression in a mouse model of lung injury [57,58]. As in EC, in vascular smooth muscle cells (SMC) curcumin activates Nrf2 which increases aldose reductase, an important enzyme that reduces oxidative stress in phosphatidylinositol 3-kinase (PI3K)/protein kinase B (Akt) and p38 mitogen-activated protein kinase (p38 MAPK)/c-Jun $N$-terminal kinase (JNK)-dependent manners [59]. These effects of curcumin on Nrf2 pathway have also been seen in human clinical trials involving patients with type 2 diabetes mellitus who each received an oral dose of curcumin of $500 \mathrm{mg} /$ day for 15-30 days. This treatment induced an upregulation of Nrf2 in lymphocytes that controls other proteins, such as $\mathrm{NAD}(\mathrm{P}) \mathrm{H}$ quinone dehydrogenase 1 (NQO1), reduces inflammatory markers, and reduces plasma MDA levels [60]. In addition, curcumin supplementation of the diet increases $\mathrm{NO}$ bioavailability and inhibits the expression of pro-oxidative NADPH oxidase 2 (NOX-2) enzyme in rats [61]. Curcumin inhibits NF- $\mathrm{BB}$ and further decreases the expression of pro-inflammatory cytokines such as TNF- $\alpha$, IL-1 $\beta$ and IL-6 both in vitro and in vivo [62].

There is growing interest in using curcumin to reduce vascular disease, in part due to its demonstrated anti-inflammatory effects. Using the in vitro model of TNF- $\alpha$-activated EC, it was demonstrated that curcumin reduces the expression of VCAM-1, ICAM-1, E-selectin [63], fraktalkine and P-selectin [64], thereby inhibiting significantly monocyte adhesion through mechanisms involving the reduction of NADPH oxidase activation and consequently of the intracellular ROS production [64]. These results were confirmed in a recent study by Monfoulet et al., who demonstrated that curcumin pre-exposure reduces endothelial permeability and monocyte adhesion in both static and flow conditions [65]. In addition, most of the in vitro and in vivo studies confirm that curcumin administration determines the lowering of MCP-1 levels by downregulation of the MAPK and NF- $\mathrm{BB}$ signaling pathway [66-68]. The anti-inflammatory effects of curcumin on EC inflammatory markers were demonstrated also in vivo in various animal models. Tsai et al. evidenced the decrease of VCAM-1, ICAM-1 and CRP levels after curcumin supplementation to rats fed with a high-sucrose and high fat diet. The mechanisms that determine the improvement of the vascular function in this animal model involved an enhanced $\mathrm{NO}$ production and a reduction of the oxidative stress due to the increase of antioxidant enzyme activities [69]. SMC, an important component of the vascular wall, participates in the characteristic inflammatory process of atherosclerosis. In an in vitro study, Han et al. demonstrated that migration of human aortic SMC isolated from spontaneously hypertensive rats (SHR) or normal rats exposed to angiotensin II (AngII) was significantly inhibited by curcumin through the reduction of NLRP3/NF- $\mathrm{kB}$ signaling pathway [70]. The results were confirmed in vivo; it was demonstrated that administration of curcumin in SHR reduced intima-media thickness due to the inhibition of NF-KB and NLRP3 inflammasome and matrix metallopeptidase 9 (MMP-9) expression [70,71]. Yin et al. showed that curcumin inhibited caspase-1 activation and IL-1 $\beta$ secretion through suppressing lipopolysaccharide (LPS) priming and NLRP3 inflammasome in mouse bone marrow-derived macrophages, and confirmed these results in vivo in a model of high-fat diet-induced insulin resistance in wild-type C57BL/6 mice [72]. Interestingly, in an in vitro study, Chen et al. demonstrated that curcumin inhibits the M1 inflammatory phenotype of RAW264.7 macrophages as a result of the direct activation of the inhibitor protein $k \mathrm{~B}-\alpha(\mathrm{IkB}-\alpha)$ and polarizes the macrophages to become anti-inflammatory M2 phenotype through the activation of PPAR $\gamma$ [73]. Later on, the same group reported that curcumin dramatically reduced oxLDL-induced IL-1 $\beta$, IL- 6 and TNF- $\alpha$ cytokine production in M1 derived from M0 RAW264.7 macrophages [74].

In vivo studies demonstrated the benefic effects of curcumin to reduce the inflammatory burden present in the ischemia/reperfusion (I/R) in different organs by modulating the expression of different signaling pathways. In the brain tissue of rats after cerebral ischemia, curcumin decreased TNF- $\alpha$ and IL-6 levels via activation of SIRT-1 [75]; reduced TNF- $\alpha$, IL-1 $\beta$, IL-6, and high mobility group box 1 (HMGB1) by inhibition of the Janus kinase 2 (JAK2)/signal transducers and activator of transcription 3 (STAT3) signaling pathway [76]; and inhibited ICAM-1 and MMP-9 by downregulating NF-kB and elevating Nrf2 [77] or reduced TNF- $\alpha$ and IL-1 $\beta$ by inhibiting the TLR2/4/NF-kB signaling pathway [78]. 
It was reported that curcumin inhibits the activation of JNK and activator protein 1 (AP-1) transcription factor, and also the phosphorylation and degradation of IкB- $\alpha$ [79].

In a recent meta-analysis that proposed to evaluate the therapeutic effect of curcumin in mouse models of atherosclerosis, Lin et al. found that curcumin significantly decreases the aortic atherosclerotic lesion area, and the serum lipid levels (TC, TG and LDL-C) and inflammatory markers (TNF- $\alpha$ and IL-1 $\beta$ ) [80]. In addition, Lin et al. highlighted the dose-response relation between curcumin and its protective effect on atherosclerosis, showing that the effect on decreasing the aortic lesion area is stronger in low and medium dosages $(<207 \mathrm{mg} / \mathrm{kg}$ BW/day) and weaker when the dose was more than $207 \mathrm{mg} / \mathrm{kg} \mathrm{BW/day,} \mathrm{becoming} \mathrm{pro-atherogenic} \mathrm{when} \mathrm{the} \mathrm{dose} \mathrm{reached} 347 \mathrm{mg} / \mathrm{kg}$ BW/day [80]. Clinical trials focusing on curcumin effects in atherosclerosis progression gave dissimilar results, some of them evidencing that curcumin has no effect on risk factors of atherosclerosis $[81,82]$, while others reporting an atheroprotective effect of curcumin by improvement of the lipidic profile in patients with metabolic syndrome, patients taking curcumin extract capsules (630 mg thrice daily) for 12 weeks [83]. In a pilot study, Panahi et al. demonstrated that administration of curcuminoids ( $500 \mathrm{mg} /$ day, for 4 weeks) to subjects with pulmonary problems reduces the inflammatory mediators' expression: IL-6, IL-8, TNF- $\alpha$, transforming growth factor $\beta$ (TGF- $\beta$ ), high sensitivity C-reactive protein (hsCRP) and MCP-1 [84]. There are many studies supporting the anti-inflammatory properties of curcumin; however, of great importance is the establishment of a proper treatment with regard to the dose and time of administration.

To improve curcumin stability in vivo, different types of nanocarriers have been described for encapsulation. Thus, lipid nanoemulsions loaded with curcumin and functionalized with a cell-penetrating peptide were better taken up and internalized by human EC compared to the non-functionalized lipid nanoemulsions. This formulation of curcumin demonstrated anti-inflammatory effects by reducing the monocytes adhesion to TNF- $\alpha$ activated human EC [85].

In the last decade, published data evidenced that some phenolic compounds are able to perform a fine-tuning regulation of the mechanisms underlying oxidative and inflammatory stress by modulating the expression of epigenetic factors associated with RNA function, such as ncRNAs. Accordingly, recent in vitro and in vivo experiments showed that specific miRNAs mediate the molecular mechanisms affected by curcumin. Thus, treatment of murine Raw264.7 and human THP-1 macrophages with curcumin significantly reduced miR-155 expression through the modulation of PI3K/Akt pathway [86]. In the same report, septic mice obtained by LPS intraperitoneal injection were treated orally with curcumin, and a significant reduction of miR-155 expression and Akt phosphorylation in the liver and kidney was observed [86]. In a recent in vivo study of Zhang et al., mice with peripheral arterial disease (PAD) and a normal glycaemic profile were treated with curcumin [87]. They reported that curcumin treatment improved perfusion recovery, increased capillary density and increased miR-93 expression in ischemic muscle tissue. Moreover, in cultured EC under simulated ischemia, curcumin improved cell viability and enhanced tube formation. These data proved that curcumin may have beneficial effects in non-diabetic PAD by improving angiogenesis, which may have been achieved partially via the promotion of miR-93 expression [87]. In another in vivo experiment, after curcumin administration, C57BL/6 mice were subjected to left anterior descending coronary artery occlusion [88]. Geng et al. showed that curcumin administration significantly reduced the infarct size compared with control animals, increased miR-7a/b expression and downregulated the expression of transcription factor specific protein 1 (SP1). In hypoxia-induced mouse cardiac myocytes (MCM), curcumin led to the decrease of cell apoptosis. The authors suggested that curcumin pretreatment protected against hypoxia-induced MCM apoptosis through the upregulation of $\mathrm{miR}-7 \mathrm{a} / \mathrm{b}$ and the downregulation of SP1 expression [88].

Curcumin was reported to modulate some miRNAs that are dysregulated in diabetes. In a study conducted by Tian et al., miR-17-5p was proven to stimulate adipogenic differentiation of mouse 3T3-L1 cells [89]. This gene encodes a key Wnt signaling pathway effector, and its human homologue transcription factor 7 like-2 (TCF7L2) is a highly diabetes risk gene. After treatment with curcumin, 
a decrease of miR-17-5p expression was observed, together with an increase of its target gene, Tcf712, in 3T3-L1 adipocyte cells. The authors also reported an elevation of miR-17-5p expression in mouse epididymal fat tissue in response to high fat diet. The authors suggested that miR-17-5p is among the central switches of adipogenic differentiation, activating adipogenesis via repressing the Wnt signaling pathway effector Tcf712, and its own expression is nutritionally regulated by curcumin [89].

Caffeic acid (3,4-dihydroxycinnamic acid) (Figure 1) is the major dietary hydroxycinnamic acid and is found in food, mainly as caffeic acid phenethyl ester (CAPE) or chlorogenic acid (5-O-caffeoylquinic acid), which results from its conjugation with quinic acid. The chlorogenic acid is one of the most widely consumed polyphenols, being present in many fruits (blueberries, apples, pears), vegetables (lettuce, potatoes, eggplants), and beverages, including coffee (caffeinated or decaffeinated), wine and tea. Regular consumption of coffee results in the ingestion of $0.5-1 \mathrm{~g}$ of chlorogenic acid and 250-500 mg of caffeic acid/day [90-92]. CAPE has poor bioavailability attributed to its low aqueous solubility, and in the plasma undergoes rapid hydrolysis to caffeic acid as the major metabolite. To overcome the poor bioavailability of CAPE, different formulations such as chemical modifications or microencapsulation in cyclodextrins were developed with success, the aqueous solubility of CAPE was notably increased [93]. The low bioavailability of caffeic acid (14.7\%) is due to the low intestinal absorption and low permeability across the intestinal cells [94]. No formulations of caffeic acid to be used for CVD treatment have been developed at present.

CAPE has been reported to have antioxidant and anti-inflammatory properties [95]. It was demonstrated that CAPE induces the expression of redox-sensitive HO-1 [96] through activation of the Kelch-like ECH-associated protein 1 (Keap1)/Nrf2/antioxidant response element (ARE) pathway [97], and consequently generates the transcription and translation of detoxifying and antioxidant phase II cytoprotective enzymes. Nrf2 is bound to Keap1 in the cytoplasm before activation, and once inducers react with the sulfhydryl groups of Keap1, Nrf2 is released and eventually translocated into the nucleus, where it binds to and activates ARE, which acts as a promoter/enhancer regulating the genes of the mentioned antioxidant enzymes [98]. The Nrf2/ARE pathway can be also activated through Nrf2 phosphorylation by PI3K/Akt, extracellular signal-regulated kinases (ERK) or MAPK [97]. In addition, administration of CAPE to rats stimulates PON1 expression in the lung exposed to inflammatory stimuli [99].

The benefic effect of caffeic acid on inflammatory stress is not very well documented. It was reported that caffeic acid can reduce monocyte adhesion to TNF- $\alpha$-activated human umbilical vein EC (HUVECs) by reducing the expression of VCAM-1, ICAM-1, E-selectin and MCP-1. These beneficial effects were attributed to the reduction of NF- $\mathrm{B}$ p 65 translocation from cytosol to nucleus, thereby decreasing the formation of NF-KB-DNA complex [100]. A relatively recent in vitro study confirmed these results and added new data, demonstrating that caffeic acid exerts anti-inflammatory effects on HUVEC exposed to glycated LDL (gLDL) by reducing the secretion of CRP, VCAM-1 and MCP-1. The downregulation of all these pro-inflammatory molecules is possible due to the inhibition of the receptor for advanced glycation end products (RAGE) expression and diminution of the oxidative stress (by reducing NOX4 and p22phox subunits of NADPH oxidase) and of the endoplasmic reticulum stress [101].

In vivo, it was shown that the caffeic acid reduces the plasma TNF- $\alpha$, IL- 6 and IL- 8 in rats receiving a high-fructose diet by decreasing the oxidative stress due to restoring of the antioxidant enzymes concentration (SOD, catalase, GSH-Px, glutathione reductase and glucose 6-phosphate dehydrogenase) [102]. In a very interesting in silico study, the caffeic acid was identified as a potential therapeutic agent having anti-inflammatory potential due to its interactions with cyclooxygenase-1 (COX-1) and 2 (COX-2), coagulation factor Xa (FXa) and integrin $\alpha \mathrm{IIb} \beta 3$ proteins, which are directly or indirectly participants in the thrombosis pathways [103].

Another molecular mechanism associated with the positive effects of caffeic acid in ameliorating the lipid metabolism and oxidative and inflammatory stress is the regulation of epigenetic factors, in particular, miRNAs. Murase et al. showed that in vitro treatment of Hepa1-6 hepatocytes 
with coffee polyphenols significantly increased cellular miR-122 expression, and reduced sterol regulatory element-binding transcription factor 1c (SREBP-1c) expression [104]. Using high-fat diet/streptozotocin-induced diabetic rats, Matboli et al. showed that caffeic acid intake induced improvement in albumin excretion, blood glucose, reduced renal mesangial matrix extension with increased vacuolation and reappearance of autophagosomes [105]. Additionally, they demonstrated that caffeic acid treatment stimulates autophagy genes with simultaneous reduction in their epigenetic regulators: $\mathrm{miR}-133 \mathrm{~b}, \mathrm{miR}-342$ and miR-30a. These data suggest that caffeic acid can modulate the autophagy pathway through inhibition of autophagy regulatory miRNAs that could explain its curative properties against diabetic kidney disease [105].

\subsection{Stilbenes}

Resveratrol (trans-3,5,4'-trihydroxystilbene) has a C6-C2-C6 structure containing three hydroxyl groups, which functions as a UV protectant of plants and defender against pathogenic infections (Figure 2). The food sources of resveratrol (RSV) are red wine, grapes, peanuts, passion fruit, white tea, plums and raspberries [106]. Oral ingestion of RSV is the most feasible route of administration, but the compound has low water solubility $(\sim 30 \mathrm{mg} / \mathrm{L})$; it is rapidly metabolized, and consequently has a poor bioavailability. A slight increase in RSV solubility considerably enhances its bioavailability [107]. After ingestion, RSV is absorbed in the small intestine and then released into the bloodstream where it can bind to albumin and lipoproteins that further deliver RSV to the cells of the peripheral tissue. RSV is well tolerated and its plasma concentration depends on the dose consumed, but not in a linear relation. High oral doses $(1 \mathrm{~g} / \mathrm{kg}$ ) may generate side effects (nausea, abdominal pain) [107]. Thus, improving RSV bioavailability will straighten its potential as a therapeutic agent. Recently the researchers have tried to increase RSV bioavailability by nanoencapsulation in lipid nanocarriers or liposomes, nanoemulsions, micelles, insertion into polymeric particles, solid dispersions and nanocrystals [108]. The results are promising, but further studies are needed to improve these methodological approaches and to compare effects of the most valuable strategies in the same trial.

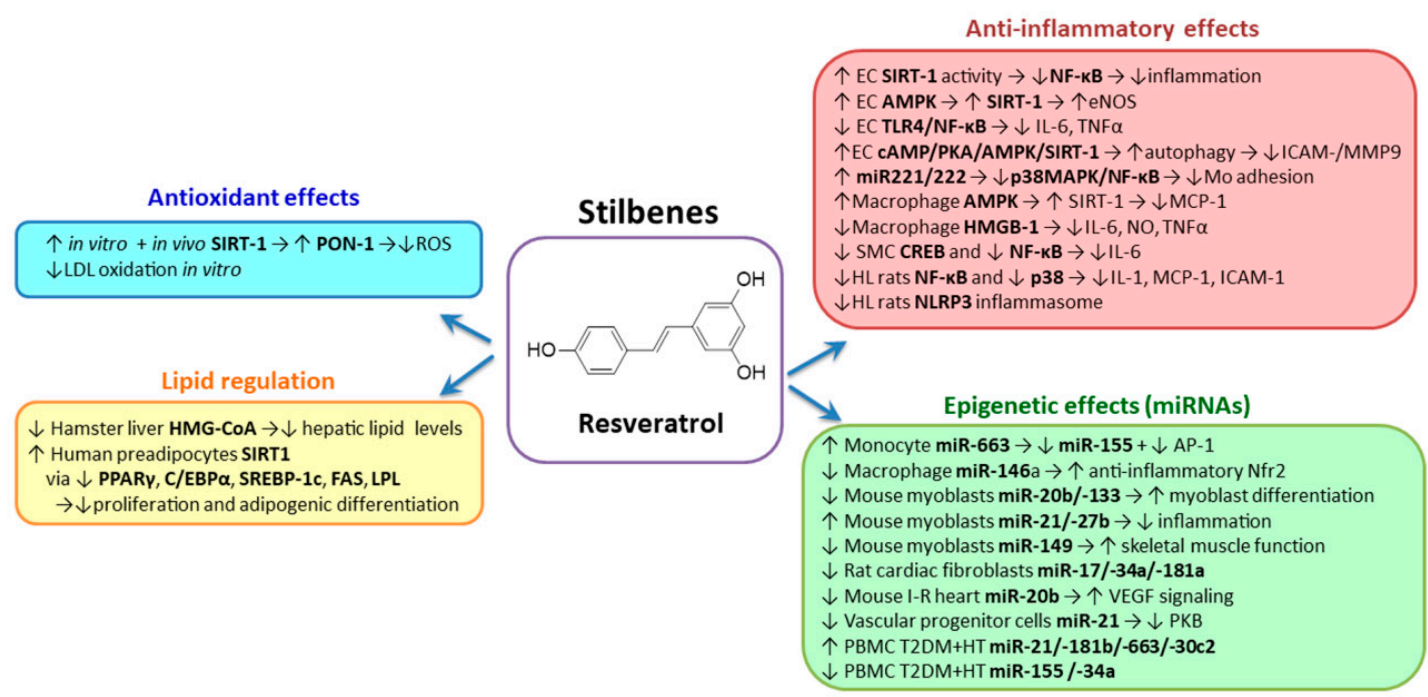

Figure 2. Resveratrol's chemical structure and its demonstrated effects of improving cardiovascular disease outcomes.

The lipid-lowering action of RSV is based on its capacity to reduce the level and activity of HMG-CoA reductase that has been demonstrated in the livers of hamsters with diet-induced dyslipidaemia [109]. Studies conducted in humans are controversial, some of them evidencing a reduction of LDL-C and an increase of HDL-C $[110,111]$, and others showing no effect of RSV on plasma lipid profile [112]. RSV has important effects on adipose tissue due to its ability to inhibit 
differentiation of preadipocytes and stimulation of lipolysis. Thus, RSV inhibits proliferation and adipogenic differentiation of human preadipocytes by a SIRT1-dependent mechanism and in the $3 \mathrm{~T} 3$ cells downregulate the expression of PPAR $\gamma$, CCAAT-enhancer-binding proteins $\alpha(\mathrm{C} / \mathrm{EBP} \alpha)$, SREBP-1c, FAS and lipoprotein lipase (LPL), which are important regulators of the lipolysis [113]. RSV has protective effects in terms of CVD risk due to its capacity to improve PON1 activity. Experiments performed in vitro and in vivo evidenced the positive effects of quercetin/RSV on PON1 activity [95,114-116]. The mechanisms responsible for this effect might be the activation of SIRT-1, which is known as activator of LXR, important regulator of PON1 gene [117]. The antioxidant potential of RSV was evidenced by inhibiting macrophages-induced in vitro oxidation of LDL [118]. The ability of RSV to exert antioxidant effects in humans is still under investigation.

Numerous studies reveal that the benefic effects of RSV are due to its potential to activate several important anti-inflammatory targets [119], although the exact mechanisms of action have not been clearly elucidated [120]. It was shown that the main target of RSV is SIRT-1, and its binding determines modifications of the SIRT-1 structure that enhances the binding of SIRT-1 to its substrates [121]. An important substrate of SIRT-1 is p65 of NF- KB (RelA) [122], the key transcription factor involved in regulation of inflammatory cytokines [123]. SIRT-1 activation by RSV determines the inhibition of RelA acetylation, which in turn decreases NF- $k B$ expression [124]. In addition, RSV inhibits p300 expression and promotes the IкB- $\alpha$ degradation [125]. Another molecular target of RSV is AMP-activated protein kinase (AMPK), a protein that controls the activity of SIRT-1 by regulating the available cellular levels of NAD ${ }^{+}$[126]. Beside SIRT-1, AMPK is known to activate eNOS in EC. A recent clinical trial involving primary hypertensive patients evidenced that addition of a micronized formulation of RSV to standard antihypertensive therapy is sufficient to normalize the blood pressure, without additional antihypertensive drugs [127]. Other targets of RSV were identified by different other groups: TLR4 [128,129], miR-221/222 [130] and p38 MAPK [131,132].

RSV induces the decrease of endothelial activation and vascular inflammation, and improves the endothelial function. It was demonstrated that RSV determines the decrease of IL- 6 and TNF- $\alpha$ via the TLR4/myeloid differentiation primary response gene 88 (MyD88)/NF- $\mathrm{kB}$ signal transduction pathway in HUVECs exposed to LPS [128]. In addition, it was reported that pre-incubation with RSV reduced the TNF- $\alpha$-induced ICAM-1 secretion, as well as the intracellular expression of ICAM- 1 and MMP-9 in EC by inducing autophagy, mediated in part through the activation of the CAMP/protein kinase A (PKA)/AMPK/SIRT-1 signaling pathway [133]. Liu et al. demonstrated that RSV decreases ICAM-1 expression and monocyte adhesion to TNF- $\alpha$-exposed HUVECs by stimulating miR-221/-222 production, which determines $\mathrm{p} 38 \mathrm{MAPK} / \mathrm{NF}-\mathrm{KB}$ inhibition [130].

In THP-1 human macrophages stimulated with LPS, RSV pretreatment inhibited foam cells formation and reduced MCP-1 secretion, while increasing SIRT-1 and AMPK [134]. RSV significantly reduced the levels of secreted IL-6, NO and TNF- $\alpha$ in RAW264.7 cells exposed to LPS by attenuating HMGB-1 expression [135]. Other mechanisms of RSV action in LPS-exposed macrophages involve the attenuation of TLR4- TNF receptor-associated factor 6 (TRAF6), MAPK and Akt pathways [136].

The anti-inflammatory properties of RSV were demonstrated also in SMC. Inanaga et al. showed that RSV attenuates Ang II-induced IL-6 protein in the supernatant of vascular SMC in a dose-dependent manner. These effects were attributed to the ability of RSV to reduce the activity of cAMP-response element-binding protein (CREB) and NF- $\mathrm{kB}$, two transcription factors which are critical for Ang II-induced IL-6 gene expression [137]. In addition, Zhang et al. demonstrated that RSV reduced the proliferation of vascular SMC exposed to Ang II by inhibiting ERK1/2 phosphorylation and NF-kB transcriptional activity [138].

The anti-inflammatory properties of RSV were demonstrated also in vivo. Using hyperlipidemic rats, Deng et al. demonstrated that RSV decreases the serum levels of IL-1 $\beta$ and reduces MCP-1, ICAM-1, p65 NF- $\mathrm{kB}$ and p38 MAPK mRNA and protein expression in the thoracic aortas samples [139]. In addition, NLRP3 inflammasome oligomerization was also decreased in the aortic tissue, in parallel with the upregulation of SIRT-1 expression [139]. Interestingly, Chang and colleagues previously 
demonstrated that RSV reduces inflammation, such as aortic macrophage infiltration and NF- $\mathrm{KB}$ expression in apoE-deficient mice fed with a high-cholesterol diet [140]. Using the model of an I/R-injured rat, Cong et al. demonstrated that RSV reduced the myocardial infarct area, in parallel with a reduction of serum and myocardial TNF- $\alpha$ levels through a mechanism dependent on NO production [141]. Li et al. confirmed the previous in vivo study, demonstrating that RSV significantly reduces myocardial infarct size and myocardial apoptosis, serum and myocardial TNF- $\alpha$ production by a mechanism dependent on TLR4/NF-KB attenuation and NO production [142].

The results concerning anti-inflammatory potential of RSV in humans were contradictory, some studies evidencing a positive effect in healthy people [143], others showing no effects in postmenopausal women [144]. The contrasting results suggest that in order to obtain beneficial effects, the dose and the way of administration have to be carefully analyzed. It was suggested that a moderate $(>450 \mathrm{mg})$ continuous intake is better than a single, higher dose administration [145].

Recent in vitro and in vivo experiments proved that RSV positively regulates the mechanisms underlying oxidative and inflammatory stress by modulating the expression of a set of specific miRNAs. Tili et al. showed that RSV upregulates miR-663 in human THP-1 and circulating monocytes, this miRNA being proven as anti-inflammatory by inducing the decrease of AP-1 transcriptional activity [146]. Moreover, they showed that RSV impairs AP-1 upregulation induced by LPS at least in part by targeting JunB and JunD transcripts. In contrast, RSV impairs the LPS-induced upregulation of pro-inflammatory miR-155 in a manner dependent of increasing miR-663 levels [147]. These data suggest the potential modulation of miR-663 levels to stimulate the anti-inflammatory effects of RSV in metabolic disorders associated with elevated levels of miR-155. Since many in vitro experiments use high concentrations of phenolic compounds and do not reproduce their physiological in vivo plasma levels, Bigagli et al. incubated RAW264.7 macrophages with corresponding plasma physiological concentrations of RSV, hydroxytyrosol and oleuropein [148]. They showed that only RSV and hydroxytyrosol (at $10 \mu \mathrm{M}$ ) decreased miR-146a, which is known to target Nrf2 responsible for inhibiting pro-inflammatory mediators. In addition, the authors showed that Nrf2 was increased by RSV and hydroxytyrosol after in vitro stimulation of murine macrophages with LPS [148]. Lançon et al. reported that of 26 miRNAs were increased (miR-21 and miR-27b) in prevalence by RSV in mouse C2C12 skeletal myoblasts, while other 20 miRNAs (miR-20b and miR-133, a muscle-specific miRNA known to target genes involved in myoblast differentiation) were downregulated $[149,150]$. Additionally, miR-149 was downregulated by RSV, this miRNA having potential role in the regulation of skeletal muscle functionality. Recently, Zhang et al. demonstrated that RSV can inhibit in vitro the TGF- $\beta 1$-induced proliferation of rat cardiac fibroblasts (CF) and collagen secretion [151]. RSV also decreased miR-17, miR-34a and miR-181a in TGF- $\beta 1$-treated CF. The authors suggested that the inhibitory effect of RSV is mediated by the downregulation of miR-17 and the regulation of Smad7 [151].

In an in vivo study, Mukhopadhyay et al. reported the cardioprotective effect of RSV and proposed a RSV-induced miRNAs profile in a rat I/R model [152]. They reported that RSV significantly downregulated miR-20b, which might modulate vascular endothelial growth factor (VEGF) signaling. This downregulation of miR-20b was proposed to be linked with the potent anti-angiogenic action of RSV in the ischemic myocardium and with the synergic effects of RSV and $\gamma$-tocotrienol. An elegant and complex study performed by Campagnolo et al. showed that RSV can induce the expression of endothelial markers, such as CD31, VE-cadherin and eNOS in vascular resident progenitor cells and embryonic stem cells [153]. They also demonstrated that RSV significantly reduced miR-21 expression in these cells, which in turn diminished protein kinase B (PKB) phosphorylation. This signaling cascade reduced the nuclear $\beta$-catenin, inducing endothelial marker expression and increasing tube-like formation by progenitor cells. Additionally, the authors showed that vascular progenitor cells treated ex vivo with RSV produced better endothelialization of the decellularized vessels. Moreover, they demonstrated that RSV-enriched diet reduces lesion formation in a mouse model of vessel graft [153].

Tomé-Carneiro et al. performed a randomized placebo-controlled study with type-2 diabetic and hypertensive men, who received capsules containing either placebo (maltodextrin), grape extract 
(laking RSV) (GE) or grape extract with over $8 \mathrm{mg}$ of RSV (GE-RES) during one year [154]. Their results show that supplementation with GE or GE-RES did not affect body weight, blood pressure, glucose, $\mathrm{HbA1c}$ or lipids, beyond the values regulated by gold standard medication in these patients. They also found molecular changes in peripheral blood mononuclear cells (PBMC), evidenced by the significantly reduced expression of the pro-inflammatory cytokines-macrophage inflammatory protein $1 \alpha(\mathrm{MIP} 1 \alpha), \mathrm{CCL} 3, \mathrm{IL}-1 \beta$ and TNF- $\alpha$-and increased expression of transcriptional repressor leucine-rich repeat flightless-interacting protein 1 (LRRFIP-1) in PBMC from patients taking the GE-RES extract for 12 months [154]. Additionally, a GE-RES treatment-associated modulation of miRNAs involved in the inflammatory response was noticed, demonstrated by the increase of a set of miRNAs miR-21, miR-181b, miR-663 and miR-30c2, together with a decrease of miR-155 and miR-34a in PBMC after GE-RES treatment, as compared to the control group. These data provide evidence for the in vivo modulation of inflammatory miRNAs in PBMC by RSV in circulating immune cells of diabetic hypertensive medicated patients and support a beneficial immunomodulatory effect in these patients [154].

\subsection{Flavonoids Group}

Flavonoids (including flavonols, flavones, flavanones, flavanols, isoflavones and anthocyanidins) exert multiple beneficial effects. The food sources of flavonoids are berries, black tea, celery, citrus fruits, green tea, olives, onions, oregano, purple grapes, purple grape juice, soybean, soy products, vegetables, whole wheat and wine [155].

\subsubsection{Flavonols}

Quercetin (3,3', $4^{\prime}, 5,7$-pentahydroxylflavone) (Figure 3) is administered as quercetin-3-glucoside (isoquercetin) which is hydrolyzed to quercetin in the small intestine, rapidly absorbed and then transferred into the blood. Vegetables that are important sources of quercetin are apples, grapes, berries, black tea, green tea, red onions, kale, leeks, broccoli, apricots, pepper, red wine and tomatoes [155]. A very recent study shows that quercetin alters the gut microbiota and reduces the atherogenic lipids, such as cholesterol and lysophosphatidic acids, all these effects being associated with the diminution of atherosclerotic lesions area [156]. Unlike most phenolic compounds, quercetin has a relatively high bioavailability. It is absorbed in the small intestine, then undergoes different transformations in the small intestine, colon, liver and kidney. Quercetin that is not intestinally absorbed is further subjected to colon microflora metabolization. Ingested quercetin is rapidly eliminated as metabolites through feces and urine. The bioavailability of quercetin orally administered to humans was estimated at $\sim 45 \%$ with $3.3-5.7 \%$ of the dose found in the urine and $0.2-4.6 \%$ in the feces $[113,157]$.

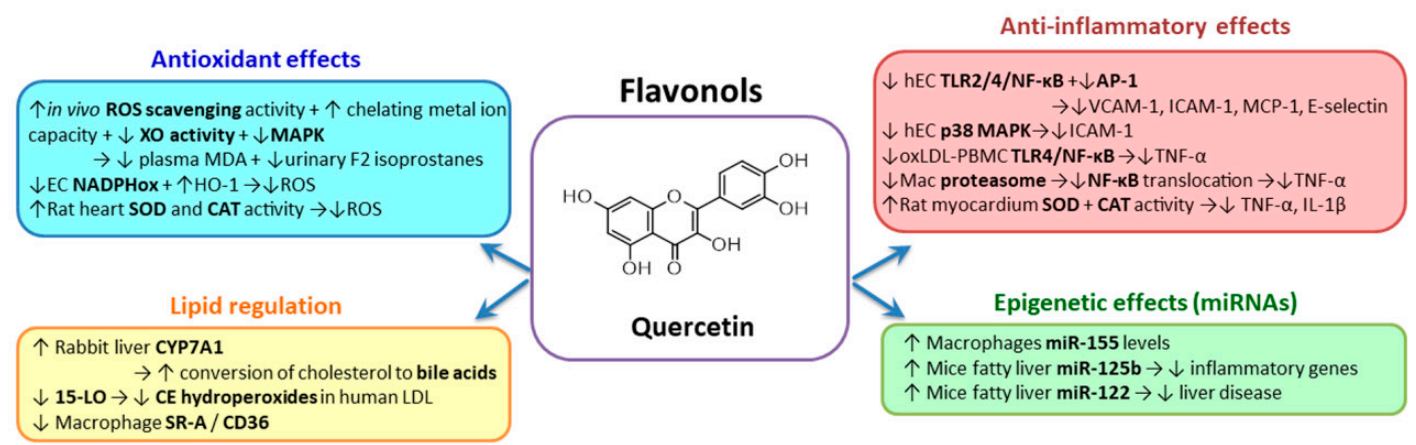

Figure 3. Quercetin chemical structure and beneficial effects in the context of cardiovascular diseases.

Quercetin is efficient at stimulating cytochrome P450 and CYP7A1 levels, and the conversion of cholesterol to bile acids in the liver of rabbits fed with a high fat diet [158]. By inhibition of 15-lipoxygenase, quercetin and its monoglucoside derivatives inhibits cholesteryl ester hydroperoxides 
formation in human LDL [158]. Antioxidant quercetin metabolites like quercetin-3-glucuronide (Q3GA) are taken-up by the human macrophages present in the intima and convert them to methylated derivatives, which suppress the gene expression of scavenger receptors SR-A and CD36 [159].

The data supporting the antioxidant potential of quercetin are contradictory. Thus, administration of quercetin at $10 \mathrm{mg} / \mathrm{kg}$ bodyweight for 13 weeks was shown to downregulate NADPH oxidase and increase eNOS activity, improving the endothelial function in hypertensive male rats [160], while a higher dose (1.5 g quercetin/kg diet for 5-11 weeks) was not associated with a reduced risk of developing CVD in hypertensive rats [161]. In such situation it is necessary to test the compound in the same experimental model, but at several concentrations to determine the optimum and identify the harmful one. In vivo, the antioxidant potential of quercetin was expressed as lower levels of urinary isoprostane F2 and plasma MDA, that could be due to the ability of quercetin to scavenge ROS, chelate metal ions, reduce xanthine oxidase activity and to inhibit the MAPK pathway $[162,163]$. The mechanism by which quercetin increases eNOS activity in a dose-dependent manner involves the phosphorylation on Ser1179 by cAMP/PKA pathway [164]. The antioxidant potential of quercetin is also reflected in the decrease of the oxidation levels of LDL [165]. In addition, quercetin reduces the activities of SIRT-1 and AMPK, upregulates HO-1 and decreases the expression of oxLDL-induced NOX2 and NOX4 in human EC [166]. Kaempferol (50 or $100 \mathrm{mg} / \mathrm{kg}$ for 4 weeks), another member of the flavonols group, reduces atherosclerotic lesions area in apoE-deficient mice through mechanisms involving reduction of the aortic ROS production and osteopontin downregulation [167]. Furthermore, kaempferol diminishes oxLDL-enhanced apoptosis of EC based on the upregulation of autophagy by inhibition of PI3K/Akt/mammalian target of rapamycin (mTOR) pathway [168].

Extensive studies using in vitro or in vivo models clearly indicate that quercetin manifests anti-atherosclerotic effects, in part due to its anti-inflammatory properties. In vitro studies demonstrate that quercetin reduces the expression of VCAM-1, ICAM-1, E-selectin or MCP-1 in cultured human EC exposed to different pro-inflammatory stimuli. The molecular mechanisms involve modulation of TLR2/4/NF-kB and AP-1 transcription factor. In addition, it was demonstrated that quercetin reduces ICAM-1 in EC exposed to uremic media by downregulating p38 MAPK [169-172]. Anti-inflammatory properties of quercetin were demonstrated also in monocytes/macrophages. It was demonstrated that TNF- $\alpha$ released by oxLDL-exposed human PBMC is reduced by quercetin through modulation of TLR/NF- $\kappa B$ signaling pathway [170]. In LPS-stimulated macrophages isolated from C57BL/6 and $\mathrm{BALB} / \mathrm{c}$ mice, quercetin reduces the secretion of TNF- $\alpha$ and NO produced by the inducible NO synthase (iNOS) by a mechanism involving the inhibition of proteasome, which determines a diminished proteolytic degradation of phospho-I $\kappa \mathrm{B}$ protein, resulting in the decreased translocation of activated NF- $\mathrm{KB}$ to the nucleus [173].

The decrease of the atherosclerotic lesions was not associated with the improvement of the lipid profile, but with the decreased inflammatory stress, measured as decreased IL-1 receptor, IKK and STAT3 $[169,174]$. In the rat model of acute myocardial infarction, quercetin administration determined the reduction of TNF- $\alpha$, IL-1 $\beta$ expression in the myocardial tissue, in parallel with an increase of the antioxidant SOD and catalase activities [175]. Recently, a few clinical studies regarding the anti-inflammatory effects of quercetin in human subjects were published, but the results are controversial. A double-blind randomized clinical trial designed to measure the anti-inflammatory effects of quercetin $(500 \mathrm{mg}$ ) administrated for 10 weeks to women with type 2 diabetes reported no differences between groups [176]. Another study conducted on stable angina patients receiving $120 \mathrm{mg} /$ day quercetin for two months showed a statistically significant reduction of IL-1 $\beta$ levels and attenuated TNF- $\alpha$ and IL-10 levels in treated patients' plasma, and decreased transcriptional activity of NF-kB in PBMC [177]. Several studies were done to evaluate the safety of quercetin administration to humans [178]. The conclusion of these studies was that up to $5000 \mathrm{mg}$ /day quercetin supplementation for four weeks does not cause adverse effects.

In addition, quercetin can exert its positive effects on the regulation of oxidative and inflammatory stress by modulating the expression of specific miRNAs. Thus, Boesch-Saadatmandi et al. reported that 
quercetin and isorhamnetin upregulated miR-155 levels in LPS-activated macrophages, but quercetin metabolites, such as quercetin-3-glucoronide, did not modify miR-155 expression [179]. An in vivo study of the same group showed that addition of quercetin to high-fat diet fed C57BL/6J mice significantly increases hepatic expression of miR-125b, a negative regulator of inflammatory genes, and miR-122, known to be involved in lipid metabolism and pathogenesis of liver diseases [180]. These data suggest that miRNAs could represent potential targets of quercetin in the CVD prevention or treatment.

\subsubsection{Flavones}

Apigenin (4',5,7-trihydroxy-flavone) is one of the major monomeric flavonoids existing in the diet and is found in a glycosylated form, with the tricyclic core structure linked to a sugar moiety through hydroxyl groups (O-glycosides) or directly to carbon (C-glycosides) (Figure 4). Apigenin is present in fresh parsley, vine spinach, celery seed, green celery heart, chinese celery, dried oregano, chamomile tea, red and white sorghum, rutabagas, oranges, kumquats, onions, wheat sprouts, tea and cilantro [181]. Apigenin-glycosides can be hydrolyzed in vivo into apigenin or chrysin. Oral bioavailability of apigenin is relatively low due to its poor solubility and because the main part of the ingested apigenin is either excreted unabsorbed or is rapidly metabolized after absorption. In vivo, after ingestion, apigenin is subjected to sulfation and glucuronidation, the absorbed apigenin being present in tissues (mainly hepatic and small intestin) as glucuronide, sulfate conjugates or luteolin [182].

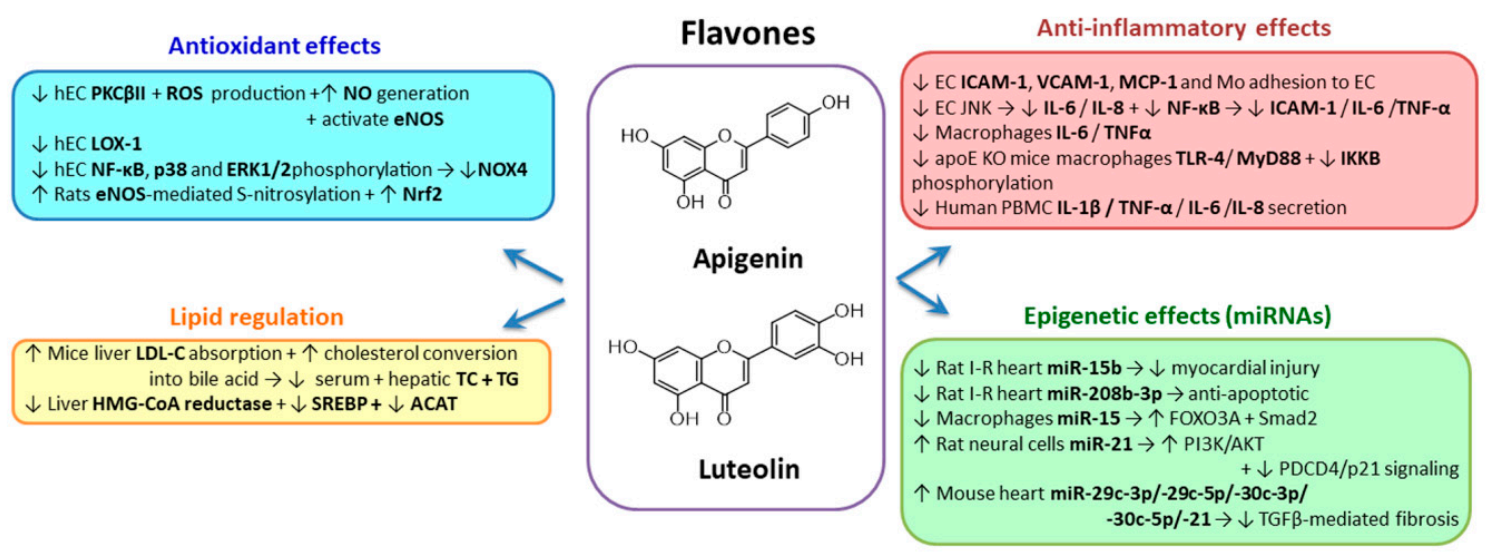

Figure 4. Antioxidant, anti-inflammatory, lipid-lowering and epigenetic mechanisms to improve cardiovascular diseases outcomes demonstrated by apigenin and luteolin.

Apigenin decreased the serum and hepatic levels of TC and TG in hyperlipidemic mice by promoting liver LDL-C absorption and increasing the conversion of hepatic cholesterol into bile acid [183]. In addition, apigenin markedly lowered the levels of hepatic enzymes involved in the synthesis of TG and cholesterol esters in HFD-induced obese mice, thereby ameliorating hepatic steatosis [184].

Data supporting the protective role of apigenin on the vascular wall in diabetes reveal the impeding of the endothelial dysfunction by inhibition of high-glucose-mediated protein kinase C $\beta$ II (PKC $\beta$ II) upregulation and ROS production, while stimulating NO generation [185]. The molecular mechanism of eNOS activation by apigenin involves continuous eNOS Ser1179 phosphorylation by the PI3K/Akt pathways [186]. In addition, apigenin inhibits oxLDL receptor 1 (LOX-1) expression after stimulation of EC with high glucose and TNF- $\alpha$, LOX-1 being an important receptor involved in the uptake of modified lipoproteins and atherosclerotic plaque progression [187].

The anti-inflammatory properties of apigenin have been investigated in studies conducted in vitro and in vivo. Using cultured human EC activated with di-(2-ethylhexyl) phthalate, Wang et al. showed that apigenin suppressed the expression of ICAM-1 and inhibited THP-1 monocytic cells adhesion 
to HUVECs [188]. In addition, a dose-dependent inhibition of endothelial IL-6 and IL-8 expression was observed, and these inhibitory effects of apigenin are mediated by the JNK pathway, but not by I $\kappa B \alpha / N F-\kappa B$ or ERK pathways [188]. Apigenin inhibited NF- $\kappa B$ activation and ICAM-1 expression in EC exposed to palmitic acid [189]. In EC exposed to uremic plasma, p38 MAPK is another molecular target for apigenin [172]. Regarding the effect of apigenin on cytokine secretion, it has been shown that apigenin reduced IL-6 and TNF- $\alpha$ secretion in LPS-stimulated RAW 264.7 macrophages [190] and decreased TNF- $\alpha$ release in the media of LPS-activated macrophages [191]. Apigenin in LPS-exposed macrophages reduces TLR-4, MyD88 and phosphorylation of IKKB levels through nuclear NF- $\mathrm{KB}$ p65 signaling pathway [192]. Ren et al. confirmed these results in vivo, demonstrating that in LPS-challenged apoE deficient mice, treatment with apigenin determined the reduction of TLR-4 and NF-KB p65 levels and lessened the macrophages and SMC number in atherosclerotic regions [192]. Apigenin inhibited the expression of VCAM-1 and IкKB kinase and prevented the adhesion of U937 monocytes to EC exposed to high-glucose $(30 \mathrm{mM})$ concentrations [193]. The beneficial effects of intra-gastric administration of apigenin to type 2 diabetic (T2D) rats were expressed as decreases of the blood glucose concentration and ICAM-1 levels and improved impaired glucose tolerance [189].

Luteolin $\left(3^{\prime}, 4^{\prime}, 5,7\right.$-tetrahydroxyflavone) (Figure 4$)$ is a member of the flavones family and is found in carrots, cabbage, artichokes, tea, celery and apples [194]. Luteolin and its glucosides are absorbed quickly in the intestine. The time of maximum blood concentration is under one hour, and the maximum plasma concentration is of $1-100 \mu \mathrm{mol} / \mathrm{L}$, depending on the dose ingested and the type of food consumed; the purer the luteolin used, the faster the absorption [195].

Luteolin exerts lipid-lowering effects due to the interaction with HMG-CoA reductase, the SREBPs and acyl-CoA cholesterol acyltransferase (ACAT) in the liver [3]. In all studies available, no major side effects have been detected, confirming the good tolerability and safety of artichoke extract, but long-term safety studies are needed $[196,197]$. There are no data about luteolin effects on the EC function or atherosclerotic plaque. Luteolin was shown to impede TNF- $\alpha$-induced NOX4, which generates a decrease of ROS production in human EC. The mechanism involves the inhibition of the TNF- $\alpha$-induced transcriptional activity of NF-KB, p38 and ERK1/2phosphorylation [198]. Recently, it was shown that luteolin $(100 \mathrm{mg} / \mathrm{kg} / \mathrm{d})$ reduces cardiac I/R injury by enhancing eNOS-mediated S-nitrosylation and Nrf2 redox function in diabetic rats [199].

The effects of luteolin on monocyte adhesion to EC, a key event in triggering vascular inflammation, were evaluated in a few studies. Jia et al. demonstrated that physiological concentrations $(0.5 \mu \mathrm{M})$ of luteolin suppress TNF- $\alpha$-induced expression of MCP-1, VCAM-1 and ICAM-1 [200]. In addition,

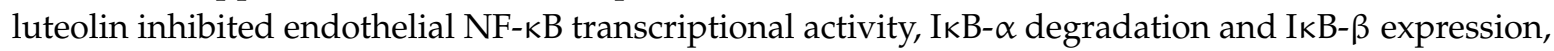
and thus reduced NF- $\mathrm{kB}$ p 65 nuclear translocation. The in vitro results were confirmed in vivo using C57BL/6 mice fed with luteolin diet supplementation. The authors show that luteolin suppresses TNF- $\alpha$-induced MCP-1 and soluble ICAM- 1 in the plasma, as well as VCAM-1 in the aorta of mice [200]. In a recent study, Zhang et al. demonstrated that a combination of luteolin $(0.5 \mu \mathrm{M})$ and curcumin $(1 \mu \mathrm{M})$ inhibits, synergistically, VCAM-1 and MCP-1, and the subsequent monocyte adhesion to EC exposed to TNF- $\alpha$ by suppressing NF-kB translocation [201]. These results were confirmed in vivo in C57BL/6 mice that received luteolin and curcumin [201]. In human monocytes exposed to high glucose concentrations, luteolin significantly reduced IL- 6 and TNF- $\alpha$ by inhibiting NF- $\kappa$ B activity [202]. Recently, it was demonstrated that luteolin effectively suppresses IL- $1 \beta$, TNF- $\alpha$, IL- 6 and IL- 8 secretion from PBMC from healthy donors incubated with LPS [203], confirming reports showing that luteolin reduces IL-6 and TNF- $\alpha$ secretion in LPS-stimulated RAW 264.7 macrophages [190]. Hong et al. evaluated the anti-inflammatory effects of luteolin in renal I/R injury in Sprague-Dawley rats and demonstrated that this natural compound attenuated serum and renal TNF- $\alpha$, IL- $1 \beta$ and IL- 6 , and the renal HMGB1 and NF- $\mathrm{kB}$ expression levels in I/R rats [204]. In addition, luteolin significantly reduced the endoplasmic reticulum stress and renal cell apoptosis caused by renal I/R injury [204]. Recently, Ding et al. demonstrated that luteolin attenuates atherosclerosis in high-fat fed apoE-/- mice by alleviating inflammation through inhibition of signal transducer and STAT3 [205]. 
Recent studies evidenced that apigenin and luteolin modulate the expression of certain epigenetic factors, in particular miRNAs, that constitute fine regulators of the oxidative and inflammatory stress. Thus, an in vivo study by Wang et al. shows that the increased cardiac miR-15b expression observed during myocardial I/R injury in rats correlates with the decreased expression of JAK2 and activity of JAK2/STAT3 pathway, with augmented myocardial apoptosis and ROS production, and aggravated heart injury [206]. Apigenin treatment of I/R rats downregulates miR-15b expression in the heart, improves the altered mechanisms and alleviates myocardial I/R injury [206]. In an in vivo report, Bian et al. showed that luteolin pretreatment induces anti-apoptotic effects by decreasing miR-208b-3p expression in myocardial tissue of I/R rats [207]. Arango et al. performed a high-throughput PCR screening of 312 miRNAs in RAW 264.7 murine macrophages and evidenced that apigenin reduces LPS-induced miR-155 expression by transcriptional regulation [208]. They further demonstrated that apigenin-reduced expression of miR-155 led to the increase of the anti-inflammatory mediators forkhead box O3a (FOXO3A) and $\alpha$ smooth-muscle-actin ( $\alpha$-SMA) and MAD-related protein 2 (Smad2) in LPS-treated murine macrophages. Arango et al. also demonstrated that in vivo apigenin or a celery-based apigenin-rich diet reduced LPS-induced expression of miR-155 and decreased TNF- $\alpha$ in lungs from LPS-treated mice, thereby diminishing the inflammatory process [208].

Zhang et al. reported recently that low concentrations of luteolin presented protective effects on $\mathrm{H}_{2} \mathrm{O}_{2}$-induced ischemic cerebrovascular disease cell viability loss, proliferation inhibition, ROS generation, oxidative stress increase and apoptosis, together with an increase of miR-21expression level [209]. Furthermore, they showed that luteolin alleviated $\mathrm{H}_{2} \mathrm{O}_{2}$-induced inactivation of PI3K/Akt pathway and activated programmed cell death protein 4 (PDCD4)/p21 pathway in PC-12 cells by upregulating miR-21 [209]. Ning et al. showed that pretreatment and post-treatment with luteolin-7-diglucuronide (L7DG), a naturally occurring flavonoid glycoside found in leaves of basil or Verbena officinalis, significantly attenuated isoproterenol-induced myocardial injury and fibrosis in mice [210]. Furthermore, L7DG pretreatment blocked isoproterenol-stimulated expression of genes encoding the enzymatic subunits of NADPH oxidase (Cyba, Cybb, Ncf1, Ncf4 and Rac2). In addition, the authors showed that L7DG pretreatment almost reversed isoproterenol-altered expression of miRNAs which were cross-talking with TGF- $\beta$-mediated fibrosis, including miR-29c-3p, miR-29c-5p, miR-30c-3p, miR-30c-5p and miR-21 [210].

\subsubsection{Flavanones}

Naringenin (4,5,7-trihydroxy-flavanone) and hesperetin (3,5,7-trihydroxy-4'-methoxyflavanone) (Figure 5) are the representative flavanones that are found in glycoside form in nature; that form favors their intestinal absorption. They are present in citrus fruits, tomatoes and cherries [211], but unfortunately have limited solubility in water. Kanaze et al. reports that oral administration of naringenin results in a low bioavailability (5.81\%) in human subjects [212]. To overcome the poor solubility and to increase naringenin use in clinical applications, several drug delivery systems have been developed. As a result, naringenin was formulated into liposomes, nanoparticles, self-nanoemulsifying drug delivery systems or nano-suspensions to assure a friendly and efficient delivery system to be used in the future [213].

It was reported that the alcoholic extracts of bergamot enriched in flavanones reduce the intestinal absorption of cholesterol and increase cholesterol excretion based on the bile acids secretion pathway [214]. Supplementation with naringenin (3\%) of the high-fat diet in LDL-R-/- mice prevented hepatic steatosis by diminishing the SREBP1c expression and fatty acid synthesis, stimulated hepatic fatty acid oxidation and progression of atherosclerosis in the aortic sinus [215]. In addition, naringenin inhibited microsomal triglyceride transfer protein (MTTP) activity in HepG2 cells, reduced TG accumulation and decreased apoB100 secretion by 50-70\% [216]. Naringenin (0.05\%) and naringin $(0.1 \%)$ reduced aortic fatty streaks in rabbits fed high-cholesterol diets by a mechanism involving reduction of hepatic ACAT activity [217]. In a clinical trial involving hypercholesterolemic patients, administration of naringin (400 mg/day, for 8 weeks) reduced plasma LDL-C and serum apoB by more 
than 14\%, without altering plasma TG or HDL-C levels [218]. Naringenin found in bergamot inhibits LDL oxidation, initiates AMPK, modulates the activation of redox-sensitive transcription factors NF- $\mathrm{B}$ induced by TNF- $\alpha$ and acts as ROS scavenger [219]. There are reports showing that hesperetin-induced eNOS expression increased NO production via phosphorylation of Src, Akt and AMPK in cultured EC, and consequently prevented hypertension by improving endothelial dysfunction in the hypertensive rat $[220,221]$. Naringenin increased the NO production diminished by the high glucose concentrations and reduced ROS production via decreased PKC $\beta I I$ expression in EC [187]. Certain epidemiologic studies evidence that the intake of drinks made from flavanone-rich citrus fruits improve endothelial function in humans [222].

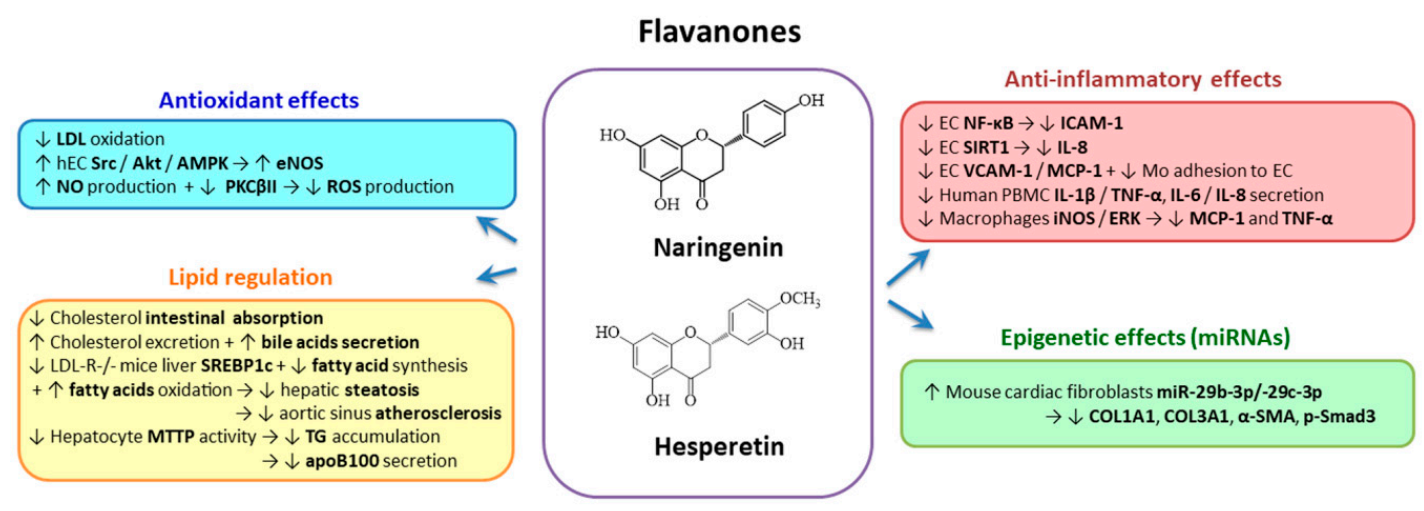

Figure 5. Chemical structure and cardioprotective mechanisms of action demonstrated by naringenin and hesperetin in experimental and clinical studies.

An in vitro study demonstrated that naringenin reduces ICAM-1 in palmitic acid exposed EC by alleviating NF-кB signaling [189]. The anti-inflammatory effects of naringenin were confirmed in vivo by the same group in a model of T2D rats [189]. It was suggested that the anti-inflammatory action of flavanones from bergamot juice is due to the activation of SIRT-1 that further inhibits the transcription of pro-inflammatory cytokine IL-8 induced by LPS in EC [223,224]. Interestingly, Testai et al. observed recently that naringenin presents structural similarity with RSV, the natural SIRT-1 activator [225]. Thus, they performed an in silico study in which they detailed the binding mode of naringenin to SIRT-1. In addition, the same group demonstrated in cultured H9c2 cardiomyocytes and in vivo in 6-month-old mice that naringenin activates SIRT-1 [225].

Hesperetin attenuated VCAM-1 upregulation and adhesion of monocytes to cultured EC induced by TNF- $\alpha$ stimulation [220]. Administration of glucosyl hesperidin (500 mg/day) to hypertriglyceridemic patients for 24 weeks significantly reduced plasma TG and apoB levels [226]. Other human studies using capsules of hesperidin $(800 \mathrm{mg})$ or naringin $(500 \mathrm{mg})$ administered for 4 weeks to moderately hypercholesterolemic individuals evidenced no alterations in plasma TC, LDL-C or TG concentrations [227]. These studies reveal that the effects of flavonoids in clinical studies depend on the metabolite used, the dose, the patient population and the length of study [228].

Using LPS-stimulated PBMC from healthy subjects, Zaragoza et al. demonstrated that naringenin decreases IL-1 $\beta$, TNF- $\alpha$, IL-6 and IL-8 production [203]. Hsu et al. showed that naringenin extracted from Nymphaea mexicana Zucc. has an important inhibitory effect on MCP-1 and TNF- $\alpha$ production in LPS-activated RAW264.7 macrophages by decreasing the expression of iNOS and ERK phosphorylation [229]. The anti-inflammatory effects of naringenin in vivo were evaluated by Raza et al., demonstrating that naringenin treatment downregulates the NF- $\kappa$ B expression levels in the brains of Wistar rats after the cerebral I/R injury [230].

Although demonstrating anti-inflammatory effects, the poor water solubility and the reduced bioavailability of naringenin restricted its therapeutic use. To overcome this limitation, naringenin formulations have been developed. In a recent study, Fuior et al. encapsulated naringenin into lipid nanoemulsions (LNs), targeted to VCAM-1 exposed on the surface of activated EC [231]. They found 
that encapsulated naringenin decreased THP-1 monocytes adhesion and transmigration to/through activated ECs by mechanisms involving the reduction of MCP-1 and diminished nuclear translocation of NF-kB [231].

A very recent study showed that naringenin modulates the expression of miRNAs involved in fine regulation of certain oxidative and inflammatory processes. It is known that the migration inhibitory factor (MIF) has antioxidant properties and is markedly increased in Ang-II-infused mouse myocardium. Starting from these data, Liang et al. showed that miR-29b-3p and miR-29c-3p are decreased in the myocardium of Ang-II-infused MIF-KO mice, but upregulated in mouse CF with MIF overexpression or by treatment with MIF protein [232]. Interestingly, miR-29b-3p and miR-29c-3p could suppress the expression of collagen type I $\alpha 1$ (COL1A1), collagen type III $\alpha 1$ (COL3A1) and $\alpha$-SMA in mouse CF by a mechanism involving the repression of the pro-fibrosis genes TGF $\beta 2$ and MMP2. Further, the authors show that naringenin could markedly reverse Ang-II-induced downregulation of miR-29b-3p and miR-29c-3p expression. Moreover, COL1A1, COL3A1, $\alpha-S M A$ and p-Smad3 expression were significantly decreased in Ang-II-treated CF by pretreatment with naringenin [232].

\subsubsection{Flavanols}

Catechins are a family of flavonoids, subgroup flavan-3-ols (flavanol) (Figure 6). The most abundant component of catechins is epigallocatechin gallate [155]. Epigallocatechin-3-gallate (EGCG) is a catechin conjugated with gallic acid. The two or more aromatic rings of these polyphenols have at least one hydroxyl group linked by a carbon bridge which is the main source for electron donor and efficiently scavenging reactive species (singlet oxygen). Catechins are present in fresh tea leaves, red wine, broad beans, apples, pears, black grapes, apricots, strawberries, blackberries, cherries, raspberries and chocolate. Cocoa is the richest source of EGCG [155]. The poor bioavailability of catechins is a consequence of their rapid degradation under physiological conditions and their low absorption in the intestinal tract by passive diffusion. To mitigate the reduced bioavailability of EGCG and to increase its effectiveness, the consumption of 8-16 cups of green tea daily is needed, but the excessive consumption of green tea has been demonstrated to be toxic [233]. Thus, other methods to increase catechins bioavailability were developed, including encapsulation into nanostructure-based drug delivery systems, molecular modification and co-administration with some other bioactive ingredients to produce a synergistic effect [234].

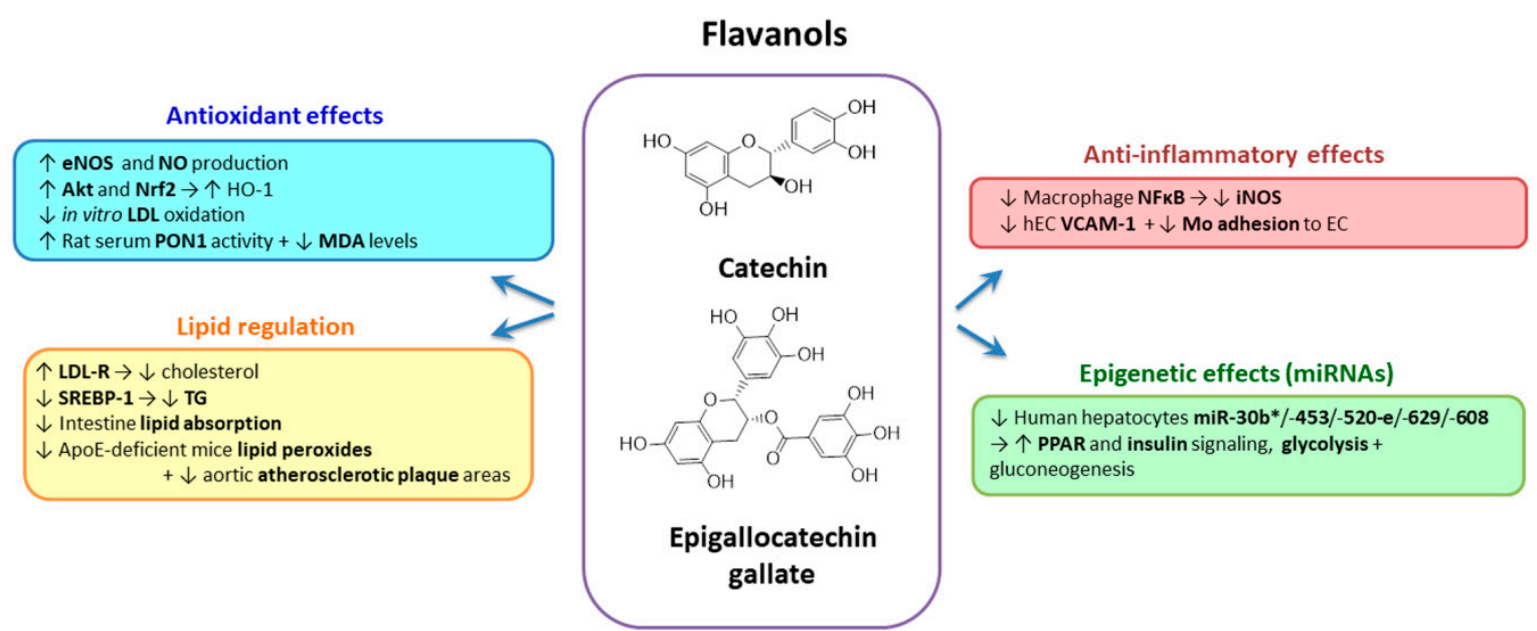

Figure 6. Chemical structures of catechin and epigallocatechin gallate and their molecular mechanisms of action to combat cardiovascular diseases.

Catechins present in the green tea are responsible for its cholesterol-lowering properties. It was shown that consumption of green tea in supplement formulation has cholesterol-lowering effects due to upregulation of liver LDL-R, thereby modulating the intracellular processing of lipids [235-237]. 
Their mechanisms of action involve inhibition of lipid absorption in the intestine by interfering with the micelle formation, emulsification, hydrolysis, solubilization and inhibition of squalene oxidase, a key enzyme in the hepatic cholesterol biosynthesis [238,239]. EGCG was described as the most potent inhibitor of lipid absorption in the intestine [48]. The EGCG ability to lower plasma lipids was associated with the consequential reduction of lipid peroxides levels and aortic atherosclerotic plaque areas in apoE-deficient mice [240]. Cocoa is a polyphenol-rich fruit that has been investigated for its potential to regulate the lipid metabolism. A special attention was given to the raise of HDL levels by cocoa ingestion. The results are controversial; the beneficial effects observed in vitro for cocoa epicatechins are not all confirmed by those in humans [241]. Besides the cholesterol lowering potential, catechins were described as having a TG lowering effect [242]. The mechanism responsible for decreasing TG is inhibition of hepatic lipogenesis, and more specifically, the inhibition of SREBP-1 [243].

A meta-analysis study concerning green tea consumption has indicated that it decreases the risk of CVD [244]. Many cardiovascular health benefits of flavanols have been reported, and one possible mechanism could be the modulation of homocysteine, its elevated concentrations being associated with increased CVD risk [245]. It was reported that in vitro EGCG reduces homocysteine-enhanced apoptosis by modulating mitochondrial-dependent signaling and PI3K/Akt/eNOS signaling in human EC [246]. In addition, epicatechin activates eNOS and increases NO production by inducing Ser633 and Ser1177 phosphorylation and Thr495 dephosphorylation. EGCG induces HO-1 expression in EC exposed to $\mathrm{H}_{2} \mathrm{O}_{2}$ through activation of Akt and $\mathrm{Nrf2}$, thereby diminishing the effects of oxidative stress [247]. Many other catechins exert antioxidant properties expressed as prevention of in vitro LDL oxidation and in humans [248]. Studies on green tea found that its administration (2\% in water) to diabetic rats increased serum PON1 activity [249]. These antioxidant mechanisms driven by catechins are responsible for the significant reduction of MDA levels measured in vivo and the protective action exerted on LDL and HDL. The molecular mechanisms by which EGCG or other catechins exert antioxidant effects need to be further explored in vivo.

Catechins from black tea are important scavengers of peroxyl, hydroxyl and superoxide radicals, singlet oxygen and lipid peroxides, NO and peroxynitrite radicals [250]. EGCG exerts also anti-inflammatory effects on macrophages pre-exposed to pro-inflammatory stimuli, such as LPS. EGCG blocks the disappearance of IкB from the cytosolic fraction, thereby obstructing NF- $\kappa \mathrm{B}$ activation, which in turn decreases the transcription of iNOS [240]. Another in vitro study evidenced that EGCG inhibits VCAM-1 expression induced by IL-1 or TNF- $\alpha$, thereby diminishing the monocytes' adhesion to cultured human EC [250].

Catechins and their derivatives were proven to contribute to beneficial health effects by the modulation of miRNAs. In human HepG2 hepatocytes, EGCG isolated from green tea was shown to differentially inhibit the expression of a set of five miRNAs (miR-30b*, miR-453, miR-520-e, miR-629 and miR-608) that are involved in inflammatory pathways, the PPAR signaling pathway, insulin signaling, glycolysis and gluconeogenesis, oxidative phosphorylation and glutathione metabolism [251]. It was demonstrated by using $1 \mathrm{H}$ NMR spectroscopy, that there was direct binding of EGCG and RSV to miR-33a and miR-122 [252]. While RSV binds miR-33a and miR-122 through an A ring interaction and increases their expression levels, EGCG decreases miR-33a and miR-122 expression by direct binding through an interaction with all rings in the molecule. Wang et al. demonstrated that EGCG binds hypoxia-inducible factor $1 \alpha(\mathrm{HIF}-1 \alpha)$ protein, a known transcriptional activator of miR-210, and interferes with Proline residues hydroxylation in the oxygen-dependent degradation domain [253]. While the hydroxylation of Proline residues is essential for the proteasome-mediated degradation of HIF-1 $\alpha$ [254], EGCG binding increases HIF-1 $\alpha$ expression and enhances miR-210 levels.

\subsubsection{Isoflavones}

Genistein (4',5,7-trihydroxyisoflavone) (Figure 7) is an isoflavone found in high quantities in soybeans and in many products based on soy. Genistein is also present in alfalfa and clover sprouts, barley meal, broccoli, cauliflower and sunflowers, caraway and clover seeds [255]. In humans, 
the plasma concentrations of genistein are dependent on the food type consumed and are highest between 2 and $12 \mathrm{~h}$ after ingestion of isoflavone-rich foods. Genistein has an absorption rate around $30 \%$ of the ingested dose. A small part of the intake of isoflavone aglycones $(10 \%)$ is absorbed from the small intestine and metabolized in the liver. Most of the ingested isoflavone (90\%) undergoes different transformations under gut microbiota action in the colon [113].
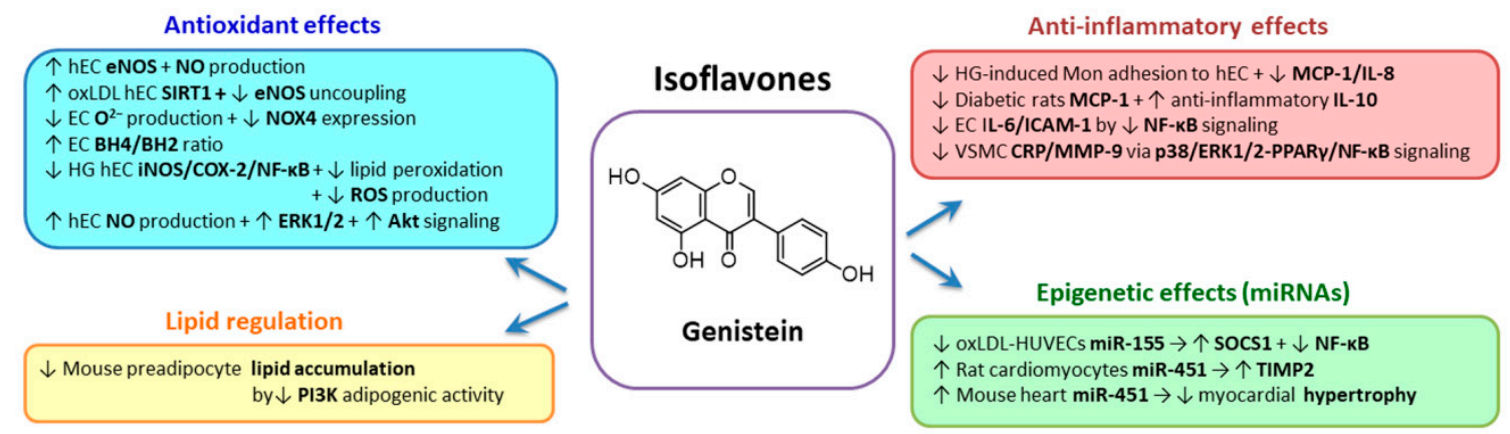

Figure 7. Chemical structure and protective effects of genistein in the context of cardiovascular diseases.

Genistein $(80 \mathrm{mM})$ induced a 67\% reduction of lipid accumulation in 3T3-L1 mouse preadipocytes, by inhibiting the adipogenic activity of PI3K, thereby exerting an anti-adipogenic action [113]. Opinions on the potential of isoflavones to reduce CVD risk are divided. Some epidemiologic studies highlight their protective effects on vascular EC, while other reports found no correlation between isoflavones consumption and reduction of CVD risk [256,257]. Exposure of human EC to 1-10 $\mu \mathrm{M}$ of genistein upregulated eNOS expression and enhanced NO production [258]. In addition, genistein prevented eNOS uncoupling by stimulating SIRT-1 pathway in human EC incubated with oxLDL. Furthermore, genistein diminished superoxide anion production and NOX4 expression, and improved the tetrahydrobiopterin $(\mathrm{BH} 4)$ /dihydrobiopterin $(\mathrm{BH} 2)$ ratio [259]. An intake of isoflavone of 50-99 mg/day was found to increase endothelial function measured as brachial flow-mediated dilation [260]. In another in vivo study, an intake of $80 \mathrm{mg}$ of soy isoflavone decreased the aortic pulse-wave velocity, another marker of CVD risk [261]. Daidzein (40 $\mu \mathrm{M})$, another member of the isoflavones group, inhibited high-glucose-induced iNOS, COX-2 and NF- $\mathrm{kB}$ expression in human EC, in parallel with the reduction of lipid peroxidation and ROS production [262]. Equol is a metabolite of daidzein produced by the intestinal microflora in the gut [263] and was described as activator of eNOS in EC by modulating the epidermal growth factor receptor (EGFR), the G-protein-coupled receptor GPR30 and mitochondrial ROS production [264]. Equol induced the relaxation of the rat aortic rings and stimulated endothelial NO production by activation of ERK1/2 and Akt signaling in human fetal EC [265]. In addition, soy isoflavones consumption by peri-menopausal women induced the increase of serum PON1 activity [95].

Studies from literature show that genistein exerts anti-inflammatory effects in vitro and in vivo by regulating different pro-inflammatory signaling pathways. Babu et al. showed that physiological concentrations of genistein significantly inhibit high glucose-induced adhesion of monocytes to human aortic EC and suppress MCP-1 and IL-8 endothelial production. These effects were due to genistein promoting PKA activity and were confirmed in diabetic $\mathrm{db} / \mathrm{db}$ mice [266]. Genistein supplementation in diabetic rats determined a statistically significant reduction of MCP-1, while increasing the anti-inflammatory IL-10 [266]. In EC exposed to homocysteine, genistein diminished the expression of IL-6 and ICAM-1 via NF-kB inhibition [267]. In a recent study, Xu et al. evaluated the effect of genistein on inflammation induced by Ang II in vascular SMC [268]. This study demonstrates that genistein decreases CRP and MMP-9 levels in SMC by regulating p38/ERK1/2-PPAR $\gamma / \mathrm{NF}-\mathrm{kB}$ signaling pathway [268]. Besides, it was shown that genistein inhibits TNF- $\alpha$ secretion in LPS-activated macrophages [191]. 
Recent studies show that genistein modulates the expression of miRNAs involved in inflammatory processes. It was reported that genistein pretreatment of HUVEC seduces in a dose-dependent manner the oxLDL-induced expressions of E-selectin, P-selectin, MCP-1, IL-8, VCAM-1 and ICAM-1. Further analyses established that the mechanism of action consists of genistein inducing reduction of miR-155 levels and elevation of the suppressor of cytokine signaling 1 (SOCS1) expression that further induces the inhibition of NF-kB signaling pathway in HUVECs [269]. A recent study of Gan et al. showed that genistein can inhibit isoproterenol-induced cardiac hypertrophy by increasing miR-451 and the tissue inhibitor of metalloproteinases 2 (TIMP2) expression (a miR-451 target gene), both in vitro in H9C2 embryonic rat cardiomyocytes and in vivo in isoproterenol-induced myocardial hypertrophy in mice [270].

\subsubsection{Anthocyanidins}

Anthocyanins and anthocyanidins are glycosylated, poly-hydroxy or poly-methoxy derivatives of flavylium cations (2-phenylchromenylium) (Figure 8). In nature, about 702 different anthocyanins and 27 anthocyanidins are present. They are water-soluble plant pigments that give red, purple or blue coloration to many fruits, flowers and leaves. The widely distributed anthocyanidins in human foods are: cyanidin, delphinidin, pelargonidin, peonidin, malvidin and petunidin. They are found in many berry fruits, eggplantss, red onion, purple cabbage and black rice [271]. Anthocyanins' bioavailability has quite large inter-individual variability, and is influenced by the food processing, availability of the enzymes involved in anthocyanins metabolism and the composition of the gut microbiota that metabolize anthocyanins [272]. After ingestion, anthocyanins appear rapidly in the circulation, reach the maximal concentration of $\sim 100 \mathrm{nM}$ within $1.5 \mathrm{~h}$ and disappear from the bloodstream by $6 \mathrm{~h}$ post consumption. The bioavailability of anthocyanins is very low $(1 \%)$, but it is increased by the absorption of their active metabolites (12.4\%) that were recently identified [271].

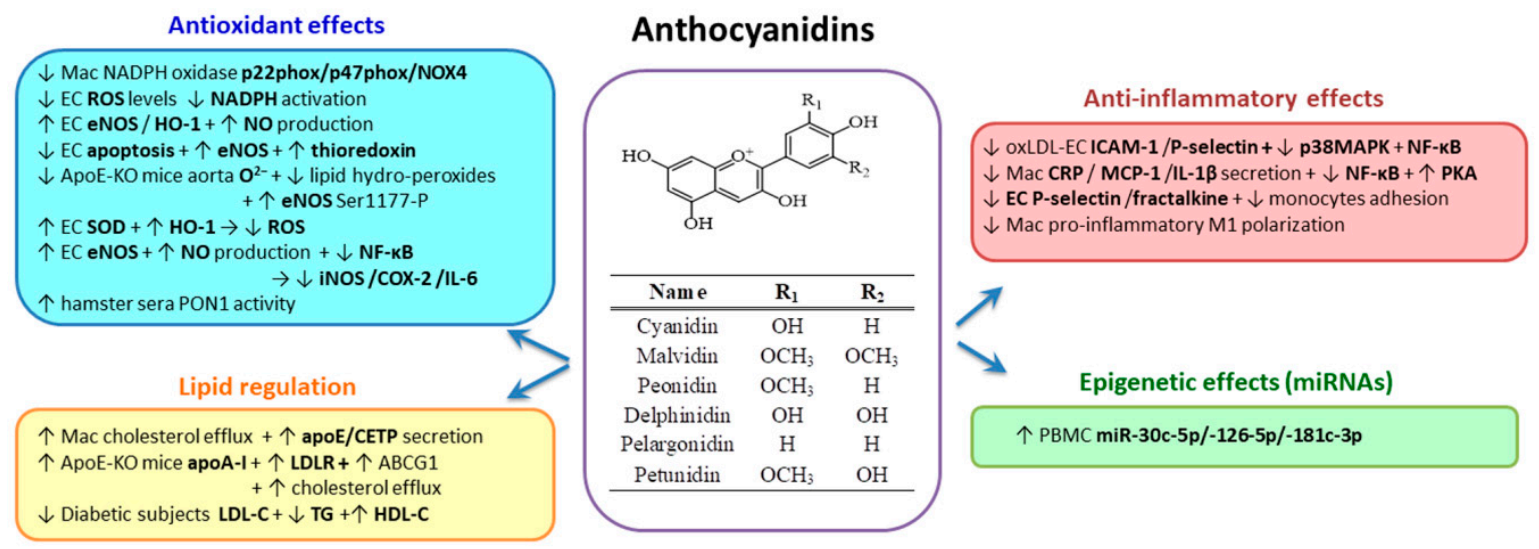

Figure 8. Anthocyanidins' classifications, chemical structures and beneficial effects for improving cardiovascular disease outcomes.

Anthocyanines/anthocyanidines and their metabolites ameliorate endothelial dysfunction and diminish the CVD risk [273]. Anthocyanins and flavonoids from bilberry (Vaccinium myrtillus) alcoholic extract can reduce the lipid deposits from the artery wall by inducing the cholesterol efflux from lipid-loaded macrophages through a mechanism involving increased secretion of apoE and CETP [274]. Anthocyanins from black elderberry (Sambucus nigra) extract induce expression of apoA-I and LDL-R in apoE-deficient mice [275]. Administration of $320 \mathrm{mg} /$ day anthocyanins to diabetic patients for 24 weeks improved their lipid profiles by significantly decreasing LDL-C and TG, and increasing HDL-C [276].

In parallel with the lipid-lowering effects, anthocyanins show antioxidant properties. Thus, the alcoholic extract of bilberries reduces the expression of NADPH oxidase subunits (p22phox, p47phox and NOX4) in lipid-loaded macrophages derived from THP-1 monocytes [274]. Mulberry 
(Morus alba) leaves have considerable amounts of flavonoids and anthocyanins. Treatment of human EC, pre-exposed to pro-inflammatory stimuli, with Morus Alba extract, inhibited the intracellular ROS levels due to reduction of NADPH oxidase activation [64]. Cyanidin-3-O-b-glucoside (C3G), a metabolite of cyanidin, has been shown to upregulate eNOS and HO-1 expression in a dose-dependent manner in EC, in parallel with an increase of NO production. The mechanism involves eNOS phosphorylation at Ser1179 and dephosphorylation of Ser116 [277,278]. Thioredoxin is one of the key regulators of intracellular redox status and it protects EC against oxidative stress. It was reported that nonaglycone cyanidin reduces TNF $\alpha$-induced apoptosis and upregulates eNOS and thioredoxin in EC [278]. Other pathways involved in EC protection by cyanidins are Akt, ERK1/2 and Src kinase positive regulation. In vivo studies show that $\mathrm{C} 3 \mathrm{G}$ intake $(2 \mathrm{~g} / \mathrm{kg}$ diet for 8 weeks) diminished the area of atherosclerotic plaques and alleviated the endothelium-dependent relaxation in fat-fed apoE-deficient mice. The underlying mechanisms of these benefic effects are: the decrease of superoxide and lipid hydroperoxide generation; the increase of Ser1177 phosphorylation in eNOS protein from the aorta; and the increase of ABCG1 expression that facilitates cholesterol efflux [279,280]. It was demonstrated that malvidin and its metabolites reduce ROS levels by upregulating SOD and HO-1 in EC [281]. In parallel, they induce eNOS expression, increase NO production and reduce peroxynitrite-induced NF-kB activation that further decreases the levels of pro-inflammatory mediators such as iNOS, COX-2 and IL-6 [282]. Anthocyanins combined with gallocatechins from Hibiscus sabdariffa extract, increase PON1 activity in hamster sera in a dose-response manner [283]. Alcoholic extract of maqui berry, another black fruit, decreases the levels of lipid peroxides and F2-isoprostanes in humans [284]. A study conducted in women shows that the dietary intake of anthocyanins is accompanied by a lower carotid-femoral pulse wave velocity and carotid intima-media thickness [285].

Chen et al. demonstrated that pretreatment with delphidin determines the reduction of ICAM-1 and P-selectin expression in oxLDL-activated EC, resulting in an inhibition of monocytes adhesion and transmigration [286]. These anti-inflammatory effects were determined by the inhibition of oxidative stress, mitigation of p38 MAPK expression and inhibition of NF- $\mathrm{kB}$ [286]. The bilberry extract diminishes the secretion of CRP, MCP-1 and IL-1 $\beta$ in lipid-loaded macrophages. These effects are driven by the inhibition of NF-KB and activation of PKA signaling pathways [274]. The Morus alba extract downregulates the pro-inflammatory molecules P-selectin and fractalkine, decreasing monocytes adhesion to EC [64]. In a recent study, Lee et al. demonstrated that anthocyanin-rich blackcurrant extract exerts anti-inflammatory action by repressing the pro-inflammatory M1 polarization of mouse bone marrow-derived macrophages and human THP-1 cells [287].

The effects of anthocyanins and their metabolites on miRNAs expression are still largely unknown, only a few studies having been published. Rodriguez-Mateos et al. performed, recently, a nutrigenomic study to explore the mechanism of action of anthocyanins in vivo [288]. They analyzed mRNAs and miRNAs in PBMC isolated from healthy volunteers at the beginning and the end of a 28-day period of anthocyanins-enriched vitamin mix or blueberry consumption. The results of the microarray analysis in PBMC showed that a daily blueberry consumption led to differential expression ( $>1.2$-fold) of 608 genes and three miRNAs (miR-30c-5p, miR-126-5p and miR-181c-3p). The most striking finding was a 13-fold increase of miR-181c expression evidenced in PMBC. Specific patterns of 13 metabolites were proven as independent predictors of mRNA expression alteration, and pathway enrichment analysis revealed significantly modulated biological processes involved in cell adhesion, migration, immune response and cell differentiation [288].

Anthocyanins are well tolerated and have no side effects, but their bioavailability is rather low, and they are rapidly transformed into phenolic acid derivates [289]. For this reason, additional experiments should be performed to develop new formulation of these natural active compounds to increase their protection, bioavailability and efficiency in vivo. Further studies are also desirable to assess the clinical efficiency of anthocyanins in different populations and to evaluate their benefic effects exerted on arteries affected by atherosclerosis. 


\subsection{Guaiacols Group}

Gingerols and shogaols are the most abundant active compounds of ginger (Zingiber officinale) rhizomes that are used since old times in the treatment of various symptoms and as dietary supplement in drinks and food products $[290,291]$. Gingerols differ in the length of their unbranched alkyl side chains, [6]-gingerol being the most abundant type in fresh ginger root, followed by [10]-gingerol and [8]-gingerol (Figure 9). Dehydration of these major gingerols generates the corresponding shogaols (Shao et al., 2010). The low solubility of the orally ingested gingerols generates their low bioavailability. These compounds are not completely free of side effects due to their interactions with other pharmaceutical active compounds, the gingerols acting as bioenhancers of certain drugs. Possible technological solutions for enhancing gingerols solubility and bioavailability, and preventing their harmful interactions comprise the microemulsions and nanocarriers/nanoparticles formulations of gingerols. Some liposomal ginger products were developed to increase their bioavailability. These structures are not degraded in the stomach, can enter liver cells, but their benefic effects remain to be demonstrated by in vivo studies [292].

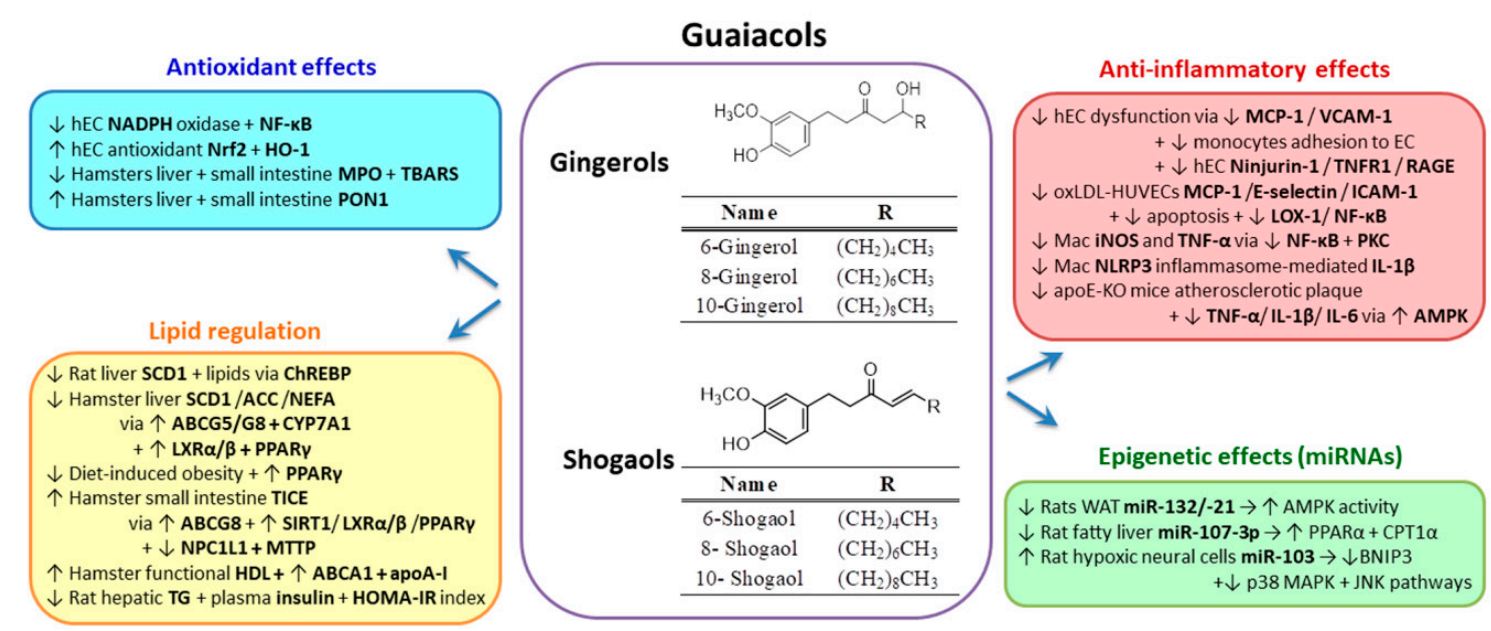

Figure 9. Guaiacols' classifications, chemical structures and molecular mechanisms of action to reduce cardiovascular diseases.

Ginger extract (GEx) exerts lipid-lowering effects, reduces stearoyl CoA desaturase 1 (SCD1) gene expression and accumulation of lipids in the liver of rats fed a fructose diet through a pathway mediated by hepatic carbohydrate response element-binding protein [293]. Recently, it was shown that a GEx, with very well characterized composition in gingerols and shogaols, diminishes the fatty acid production in hyperlipidemic conditions by reducing SCD1, ACC and non-esterified fatty acids levels in the liver and plasma of hyperlipidemic hamster [294]. The lipid-lowering properties of gingerols and shogaols can be also explained by the enhancement of hepatic cholesterol excretion into bile fluids, based on the induction of ABCG5/G8 and CYP7A1 expression in the liver of hyperlipidemic hamster. Lei et al. reported that the treatment with gingerol and shogaol-enriched GEx upregulates hepatic CYP7A1 [295]. The increase of ABCG5/G8 and CYP7A1 levels can be due to the induction of their transcription regulators $L X R \alpha / \beta$ and PPAR $\gamma$ which are stimulated by the decrease of endoplasmic reticulum stress [294]. The upregulation of PPAR $\gamma$ by GEx was also detected by Misawa et al., who showed that GEx attenuates diet-induced obesity and improves exercise endurance capacity by activation of the PPAR $\gamma$ pathway [296]. Gingerols and shogaols stimulate TICE through stimulation of ABCG8 gene and protein expression in the small intestine, due to the upregulation of SIRT1-LXR $\alpha / \beta-P P A R \gamma$ pathway $[117,295]$. In addition, the treatment with gingerol and shogaol-enriched GEx induces the downregulation of Niemann-Pick C1-Like 1 (NPC1L1) and MTTP in the small intestine of hamster [295]. In parallel, GEx stimulates the small intestine to produce functional HDL by restoring ABCA1 levels 
and apoA-I quality and quantity through inhibition of the oxidative stress. It was reported that these processes happening in the small intestine and liver are associated with the reduction of the aortic valves lipid-deposits [117].

GEx active constituents have proven to be effective in exerting antioxidant effects on dysfunctional $\mathrm{EC}$ in culture by decreasing the expression of NADPH oxidase subunits, inhibiting NF- $\mathrm{KB}$, activating the antioxidant Nrf2 and HO-1. GEx acts in vivo as antioxidant under dyslipidemic conditions by reducing MPO and thiobarbituric acid reactive substances (TBARS) levels and increasing PON1 levels in the liver, small intestine and plasma of hyperlipidemic hamsters [117,294].

Ginger is known since ancient times for its anti-inflammatory effects that ameliorate various diseases [297]. Recent data evidence the GEx potential and its major components, 6-gingerol and shogaol, to exert anti-inflammatory effects in EC by reversing TNF $\alpha$-induced EC dysfunction. Their mechanisms of action involve reduction of MCP-1, VCAM-1 and monocytes adhesion to EC, due to the decrease of Ninjurin-1, TNF $\alpha$ receptor 1 and RAGE expression [298]. Wang et al. demonstrated that 6-shogaol decreases MCP-1, E-selectin and ICAM-1 and the apoptosis of HUVECs exposed to oxLDL by inhibiting LOX-1, oxidative stress and NF-KB signaling [299]. Beneficial effects of 6-gingerol and 6-shogaol were demonstrated also in macrophages. In LPS-stimulated macrophages, 6-gingerol decreased iNOS and TNF- $\alpha$ expression by inhibiting NF- $\mathrm{kB}$ and PKC signaling [300]. In another study, 6-shogaol significantly inhibited the canonical NLRP3 inflammasome-mediated IL-1 $\beta$ secretion in THP-1 macrophages stimulated with LPS [301]. In a recent in vivo study, Wang et al. demonstrated that administration of 6-gingerol to fat-fed apoE-deficient mice determines the reduction of atherosclerosis, expressed as decreased plaque formation and reduced levels of pro-inflammatory cytokines (TNF- $\alpha$, IL-1 $\beta$, and IL-6) by a mechanism mediated in part by AMPK activation [302].

Knowing the GEx pleiotropic effects, several groups investigated its potential to modulate epigenetic factors associated with ncRNA. As the main active ingredient of ginger, 6-gingerol, was shown to significantly improve lipid metabolism abnormalities in adult rodents. A few studies have reported its molecular effects on age-related non-alcoholic fatty liver disease (NAFLD), as well as on epigenetic factors. In an in vivo recent study in aged rats, Li et al. demonstrated that 6-gingerol brought to normal the hepatic TG content, plasma insulin and HOMA-IR index of ageing rats [303]. Mechanistically, they showed that 6-gingerol modulates lipid metabolism by increasing $\beta$-oxidation and decreasing lipogenesis, through activation of liver PPAR $\alpha$ and carnitine palmitoyl-transferase $1 \alpha$ $(\mathrm{CPT} 1 \alpha)$, and inhibition of diacylglycerol O-acyltransferase 2 (DGAT-2) expression at translational level, but not at transcriptional level, to ameliorate ageing-associated hepatosteatosis. The authors further analyzed miRNAs targeting PPAR $\alpha$ and CPT1 $\alpha$ genes and reported that ageing significantly increased hepatic miR-34a expression in rats. Interestingly, 6-gingerol showed minimal effect on hepatic miR-34a. Additionally, 6-gingerol significantly decreased hepatic miR-107-3p level, thereby increasing PPAR $\alpha$ and CPT1 $\alpha$ genes [303]. Kim et al. investigated molecular factors involved in lipid metabolism and inflammation of the white adipose tissue (WAT), including miRNAs, modulated by GEx in Sprague-Dawley rats fed a high-fat diet [304]. They reported that GEx reduced body weight and WAT mass, mRNA levels of adipogenic genes, PPAR $\gamma$, adipocyte protein 2 (aP2), as well as pro-inflammatory cytokines (TNF $\alpha$, IL-6 and MCP-1). Obese rats expressed increased expression of miR-21 and miR-132 in WAT. Additionally, this report showed downregulated expression of miR-132 and miR-21 in WAT of rats after GEx administration, in parallel with a greater AMPK activity. The authors assumed that the reduced miR-21 and miR-132 levels could be associated with the post-translational regulation of genes involved in adipogenesis and inflammation in high-fat diet fed rats [304].

It has been reported that some phenolic compounds such as curcumin, RSV, quercetin, EGCG and genistein can interfere with assays via a number of different mechanisms (are potential pan-assay interference compounds-PAINS) and/or are considered invalid metabolic panaceas (IMPs) [305,306]. We recommend that this "warning bell" should be very seriously taken in consideration by the researchers that intend to extend the research in the field of phytochemicals therapeutic potential. The present review has taken in consideration only the phenolic compounds with known molecular 
mechanisms in vitro and in vivo, precisely to support their specific actions, and does not propose them as panacea.

\section{Conclusions}

This review amassed consistent knowledge concerning the mechanisms of action of the phenolic compounds, which ascertain their therapeutic potential to prevent or treat CVD. Phenolic compounds can regulate lipid metabolism and balance the oxidative and inflammatory stress through various epigenetic, transcriptional and translational mechanisms that have been demonstrated in vitro and in animal models; some of them have been confirmed in humans.

Phenolic compounds have various pharmacological properties and the present review highlighted those having robust potential to amend dyslipidemia or to diminish the oxidative and inflammatory stress, important risk factors for CVD. Thus, remarkable lipid-regulatory properties have the phenols from hydroxycinnamic acid, flavanols, anthocyanidines and guaiacols groups. They inhibit the lipid absorption in the small intestine; stimulate the cholesterol efflux from atheroma and cholesterol excretion through gallbladder or small intestine; and imped de novo lipid synthesis in the liver. The molecular mechanisms responsible for these effects involve activation of transcription regulators (SIRT-1, LXRs, PPARs). Important antioxidant and anti-inflammatory effects are described for almost all presented phenolic compounds, the main mechanisms of action being inhibition of NLRP3 inflammasome and NF-kB; activation of Nrf2 and Akt, and the consequent stimulation of eNOS and antioxidant enzymes, and inhibition of NADPH oxidase. All these processes are susceptible to be regulated at the epigenetic level, an increasing number of miRNAs modulating them being depicted. Interestingly, certain phenolic compounds, such as resveratrol and naringenin, bind directly to the genes to regulate various proteins synthesis.

Most of these findings come from experiments performed either in vitro or in vivo (experimental animals). Many of these outcomes have been consistently achieved from clinical studies, but some of them still need to be proved in humans. More studies are needed to widen the knowledge concerning the molecular actions of the phenolic compounds; some of them are not completely understood or are still controversial. Since the results obtained until now on improving the human health are promising, more studies in humans are needed to validate the beneficial effects of phenolic compounds in CVD. Additional clinical trials are warranted, but with improvement and standardization of the study design, formulations and doses to be assessed. Further investigations are necessary using larger and longer studies to better define the therapeutic role of phenolic compounds.

Herbal medication has lower adverse effects compared to synthetic drugs and thus presents the advantage that they can be used for a longer period of time. Many of the plant phenolic compounds exert their effects through different mechanisms, and we might expect additive effects when taken in combination, but this has to be scientifically proven. In many cases, it was demonstrated that the biologically active compounds are more efficient in plant extracts compared to the purified molecular components, the data supporting the synergistic action of plants' active compounds. Analyses comparing intake of phenolic compounds in different formulation (powder capsules, alcoholic extracts or encapsulation in nanocarriers) have produced conflicting results. Thus, greater attention should be given to combinations of phenolic compounds, their doses and formulations for administration. Further studies are needed to develop new forms of delivery for such natural bioactive compounds to improve compliance of patients at risk for CVD, and ensure their increased bioavailability, thereby creating more efficient products than the commercially available ones at present.

In the present review we have focused on the molecular mechanisms of action of the phenolic compounds that target dyslipidemia, oxidative and inflammatory stress, the main risk factors in the atherosclerotic process. We hope that we convinced the reader that their multiple benefic effects warrant their use as CVD remedies, complementarily to allopathic drugs. Consumption of foods containing natural phenolic compounds should be encouraged for people with low to moderate CVD 
risks; those who are preventive, and those who are at the same time on the prescription drugs to lower the incidence of fatal cardiovascular events.

Author Contributions: Conceptualization, L.T., A.V.S. and C.S.S.; writing-original draft preparation, L.T., G.M.S., L.S.N., M.D. and C.S.S.; writing-review and editing, L.T., C.S.S. and A.V.S. All authors have read and agreed to the published version of the manuscript.

Funding: This work was supported by the Romanian Academy.

Conflicts of Interest: The authors declare no conflict of interest.

\section{References}

1. European Society of Cardiology. 2019 ESC/EAS guidelines for the management of dyslipidaemias: Lipid modification to reduce cardiovascular risk. Atherosclerosis 2019, 290, 140-205. [CrossRef]

2. Bloom, D.E.; Cafiero, E.T.; Jané-Llopis, E.; Abrahams-Gessel, S.; Bloom, L.R.; Fathima, S.; Feigl, A.B.; Gaziano, T.; Mowafi, M.; Pandya, A.; et al. The Global Economic Burden of Non-Communicable Diseases; World Economic Forum: Geneva, Switzerland, 2011.

3. Cicero, A.F.G.; Colletti, A.; Bajraktari, G.; Descamps, O.; Djuric, D.M.; Ezhov, M.; Fras, Z.; Katsiki, N.; Langlois, M.; Latkovskis, G.; et al. Lipid-lowering nutraceuticals in clinical practice: Position paper from an International Lipid Expert Panel. Nutr. Rev. 2017, 75, 731-767. [CrossRef] [PubMed]

4. Sando, K.R.; Knight, M. Nonstatin therapies for management of dyslipidemia: A review. Clin. Ther. 2015, 37, 2153-2179. [CrossRef] [PubMed]

5. Uehara, Y.; Chiesa, G.; Saku, K. High-Density Lipoprotein-Targeted Therapy and Apolipoprotein A-I Mimetic Peptides. Circ. J. 2015, 79, 2523-2528. [CrossRef] [PubMed]

6. Musunuru, K. Atherogenic dyslipidemia: Cardiovascular risk and dietary intervention. Lipids 2010, 45, 907-914. [CrossRef]

7. Sima, A.V.; Stancu, C.S.; Simionescu, M. Vascular endothelium in atherosclerosis. Cell Tissue Res. 2009, 335, 191-203. [CrossRef]

8. Pavlovic, J.; Kavousi, M.; Ikram, M.A.; Leening, M.J.G. Updated treatment thresholds in the 2019 ESC/EAS dyslipidaemia guidelines substantially expand indications for statin use for primary prevention at population level: Results from the Rotterdam Study. Atherosclerosis 2020. [CrossRef]

9. Wolin, M.S. Interactions of oxidants with vascular signaling systems. Arterioscler. Thromb. Vasc. Biol. 2000, 20, 1430-1442. [CrossRef]

10. Puddu, P.; Puddu, G.M.; Cravero, E.; De Pascalis, S.; Muscari, A. The emerging role of cardiovascular risk factor-induced mitochondrial dysfunction in atherogenesis. J. Biomed. Sci. 2009, 16, 112. [CrossRef]

11. Wattanapitayakul, S.K.; Bauer, J.A. Oxidative pathways in cardiovascular disease: Roles, mechanisms, and therapeutic implications. Pharmacol. Ther. 2001, 89, 187-206. [CrossRef]

12. Valko, M.; Leibfritz, D.; Moncol, J.; Cronin, M.T.; Mazur, M.; Telser, J. Free radicals and antioxidants in normal physiological functions and human disease. Int. J. Biochem. Cell Biol. 2007, 39, 44-84. [CrossRef] [PubMed]

13. Yang, Y.; Duan, W.; Lin, Y.; Yi, W.; Liang, Z.; Yan, J.; Wang, N.; Deng, C.; Zhang, S.; Li, Y.; et al. SIRT1 activation by curcumin pretreatment attenuates mitochondrial oxidative damage induced by myocardial ischemia reperfusion injury. Free Radic. Biol. Med. 2013, 65, 667-679. [CrossRef] [PubMed]

14. Martindale, J.L.; Holbrook, N.J. Cellular response to oxidative stress: Signaling for suicide and survival. J. Cell. Physiol. 2002, 192, 1-15. [CrossRef] [PubMed]

15. Lee, J.H.; Khor, T.O.; Shu, L.; Su, Z.Y.; Fuentes, F.; Kong, A.N. Dietary phytochemicals and cancer prevention: Nrf2 signaling, epigenetics, and cell death mechanisms in blocking cancer initiation and progression. Pharmacol. Ther. 2013, 137, 153-171. [CrossRef]

16. Ortiz-Munoz, G.; Couret, D.; Lapergue, B.; Bruckert, E.; Meseguer, E.; Amarenco, P.; Meilhac, O. Dysfunctional HDL in acute stroke. Atherosclerosis 2016, 253, 75-80. [CrossRef]

17. Carnuta, M.G.; Stancu, C.S.; Toma, L.; Sanda, G.M.; Niculescu, L.S.; Deleanu, M.; Popescu, A.C.; Popescu, M.R.; Vlad, A.; Dimulescu, D.R.; et al. Dysfunctional high-density lipoproteins have distinct composition, diminished anti-inflammatory potential and discriminate acute coronary syndrome from stable coronary artery disease patients. Sci. Rep. 2017, 7, 7295. [CrossRef] 
18. Parhofer, K.G. Increasing HDL-cholesterol and prevention of atherosclerosis: A critical perspective. Atheroscler. Suppl. 2015, 18, 109-111. [CrossRef]

19. Variji, A.; Shokri, Y.; Fallahpour, S.; Zargari, M.; Bagheri, B.; Abediankenari, S.; Alizadeh, A.; Mahrooz, A. The combined utility of myeloperoxidase (MPO) and paraoxonase 1 (PON1) as two important HDL-associated enzymes in coronary artery disease: Which has a stronger predictive role? Atherosclerosis 2019, 280, 7-13. [CrossRef] [PubMed]

20. Nguyen, M.T.; Fernando, S.; Schwarz, N.; Tan, J.T.; Bursill, C.A.; Psaltis, P.J. Inflammation as a Therapeutic Target in Atherosclerosis. J. Clin. Med. 2019, 8, 1109. [CrossRef] [PubMed]

21. Zhu, Y.; Xian, X.; Wang, Z.; Bi, Y.; Chen, Q.; Han, X.; Tang, D.; Chen, R. Research Progress on the Relationship between Atherosclerosis and Inflammation. Biomolecules 2018, 8, 80. [CrossRef]

22. Bi, Y.; Chen, J.; Hu, F.; Liu, J.; Li, M.; Zhao, L. M2 Macrophages as a Potential Target for Antiatherosclerosis Treatment. Neural Plast. 2019, 2019, 6724903. [CrossRef] [PubMed]

23. Pamukcu, B.; Lip, G.Y.; Shantsila, E. The nuclear factor-kappa B pathway in atherosclerosis: A potential therapeutic target for atherothrombotic vascular disease. Thromb. Res. 2011, 128, 117-123. [CrossRef] [PubMed]

24. Sosnowska, B.; Mazidi, M.; Penson, P.; Gluba-Brzozka, A.; Rysz, J.; Banach, M. The sirtuin family members SIRT1, SIRT3 and SIRT6: Their role in vascular biology and atherogenesis. Atherosclerosis 2017, 265, 275-282. [CrossRef] [PubMed]

25. Grebe, A.; Hoss, F.; Latz, E. NLRP3 Inflammasome and the IL-1 Pathway in Atherosclerosis. Circ. Res. 2018, 122, 1722-1740. [CrossRef]

26. Botker, H.E.; Hausenloy, D.; Andreadou, I.; Antonucci, S.; Boengler, K.; Davidson, S.M.; Deshwal, S.; Devaux, Y.; Di Lisa, F.; Di Sante, M.; et al. Practical guidelines for rigor and reproducibility in preclinical and clinical studies on cardioprotection. Basic Res. Cardiol. 2018, 113, 39. [CrossRef]

27. Jacquier, A. The complex eukaryotic transcriptome: Unexpected pervasive transcription and novel small RNAs. Nat. Rev. Genet. 2009, 10, 833-844. [CrossRef]

28. Papageorgiou, N.; Tslamandris, S.; Giolis, A.; Tousoulis, D. MicroRNAs in Cardiovascular Disease: Perspectives and Reality. Cardiol. Rev. 2016, 24, 110-118. [CrossRef]

29. Gomes, C.P.C.; Schroen, B.; Kuster, G.M.; Robinson, E.L.; Ford, K.; Squire, I.B.; Heymans, S.; Martelli, F.; Emanueli, C.; Devaux, Y.; et al. Regulatory RNAs in Heart Failure. Circulation 2020, 141, 313-328. [CrossRef]

30. Moore, K.J.; Rayner, K.J.; Suarez, Y.; Fernandez-Hernando, C. microRNAs and cholesterol metabolism. Trends Endocrinol. Metab. TEM 2010, 21, 699-706. [CrossRef]

31. Bartel, D.P. MicroRNAs: Target recognition and regulatory functions. Cell 2009, 136, 215-233. [CrossRef]

32. Forman, J.J.; Coller, H.A. The code within the code: MicroRNAs target coding regions. Cell Cycle 2010, 9 , 1533-1541. [CrossRef] [PubMed]

33. Vickers, K.C.; Palmisano, B.T.; Shoucri, B.M.; Shamburek, R.D.; Remaley, A.T. MicroRNAs are transported in plasma and delivered to recipient cells by high-density lipoproteins. Nat. Cell Biol. 2011, 13, 423-433. [CrossRef] [PubMed]

34. Arroyo, J.D.; Chevillet, J.R.; Kroh, E.M.; Ruf, I.K.; Pritchard, C.C.; Gibson, D.F.; Mitchell, P.S.; Bennett, C.F.; Pogosova-Agadjanyan, E.L.; Stirewalt, D.L.; et al. Argonaute2 complexes carry a population of circulating microRNAs independent of vesicles in human plasma. Proc. Natl. Acad. Sci. USA 2011, 108, 5003-5008. [CrossRef]

35. Weber, J.A.; Baxter, D.H.; Zhang, S.; Huang, D.Y.; Huang, K.H.; Lee, M.J.; Galas, D.J.; Wang, K. The microRNA spectrum in 12 body fluids. Clin. Chem. 2010, 56, 1733-1741. [CrossRef] [PubMed]

36. Devaux, Y. Transcriptome of blood cells as a reservoir of cardiovascular biomarkers. Biochim. Biophys. Acta. Mol. Cell Res. 2017, 1864, 209-216. [CrossRef] [PubMed]

37. Cortez, M.A.; Bueso-Ramos, C.; Ferdin, J.; Lopez-Berestein, G.; Sood, A.K.; Calin, G.A. MicroRNAs in body fluids-the mix of hormones and biomarkers. Nat. Rev. Clin. Oncol. 2011, 8, 467-477. [CrossRef] [PubMed]

38. Devaux, Y.; Vausort, M.; Goretti, E.; Nazarov, P.V.; Azuaje, F.; Gilson, G.; Corsten, M.F.; Schroen, B.; Lair, M.L.; Heymans, S.; et al. Use of circulating microRNAs to diagnose acute myocardial infarction. Clin. Chem. 2012, 58, 559-567. [CrossRef]

39. Jansen, F.; Yang, X.; Proebsting, S.; Hoelscher, M.; Przybilla, D.; Baumann, K.; Schmitz, T.; Dolf, A.; Endl, E.; Franklin, B.S.; et al. MicroRNA expression in circulating microvesicles predicts cardiovascular events in patients with coronary artery disease. J. Am. Heart Assoc. 2014, 3, e001249. [CrossRef] 
40. Niculescu, L.S.; Simionescu, N.; Sanda, G.M.; Carnuta, M.G.; Stancu, C.S.; Popescu, A.C.; Popescu, M.R.; Vlad, A.; Dimulescu, D.R.; Simionescu, M.; et al. MiR-486 and miR-92a Identified in Circulating HDL Discriminate between Stable and Vulnerable Coronary Artery Disease Patients. PLoS ONE 2015, 10, e0140958. [CrossRef]

41. Simionescu, N.; Niculescu, L.S.; Carnuta, M.G.; Sanda, G.M.; Stancu, C.S.; Popescu, A.C.; Popescu, M.R.; Vlad, A.; Dimulescu, D.R.; Simionescu, M.; et al. Hyperglycemia Determines Increased Specific MicroRNAs Levels in Sera and HDL of Acute Coronary Syndrome Patients and Stimulates MicroRNAs Production in Human Macrophages. PLoS ONE 2016, 11, e0161201. [CrossRef]

42. Niculescu, L.S.; Dulceanu, M.D.; Stancu, C.S.; Carnuta, M.G.; Barbalata, T.; Sima, A.V. Probiotics administration or the high-fat diet arrest modulates microRNAs levels in hyperlipidemic hamsters. J. Funct. Foods 2019, 56, 295-302. [CrossRef]

43. Afman, L.; Milenkovic, D.; Roche, H.M. Nutritional aspects of metabolic inflammation in relation to health-insights from transcriptomic biomarkers in PBMC of fatty acids and polyphenols. Mol. Nutr. Food Res. 2014, 58, 1708-1720. [CrossRef] [PubMed]

44. Sobhani, M.; Farzaei, M.H.; Kiani, S.; Khodarahmi, R. Immunomodulatory; Anti-inflammatory/antioxidant Effects of Polyphenols: A Comparative Review on the Parental Compounds and Their Metabolites. Food Rev. Int. 2020, 1-53. [CrossRef]

45. Subramaniam, S.; Selvaduray, K.R.; Radhakrishnan, A.K. Bioactive Compounds: Natural Defense Against Cancer? Biomolecules 2019, 9, 758. [CrossRef]

46. Jamwal, R. Bioavailable curcumin formulations: A review of pharmacokinetic studies in healthy volunteers. J. Integr. Med. 2018, 16, 367-374. [CrossRef]

47. DiSilvestro, R.A.; Joseph, E.; Zhao, S.; Bomser, J. Diverse effects of a low dose supplement of lipidated curcumin in healthy middle aged people. Nutr. J. 2012, 11, 79. [CrossRef]

48. Mollazadeh, H.; Mahdian, D.; Hosseinzadeh, H. Medicinal plants in treatment of hypertriglyceridemia: A review based on their mechanisms and effectiveness. Phytomed. Int. J. Phytother. Phytopharmacol. 2019, 53, 43-52. [CrossRef]

49. Asai, A.; Nakagawa, K.; Miyazawa, T. Antioxidative effects of turmeric, rosemary and capsicum extracts on membrane phospholipid peroxidation and liver lipid metabolism in mice. Biosci. Biotechnol. Biochem. 1999, 63, 2118-2122. [CrossRef]

50. Shin, S.K.; Ha, T.Y.; McGregor, R.A.; Choi, M.S. Long-term curcumin administration protects against atherosclerosis via hepatic regulation of lipoprotein cholesterol metabolism. Mol. Nutr. Food Res. 2011, 55, 1829-1840. [CrossRef]

51. Hamer, M.; O’Donovan, G.; Stamatakis, E. High-Density Lipoprotein Cholesterol and Mortality: Too Much of a Good Thing? Arterioscler. Thromb. Vasc. Biol. 2018, 38, 669-672. [CrossRef]

52. Soetikno, V.; Sari, F.R.; Sukumaran, V.; Lakshmanan, A.P.; Mito, S.; Harima, M.; Thandavarayan, R.A.; Suzuki, K.; Nagata, M.; Takagi, R.; et al. Curcumin prevents diabetic cardiomyopathy in streptozotocin-induced diabetic rats: Possible involvement of PKC-MAPK signaling pathway. Eur. J. Pharm. Sci. 2012, 47, 604-614. [CrossRef] [PubMed]

53. Yu, W.; Wu, J.; Cai, F.; Xiang, J.; Zha, W.; Fan, D.; Guo, S.; Ming, Z.; Liu, C. Curcumin alleviates diabetic cardiomyopathy in experimental diabetic rats. PLoS ONE 2012, 7, e52013. [CrossRef]

54. Tanwar, V.; Sachdeva, J.; Kishore, K.; Mittal, R.; Nag, T.C.; Ray, R.; Kumari, S.; Arya, D.S. Dose-dependent actions of curcumin in experimentally induced myocardial necrosis: A biochemical, histopathological, and electron microscopic evidence. Cell Biochem. Funct. 2010, 28, 74-82. [CrossRef] [PubMed]

55. Nazam Ansari, M.; Bhandari, U.; Pillai, K.K. Protective role of curcumin in myocardial oxidative damage induced by isoproterenol in rats. Hum. Exp. Toxicol. 2007, 26, 933-938. [CrossRef] [PubMed]

56. Soares, M.P.; Seldon, M.P.; Gregoire, I.P.; Vassilevskaia, T.; Berberat, P.O.; Yu, J.; Tsui, T.Y.; Bach, F.H. Heme oxygenase-1 modulates the expression of adhesion molecules associated with endothelial cell activation. J. Immunol. 2004, 172, 3553-3563. [CrossRef] [PubMed]

57. Olszanecki, R.; Gebska, A.; Korbut, R. The role of haem oxygenase-1 in the decrease of endothelial intercellular adhesion molecule-1 expression by curcumin. Basic Clin. Pharmacol. Toxicol. 2007, 101, 411-415. [CrossRef]

58. Nabavi, S.F.; Barber, A.J.; Spagnuolo, C.; Russo, G.L.; Daglia, M.; Nabavi, S.M.; Sobarzo-Sanchez, E. Nrf2 as molecular target for polyphenols: A novel therapeutic strategy in diabetic retinopathy. Crit. Rev. Clin. Lab. Sci. 2016, 53, 293-312. [CrossRef] 
59. Kang, E.S.; Woo, I.S.; Kim, H.J.; Eun, S.Y.; Paek, K.S.; Kim, H.J.; Chang, K.C.; Lee, J.H.; Lee, H.T.; Kim, J.H.; et al. Up-regulation of aldose reductase expression mediated by phosphatidylinositol 3-kinase/Akt and Nrf2 is involved in the protective effect of curcumin against oxidative damage. Free Radic. Biol. Med. 2007, 43, 535-545. [CrossRef]

60. Yang, H.; Xu, W.; Zhou, Z.; Liu, J.; Li, X.; Chen, L.; Weng, J.; Yu, Z. Curcumin attenuates urinary excretion of albumin in type II diabetic patients with enhancing nuclear factor erythroid-derived 2-like 2 (Nrf2) system and repressing inflammatory signaling efficacies. Exp. Clin. Endocrinol. Diabetes 2015, 123, 360-367. [CrossRef]

61. Wongeakin, N.; Bhattarakosol, P.; Patumraj, S. Molecular mechanisms of curcumin on diabetes-induced endothelial dysfunctions: Txnip, ICAM-1, and NOX2 expressions. BioMed Res. Int. 2014, 2014, 161346. [CrossRef]

62. Zeng, C.; Zhong, P.; Zhao, Y.; Kanchana, K.; Zhang, Y.; Khan, Z.A.; Chakrabarti, S.; Wu, L.; Wang, J.; Liang, G. Curcumin protects hearts from FFA-induced injury by activating Nrf2 and inactivating NF-kappaB both in vitro and in vivo. J. Mol. Cell. Cardiol. 2015, 79, 1-12. [CrossRef] [PubMed]

63. Coban, D.; Milenkovic, D.; Chanet, A.; Khallou-Laschet, J.; Sabbe, L.; Palagani, A.; Vanden Berghe, W.; Mazur, A.; Morand, C. Dietary curcumin inhibits atherosclerosis by affecting the expression of genes involved in leukocyte adhesion and transendothelial migration. Mol. Nutr. Food Res. 2012, 56, 1270-1281. [CrossRef] [PubMed]

64. Pirvulescu, M.M.; Gan, A.M.; Stan, D.; Simion, V.; Calin, M.; Butoi, E.; Tirgoviste, C.I.; Manduteanu, I. Curcumin and a Morus alba extract reduce pro-inflammatory effects of resistin in human endothelial cells. Phytother. Res. PTR 2011, 25, 1737-1742. [CrossRef] [PubMed]

65. Monfoulet, L.E.; Mercier, S.; Bayle, D.; Tamaian, R.; Barber-Chamoux, N.; Morand, C.; Milenkovic, D. Curcumin modulates endothelial permeability and monocyte transendothelial migration by affecting endothelial cell dynamics. Free Radic. Biol. Med. 2017, 112, 109-120. [CrossRef] [PubMed]

66. Karimian, M.S.; Pirro, M.; Majeed, M.; Sahebkar, A. Curcumin as a natural regulator of monocyte chemoattractant protein-1. Cytokine Growth Factor Rev. 2017, 33, 55-63. [CrossRef]

67. Hao, Q.; Chen, X.; Wang, X.; Dong, B.; Yang, C. Curcumin Attenuates Angiotensin II-Induced Abdominal Aortic Aneurysm by Inhibition of Inflammatory Response and ERK Signaling Pathways. Evid.-Based Complement. Altern. Med. eCAM 2014, 2014, 270930. [CrossRef]

68. Wang, J.; Dong, S. ICAM-1 and IL-8 are expressed by DEHP and suppressed by curcumin through ERK and p38 MAPK in human umbilical vein endothelial cells. Inflammation 2012, 35, 859-870. [CrossRef]

69. Tsai, I.J.; Chen, C.W.; Tsai, S.Y.; Wang, P.Y.; Owaga, E.; Hsieh, R.H. Curcumin supplementation ameliorated vascular dysfunction and improved antioxidant status in rats fed a high-sucrose, high-fat diet. Appl. Physiol. Nutr. Metab. 2018, 43, 669-676. [CrossRef]

70. Han, Y.; Sun, H.J.; Tong, Y.; Chen, Y.Z.; Ye, C.; Qiu, Y.; Zhang, F.; Chen, A.D.; Qi, X.H.; Chen, Q.; et al. Curcumin attenuates migration of vascular smooth muscle cells via inhibiting NFkappaB-mediated NLRP3 expression in spontaneously hypertensive rats. J. Nutr. Biochem. 2019, 72, 108212. [CrossRef]

71. Sun, H.J.; Ren, X.S.; Xiong, X.Q.; Chen, Y.Z.; Zhao, M.X.; Wang, J.J.; Zhou, Y.B.; Han, Y.; Chen, Q.; Li, Y.H.; et al. NLRP3 inflammasome activation contributes to VSMC phenotypic transformation and proliferation in hypertension. Cell Death Dis. 2017, 8, e3074. [CrossRef]

72. Yin, H.; Guo, Q.; Li, X.; Tang, T.; Li, C.; Wang, H.; Sun, Y.; Feng, Q.; Ma, C.; Gao, C.; et al. Curcumin Suppresses IL-1beta Secretion and Prevents Inflammation through Inhibition of the NLRP3 Inflammasome. J. Immunol. 2018, 200, 2835-2846. [CrossRef] [PubMed]

73. Chen, F.; Guo, N.; Cao, G.; Zhou, J.; Yuan, Z. Molecular analysis of curcumin-induced polarization of murine RAW264.7 macrophages. J. Cardiovasc. Pharmacol. 2014, 63, 544-552. [CrossRef] [PubMed]

74. Chen, F.Y.; Zhou, J.; Guo, N.; Ma, W.G.; Huang, X.; Wang, H.; Yuan, Z.Y. Curcumin retunes cholesterol transport homeostasis and inflammation response in M1 macrophage to prevent atherosclerosis. Biochem. Biophys. Res. Commun. 2015, 467, 872-878. [CrossRef] [PubMed]

75. Miao, Y.; Zhao, S.; Gao, Y.; Wang, R.; Wu, Q.; Wu, H.; Luo, T. Curcumin pretreatment attenuates inflammation and mitochondrial dysfunction in experimental stroke: The possible role of Sirt1 signaling. Brain Res. Bull. 2016, 121, 9-15. [CrossRef] [PubMed] 
76. Wu, Y.; Xu, J.; Xu, J.; Zheng, W.; Chen, Q.; Jiao, D. Study on the mechanism of JAK2/STAT3 signaling pathway-mediated inflammatory reaction after cerebral ischemia. Mol. Med. Rep. 2018, 17, 5007-5012. [CrossRef] [PubMed]

77. Li, W.; Suwanwela, N.C.; Patumraj, S. Curcumin by down-regulating NF-kB and elevating Nrf2, reduces brain edema and neurological dysfunction after cerebral I/R. Microvasc. Res. 2016, 106, 117-127. [CrossRef]

78. Tu, X.K.; Yang, W.Z.; Chen, J.P.; Chen, Y.; Ouyang, L.Q.; Xu, Y.C.; Shi, S.S. Curcumin inhibits TLR2/4-NF-kappaB signaling pathway and attenuates brain damage in permanent focal cerebral ischemia in rats. Inflammation 2014, 37, 1544-1551. [CrossRef] [PubMed]

79. Hatcher, H.; Planalp, R.; Cho, J.; Torti, F.M.; Torti, S.V. Curcumin: From ancient medicine to current clinical trials. Cell. Mol. Life Sci. CMLS 2008, 65, 1631-1652. [CrossRef]

80. Lin, K.; Chen, H.; Chen, X.; Qian, J.; Huang, S.; Huang, W. Efficacy of Curcumin on Aortic Atherosclerosis: A Systematic Review and Meta-Analysis in Mouse Studies and Insights into Possible Mechanisms. Oxid. Med. Cell. Longev. 2020, 2020, 1520747. [CrossRef]

81. Mirzabeigi, P.; Mohammadpour, A.H.; Salarifar, M.; Gholami, K.; Mojtahedzadeh, M.; Javadi, M.R. The Effect of Curcumin on some of Traditional and Non-traditional Cardiovascular Risk Factors: A Pilot Randomized, Double-blind, Placebo-controlled Trial. Iran. J. Pharm. Res. IJPR 2015, 14, 479-486.

82. Baum, L.; Cheung, S.K.; Mok, V.C.; Lam, L.C.; Leung, V.P.; Hui, E.; Ng, C.C.; Chow, M.; Ho, P.C.; Lam, S.; et al. Curcumin effects on blood lipid profile in a 6-month human study. Pharmacol. Res. 2007, 56, 509-514. [CrossRef] [PubMed]

83. Yang, Y.S.; Su, Y.F.; Yang, H.W.; Lee, Y.H.; Chou, J.I.; Ueng, K.C. Lipid-lowering effects of curcumin in patients with metabolic syndrome: A randomized, double-blind, placebo-controlled trial. Phytother. Res. PTR 2014, 28, 1770-1777. [CrossRef]

84. Panahi, Y.; Ghanei, M.; Bashiri, S.; Hajihashemi, A.; Sahebkar, A. Short-term Curcuminoid Supplementation for Chronic Pulmonary Complications due to Sulfur Mustard Intoxication: Positive Results of a Randomized Double-blind Placebo-controlled Trial. Drug Res. 2015, 65, 567-573. [CrossRef]

85. Simion, V.; Stan, D.; Constantinescu, C.A.; Deleanu, M.; Dragan, E.; Tucureanu, M.M.; Gan, A.M.; Butoi, E.; Constantin, A.; Manduteanu, I.; et al. Conjugation of curcumin-loaded lipid nanoemulsions with cell-penetrating peptides increases their cellular uptake and enhances the anti-inflammatory effects in endothelial cells. J. Pharm. Pharmacol. 2016, 68, 195-207. [CrossRef]

86. Ma, F.; Liu, F.; Ding, L.; You, M.; Yue, H.; Zhou, Y.; Hou, Y. Anti-inflammatory effects of curcumin are associated with down regulating microRNA-155 in LPS-treated macrophages and mice. Pharm. Biol. 2017, 55, 1263-1273. [CrossRef] [PubMed]

87. Zhang, J.; Wang, Q.; Rao, G.; Qiu, J.; He, R. Curcumin improves perfusion recovery in experimental peripheral arterial disease by upregulating microRNA-93 expression. Exp. Ther. Med. 2019, 17, 798-802. [CrossRef] [PubMed]

88. Geng, H.H.; Li, R.; Su, Y.M.; Xiao, J.; Pan, M.; Cai, X.X.; Ji, X.P. Curcumin protects cardiac myocyte against hypoxia-induced apoptosis through upregulating miR-7a/b expression. Biomed. Pharmacother. 2016, 81, 258-264. [CrossRef]

89. Tian, L.; Song, Z.; Shao, W.; Du, W.W.; Zhao, L.R.; Zeng, K.; Yang, B.B.; Jin, T. Curcumin represses mouse 3T3-L1 cell adipogenic differentiation via inhibiting miR-17-5p and stimulating the Wnt signalling pathway effector Tcf712. Cell Death Dis. 2017, 8, e2559. [CrossRef]

90. El-Seedi, H.R.; El-Said, A.M.; Khalifa, S.A.; Goransson, U.; Bohlin, L.; Borg-Karlson, A.K.; Verpoorte, R. Biosynthesis, natural sources, dietary intake, pharmacokinetic properties, and biological activities of hydroxycinnamic acids. J. Agric. Food Chem. 2012, 60, 10877-10895. [CrossRef]

91. David, I.G.; Bizgan, A.M.; Popa, D.E.; Buleandra, M.; Moldovan, Z.; Badea, I.A.; Tekiner, T.A.; Basaga, H.; Ciucu, A.A. Rapid determination of total polyphenolic content in tea samples based on caffeic acid voltammetric behaviour on a disposable graphite electrode. Food Chem. 2015, 173, 1059-1065. [CrossRef]

92. Rebelo, M.J.; Rego, R.; Ferreira, M.; Oliveira, M.C. Comparative study of the antioxidant capacity and polyphenol content of Douro wines by chemical and electrochemical methods. Food Chem. 2013, 141, 566-573. [CrossRef] [PubMed]

93. Garrido, E.; Cerqueira, A.S.; Chavarria, D.; Silva, T.; Borges, F.; Garrido, J. Microencapsulation of caffeic acid phenethyl ester and caffeic acid phenethyl amide by inclusion in hydroxypropyl-beta-cyclodextrin. Food Chem. 2018, 254, 260-265. [CrossRef] [PubMed] 
94. Wang, S.J.; Zeng, J.; Yang, B.K.; Zhong, Y.M. Bioavailability of caffeic acid in rats and its absorption properties in the Caco-2 cell model. Pharm. Biol. 2014, 52, 1150-1157. [CrossRef] [PubMed]

95. Moya, C.; Manez, S. Paraoxonases: Metabolic role and pharmacological projection. Naunyn-Schmiedeberg's Arch. Pharmacol. 2018, 391, 349-359. [CrossRef]

96. Wang, X.; Stavchansky, S.; Zhao, B.; Bynum, J.A.; Kerwin, S.M.; Bowman, P.D. Cytoprotection of human endothelial cells from menadione cytotoxicity by caffeic acid phenethyl ester: The role of heme oxygenase-1. Eur. J. Pharmacol. 2008, 591, 28-35. [CrossRef]

97. Kim, J.K.; Jang, H.D. Nrf2-mediated HO-1 induction coupled with the ERK signaling pathway contributes to indirect antioxidant capacity of caffeic acid phenethyl ester in HepG2 cells. Int. J. Mol. Sci. 2014, 15, 12149-12165. [CrossRef]

98. Dinkova-Kostova, A.T.; Holtzclaw, W.D.; Cole, R.N.; Itoh, K.; Wakabayashi, N.; Katoh, Y.; Yamamoto, M.; Talalay, P. Direct evidence that sulfhydryl groups of Keap1 are the sensors regulating induction of phase 2 enzymes that protect against carcinogens and oxidants. Proc. Natl. Acad. Sci. USA 2002, 99, 11908-11913. [CrossRef]

99. Taylan, M.; Kaya, H.; Demir, M.; Evliyaoglu, O.; Sen, H.S.; Firat, U.; Keles, A.; Yilmaz, S.; Sezgi, C. The Protective Effects of Caffeic Acid Phenethyl Ester on Acetylsalicylic Acid-induced Lung Injury in Rats. J. Investig. Surg. 2016, 29, 328-334. [CrossRef]

100. Moon, M.K.; Lee, Y.J.; Kim, J.S.; Kang, D.G.; Lee, H.S. Effect of caffeic acid on tumor necrosis factor-alpha-induced vascular inflammation in human umbilical vein endothelial cells. Biol. Pharm. Bull. 2009, 32, 1371-1377. [CrossRef]

101. Toma, L.; Sanda, G.M.; Niculescu, L.S.; Deleanu, M.; Stancu, C.S.; Sima, A.V. Caffeic acid attenuates the inflammatory stress induced by glycated LDL in human endothelial cells by mechanisms involving inhibition of AGE-receptor, oxidative, and endoplasmic reticulum stress. BioFactors 2017, 43, 685-697. [CrossRef]

102. Ibitoye, O.B.; Ajiboye, T.O. Dietary phenolic acids reverse insulin resistance, hyperglycaemia, dyslipidaemia, inflammation and oxidative stress in high-fructose diet-induced metabolic syndrome rats. Arch. Physiol. Biochem. 2018, 124, 410-417. [CrossRef] [PubMed]

103. Shahbazi, S.; Sahrawat, T.R.; Ray, M.; Dash, S.; Kar, D.; Singh, S. Drug Targets for Cardiovascular-Safe Anti-Inflammatory: In Silico Rational Drug Studies. PLoS ONE 2016, 11, e0156156. [CrossRef] [PubMed]

104. Murase, T.; Misawa, K.; Minegishi, Y.; Aoki, M.; Ominami, H.; Suzuki, Y.; Shibuya, Y.; Hase, T. Coffee polyphenols suppress diet-induced body fat accumulation by downregulating SREBP-1c and related molecules in C57BL/6J mice. Am. J. Physiol. Endocrinol. Metab. 2011, 300, E122-E133. [CrossRef]

105. Matboli, M.; Eissa, S.; Ibrahim, D.; Hegazy, M.G.A.; Imam, S.S.; Habib, E.K. Caffeic Acid Attenuates Diabetic Kidney Disease via Modulation of Autophagy in a High-Fat Diet/Streptozotocin- Induced Diabetic Rat. Sci. Rep. 2017, 7, 2263. [CrossRef]

106. Hou, C.Y.; Tain, Y.L.; Yu, H.R.; Huang, L.T. The Effects of Resveratrol in the Treatment of Metabolic Syndrome. Int. J. Mol. Sci. 2019, 20, 535. [CrossRef]

107. Amri, A.; Chaumeil, J.C.; Sfar, S.; Charrueau, C. Administration of resveratrol: What formulation solutions to bioavailability limitations? J. Controll. Release 2012, 158, 182-193. [CrossRef]

108. Chimento, A.; De Amicis, F.; Sirianni, R.; Sinicropi, M.S.; Puoci, F.; Casaburi, I.; Saturnino, C.; Pezzi, V. Progress to Improve Oral Bioavailability and Beneficial Effects of Resveratrol. Int. J. Mol. Sci. 2019, 20, 1381. [CrossRef]

109. Cho, I.J.; Ahn, J.Y.; Kim, S.; Choi, M.S.; Ha, T.Y. Resveratrol attenuates the expression of HMG-CoA reductase mRNA in hamsters. Biochem. Biophys. Res. Commun. 2008, 367, 190-194. [CrossRef]

110. Kumar, B.J.; Joghee, N. Resveratrol supplementation in patients with type 2 diabetes mellitus: A prospective, open label, randomized controlled trial. Int. Res. J. Pharm. 2013, 4, 245-249. [CrossRef]

111. Movahed, A.; Nabipour, I.; Lieben Louis, X.; Thandapilly, S.J.; Yu, L.; Kalantarhormozi, M.; Rekabpour, S.J.; Netticadan, T. Antihyperglycemic effects of short term resveratrol supplementation in type 2 diabetic patients. Evid.-Based Complement. Altern. Med. eCAM 2013, 2013, 851267. [CrossRef]

112. Sahebkar, A. Effects of resveratrol supplementation on plasma lipids: A systematic review and meta-analysis of randomized controlled trials. Nutr. Rev. 2013, 71, 822-835. [CrossRef] [PubMed]

113. Luca, S.V.; Macovei, I.; Bujor, A.; Miron, A.; Skalicka-Wozniak, K.; Aprotosoaie, A.C.; Trifan, A. Bioactivity of dietary polyphenols: The role of metabolites. Crit. Rev. Food Sci. Nutr. 2020, 60, 626-659. [CrossRef] [PubMed] 
114. Gong, M.; Garige, M.; Varatharajalu, R.; Marmillot, P.; Gottipatti, C.; Leckey, L.C.; Lakshman, R.M. Quercetin up-regulates paraoxonase 1 gene expression with concomitant protection against LDL oxidation. Biochem. Biophys. Res. Commun. 2009, 379, 1001-1004. [CrossRef] [PubMed]

115. Noll, C.; Hamelet, J.; Matulewicz, E.; Paul, J.L.; Delabar, J.M.; Janel, N. Effects of red wine polyphenolic compounds on paraoxonase-1 and lectin-like oxidized low-density lipoprotein receptor-1 in hyperhomocysteinemic mice. J. Nutr. Biochem. 2009, 20, 586-596. [CrossRef] [PubMed]

116. Garige, M.; Gong, M.; Varatharajalu, R.; Lakshman, M.R. Quercetin up-regulates paraoxonase 1 gene expression via sterol regulatory element binding protein 2 that translocates from the endoplasmic reticulum to the nucleus where it specifically interacts with sterol responsive element-like sequence in paraoxonase 1 promoter in HuH7 liver cells. Metab. Clin. Exp. 2010, 59, 1372-1378. [CrossRef]

117. Barbalata, T.; Deleanu, M.; Carnuta, M.G.; Niculescu, L.S.; Raileanu, M.; Sima, A.V.; Stancu, C.S. Hyperlipidemia Determines Dysfunctional HDL Production and Impedes Cholesterol Efflux in the Small Intestine: Alleviation by Ginger Extract. Mol. Nutr. Food Res. 2019, 63, e1900029. [CrossRef]

118. Guo, R.; Su, Y.; Liu, B.; Li, S.; Zhou, S.; Xu, Y. Resveratrol suppresses oxidised low-density lipoprotein-induced macrophage apoptosis through inhibition of intracellular reactive oxygen species generation, LOX-1, and the p38 MAPK pathway. Cell. Physiol. Biochem. Int. J. Exp. Cell. Physiol. Biochem. Pharmacol. 2014, 34, 603-616. [CrossRef]

119. Bonnefont-Rousselot, D. Resveratrol and Cardiovascular Diseases. Nutrients 2016, 8, 250. [CrossRef]

120. Wicinski, M.; Socha, M.; Walczak, M.; Wodkiewicz, E.; Malinowski, B.; Rewerski, S.; Gorski, K.; Pawlak-Osinska, K. Beneficial Effects of Resveratrol Administration-Focus on Potential Biochemical Mechanisms in Cardiovascular Conditions. Nutrients 2018, 10, 1813. [CrossRef]

121. Borra, M.T.; Smith, B.C.; Denu, J.M. Mechanism of human SIRT1 activation by resveratrol. J. Biol. Chem. 2005, 280, 17187-17195. [CrossRef]

122. Yeung, F.; Hoberg, J.E.; Ramsey, C.S.; Keller, M.D.; Jones, D.R.; Frye, R.A.; Mayo, M.W. Modulation of NF-kappaB-dependent transcription and cell survival by the SIRT1 deacetylase. EMBO J. 2004, 23, 2369-2380. [CrossRef]

123. Bonizzi, G.; Karin, M. The two NF-kappaB activation pathways and their role in innate and adaptive immunity. Trends Immunol. 2004, 25, 280-288. [CrossRef]

124. Malaguarnera, L. Influence of Resveratrol on the Immune Response. Nutrients 2019, 11, 946. [CrossRef]

125. Shakibaei, M.; Buhrmann, C.; Mobasheri, A. Resveratrol-mediated SIRT-1 interactions with p300 modulate receptor activator of NF-kappaB ligand (RANKL) activation of NF-kappaB signaling and inhibit osteoclastogenesis in bone-derived cells. J. Biol. Chem. 2011, 286, 11492-11505. [CrossRef]

126. Price, N.L.; Gomes, A.P.; Ling, A.J.; Duarte, F.V.; Martin-Montalvo, A.; North, B.J.; Agarwal, B.; Ye, L.; Ramadori, G.; Teodoro, J.S.; et al. SIRT1 is required for AMPK activation and the beneficial effects of resveratrol on mitochondrial function. Cell Metab. 2012, 15, 675-690. [CrossRef]

127. Theodotou, M.; Fokianos, K.; Mouzouridou, A.; Konstantinou, C.; Aristotelous, A.; Prodromou, D.; Chrysikou, A. The effect of resveratrol on hypertension: A clinical trial. Exp. Ther. Med. 2017, 13, 295-301. [CrossRef]

128. Chen, J.; Cao, X.; Cui, Y.; Zeng, G.; Chen, J.; Zhang, G. Resveratrol alleviates lysophosphatidylcholine-induced damage and inflammation in vascular endothelial cells. Mol. Med. Rep. 2018, 17, 4011-4018. [CrossRef]

129. Zhang, Z.; Chen, N.; Liu, J.B.; Wu, J.B.; Zhang, J.; Zhang, Y.; Jiang, X. Protective effect of resveratrol against acute lung injury induced by lipopolysaccharide via inhibiting the myd88-dependent Toll-like receptor 4 signaling pathway. Mol. Med. Rep. 2014, 10, 101-106. [CrossRef]

130. Liu, C.W.; Sung, H.C.; Lin, S.R.; Wu, C.W.; Lee, C.W.; Lee, I.T.; Yang, Y.F.; Yu, I.S.; Lin, S.W.; Chiang, M.H.; et al. Resveratrol attenuates ICAM-1 expression and monocyte adhesiveness to TNF-alpha-treated endothelial cells: Evidence for an anti-inflammatory cascade mediated by the miR-221/222/AMPK/p38/NF-kappaB pathway. Sci. Rep. 2017, 7, 44689. [CrossRef]

131. Lin, J.W.; Yang, L.H.; Ren, Z.C.; Mu, D.G.; Li, Y.Q.; Yan, J.P.; Wang, L.X.; Chen, C. Resveratrol downregulates TNF-alpha-induced monocyte chemoattractant protein-1 in primary rat pulmonary artery endothelial cells by P38 mitogen-activated protein kinase signaling. Drug Des. Dev. Ther. 2019, 13, 1843-1853. [CrossRef]

132. Pan, W.; Yu, H.; Huang, S.; Zhu, P. Resveratrol Protects against TNF-alpha-Induced Injury in Human Umbilical Endothelial Cells through Promoting Sirtuin-1-Induced Repression of NF-KB and p38 MAPK. PLoS ONE 2016, 11, e0147034. [CrossRef] 
133. Chen, M.L.; Yi, L.; Jin, X.; Liang, X.Y.; Zhou, Y.; Zhang, T.; Xie, Q.; Zhou, X.; Chang, H.; Fu, Y.J.; et al. Resveratrol attenuates vascular endothelial inflammation by inducing autophagy through the cAMP signaling pathway. Autophagy 2013, 9, 2033-2045. [CrossRef]

134. Park, D.W.; Baek, K.; Kim, J.R.; Lee, J.J.; Ryu, S.H.; Chin, B.R.; Baek, S.H. Resveratrol inhibits foam cell formation via NADPH oxidase 1- mediated reactive oxygen species and monocyte chemotactic protein-1. Exp. Mol. Med. 2009, 41, 171-179. [CrossRef]

135. Yang, Y.; Li, S.; Yang, Q.; Shi, Y.; Zheng, M.; Liu, Y.; Chen, F.; Song, G.; Xu, H.; Wan, T.; et al. Resveratrol reduces the proinflammatory effects and lipopolysaccharide- induced expression of HMGB1 and TLR4 in RAW264.7 cells. Cell. Phys. Biochem. Int. J. Exp. Cell. Physiol. Biochem. Pharmacol. 2014, 33, 1283-1292. [CrossRef]

136. Jakus, P.B.; Kalman, N.; Antus, C.; Radnai, B.; Tucsek, Z.; Gallyas, F., Jr.; Sumegi, B.; Veres, B. TRAF6 is functional in inhibition of TLR4-mediated NF-kappaB activation by resveratrol. J. Nutr. Biochem. 2013, 24, 819-823. [CrossRef]

137. Inanaga, K.; Ichiki, T.; Matsuura, H.; Miyazaki, R.; Hashimoto, T.; Takeda, K.; Sunagawa, K. Resveratrol attenuates angiotensin II-induced interleukin-6 expression and perivascular fibrosis. Hypertens. Res. 2009, 32, 466-471. [CrossRef]

138. Zhang, J.; Chen, J.; Yang, J.; Xu, C.W.; Pu, P.; Ding, J.W.; Jiang, H. Resveratrol attenuates oxidative stress induced by balloon injury in the rat carotid artery through actions on the ERK1/2 and NF-kappa B pathway. Cell. Phys. Biochem. Int. J. Exp. Cell. Physiol. Biochem. Pharmacol. 2013, 31, 230-241. [CrossRef]

139. Deng, Z.Y.; Hu, M.M.; Xin, Y.F.; Gang, C. Resveratrol alleviates vascular inflammatory injury by inhibiting inflammasome activation in rats with hypercholesterolemia and vitamin D2 treatment. Inflamm. Res. 2015, 64, 321-332. [CrossRef]

140. Chang, G.R.; Chen, P.L.; Hou, P.H.; Mao, F.C. Resveratrol protects against diet-induced atherosclerosis by reducing low-density lipoprotein cholesterol and inhibiting inflammation in apolipoprotein E-deficient mice. Iran. J. Basic Med. Sci. 2015, 18, 1063-1071.

141. Cong, X.; Li, Y.; Lu, N.; Dai, Y.; Zhang, H.; Zhao, X.; Liu, Y. Resveratrol attenuates the inflammatory reaction induced by ischemia/reperfusion in the rat heart. Mol. Med. Rep. 2014, 9, 2528-2532. [CrossRef]

142. Li, J.; Xie, C.; Zhuang, J.; Li, H.; Yao, Y.; Shao, C.; Wang, H. Resveratrol attenuates inflammation in the rat heart subjected to ischemia-reperfusion: Role of the TLR4/NF-kappaB signaling pathway. Mol. Med. Rep. 2015, 11, 1120-1126. [CrossRef] [PubMed]

143. Espinoza, J.L.; Trung, L.Q.; Inaoka, P.T.; Yamada, K.; An, D.T.; Mizuno, S.; Nakao, S.; Takami, A. The Repeated Administration of Resveratrol Has Measurable Effects on Circulating T-Cell Subsets in Humans. Oxid. Med. Cell. Longev. 2017, 2017, 6781872. [CrossRef] [PubMed]

144. Yoshino, J.; Conte, C.; Fontana, L.; Mittendorfer, B.; Imai, S.; Schechtman, K.B.; Gu, C.; Kunz, I.; Rossi Fanelli, F.; Patterson, B.W.; et al. Resveratrol supplementation does not improve metabolic function in nonobese women with normal glucose tolerance. Cell Metab. 2012, 16, 658-664. [CrossRef] [PubMed]

145. Ramirez-Garza, S.L.; Laveriano-Santos, E.P.; Marhuenda-Munoz, M.; Storniolo, C.E.; Tresserra-Rimbau, A.; Vallverdu-Queralt, A.; Lamuela-Raventos, R.M. Health Effects of Resveratrol: Results from Human Intervention Trials. Nutrients 2018, 10, 1892. [CrossRef] [PubMed]

146. Tili, E.; Michaille, J.J.; Adair, B.; Alder, H.; Limagne, E.; Taccioli, C.; Ferracin, M.; Delmas, D.; Latruffe, N.; Croce, C.M. Resveratrol decreases the levels of miR-155 by upregulating miR-663, a microRNA targeting JunB and JunD. Carcinogenesis 2010, 31, 1561-1566. [CrossRef] [PubMed]

147. Michaille, J.J.; Piurowski, V.; Rigot, B.; Kelani, H.; Fortman, E.C.; Tili, E. MiR-663, a MicroRNA Linked with Inflammation and Cancer That Is under the Influence of Resveratrol. Medicines 2018, 5, 74. [CrossRef]

148. Bigagli, E.; Cinci, L.; Paccosi, S.; Parenti, A.; D’Ambrosio, M.; Luceri, C. Nutritionally relevant concentrations of resveratrol and hydroxytyrosol mitigate oxidative burst of human granulocytes and monocytes and the production of pro-inflammatory mediators in LPS-stimulated RAW 264.7 macrophages. Int. Immunopharmacol. 2017, 43, 147-155. [CrossRef]

149. Lancon, A.; Kaminski, J.; Tili, E.; Michaille, J.J.; Latruffe, N. Control of MicroRNA expression as a new way for resveratrol to deliver its beneficial effects. J. Agric. Food Chem. 2012, 60, 8783-8789. [CrossRef]

150. Chen, J.F.; Mandel, E.M.; Thomson, J.M.; Wu, Q.; Callis, T.E.; Hammond, S.M.; Conlon, F.L.; Wang, D.Z. The role of microRNA-1 and microRNA-133 in skeletal muscle proliferation and differentiation. Nat. Genet. 2006, 38, 228-233. [CrossRef] 
151. Zhang, Y.; Lu, Y.; Ong'achwa, M.J.; Ge, L.; Qian, Y.; Chen, L.; Hu, X.; Li, F.; Wei, H.; Zhang, C.; et al. Resveratrol Inhibits the TGF-beta1-Induced Proliferation of Cardiac Fibroblasts and Collagen Secretion by Downregulating miR-17 in Rat. BioMed Res. Int. 2018, 2018, 8730593. [CrossRef]

152. Mukhopadhyay, P.; Mukherjee, S.; Ahsan, K.; Bagchi, A.; Pacher, P.; Das, D.K. Restoration of altered microRNA expression in the ischemic heart with resveratrol. PLoS ONE 2010, 5, e15705. [CrossRef]

153. Campagnolo, P.; Hong, X.; di Bernardini, E.; Smyrnias, I.; Hu, Y.; Xu, Q. Resveratrol-Induced Vascular Progenitor Differentiation towards Endothelial Lineage via MiR-21/Akt/beta-Catenin Is Protective in Vessel Graft Models. PLoS ONE 2015, 10, e0125122. [CrossRef]

154. Tome-Carneiro, J.; Larrosa, M.; Yanez-Gascon, M.J.; Davalos, A.; Gil-Zamorano, J.; Gonzalvez, M.; Garcia-Almagro, F.J.; Ruiz Ros, J.A.; Tomas-Barberan, F.A.; Espin, J.C.; et al. One-year supplementation with a grape extract containing resveratrol modulates inflammatory-related microRNAs and cytokines expression in peripheral blood mononuclear cells of type 2 diabetes and hypertensive patients with coronary artery disease. Pharmacol. Res. 2013, 72, 69-82. [CrossRef]

155. Cione, E.; La Torre, C.; Cannataro, R.; Caroleo, M.C.; Plastina, P.; Gallelli, L. Quercetin, Epigallocatechin Gallate, Curcumin, and Resveratrol: From Dietary Sources to Human MicroRNA Modulation. Molecules 2019, 25, 63. [CrossRef]

156. Nie, J.; Zhang, L.; Zhao, G.; Du, X. Quercetin reduces atherosclerotic lesions by altering the gut microbiota and reducing atherogenic lipid metabolites. J. Appl. Microbiol. 2019, 127, 1824-1834. [CrossRef]

157. Rasouli, H.; Farzaei, M.H.; Khodarahmi, R. Polyphenols and their benefits: A review. Int. J. Food Prop. 2017, 20, 1700-1741. [CrossRef]

158. Basu, A.; Das, A.S.; Majumder, M.; Mukhopadhyay, R. Antiatherogenic Roles of Dietary Flavonoids Chrysin, Quercetin, and Luteolin. J. Cardiovasc. Pharmacol. 2016, 68, 89-96. [CrossRef]

159. Kawai, Y.; Nishikawa, T.; Shiba, Y.; Saito, S.; Murota, K.; Shibata, N.; Kobayashi, M.; Kanayama, M.; Uchida, K.; Terao, J. Macrophage as a target of quercetin glucuronides in human atherosclerotic arteries: Implication in the anti-atherosclerotic mechanism of dietary flavonoids. J. Biol. Chem. 2008, 283, 9424-9434. [CrossRef]

160. Sanchez, M.; Galisteo, M.; Vera, R.; Villar, I.C.; Zarzuelo, A.; Tamargo, J.; Perez-Vizcaino, F.; Duarte, J. Quercetin downregulates NADPH oxidase, increases eNOS activity and prevents endothelial dysfunction in spontaneously hypertensive rats. J. Hypertens. 2006, 24, 75-84. [CrossRef]

161. Carlstrom, J.; Symons, J.D.; Wu, T.C.; Bruno, R.S.; Litwin, S.E.; Jalili, T. A quercetin supplemented diet does not prevent cardiovascular complications in spontaneously hypertensive rats. J. Nutr. 2007, 137, 628-633. [CrossRef] [PubMed]

162. Duarte, J.; Galisteo, M.; Ocete, M.A.; Perez-Vizcaino, F.; Zarzuelo, A.; Tamargo, J. Effects of chronic quercetin treatment on hepatic oxidative status of spontaneously hypertensive rats. Mol. Cell. Biochem. 2001, 221, 155-160. [CrossRef]

163. Min, Z.; Yangchun, L.; Yuquan, W.; Changying, Z. Quercetin inhibition of myocardial fibrosis through regulating MAPK signaling pathway via ROS. Pak. J. Pharm. Sci. 2019, 32, 1355-1359.

164. Li, P.G.; Sun, L.; Han, X.; Ling, S.; Gan, W.T.; Xu, J.W. Quercetin induces rapid eNOS phosphorylation and vasodilation by an Akt-independent and PKA-dependent mechanism. Pharmacology 2012, 89, 220-228. [CrossRef] [PubMed]

165. Bhaskar, S.; Sudhakaran, P.R.; Helen, A. Quercetin attenuates atherosclerotic inflammation and adhesion molecule expression by modulating TLR-NF-kappaB signaling pathway. Cell. Immunol. 2016, 310, 131-140. [CrossRef] [PubMed]

166. Hung, C.H.; Chan, S.H.; Chu, P.M.; Tsai, K.L. Quercetin is a potent anti-atherosclerotic compound by activation of SIRT1 signaling under oxLDL stimulation. Mol. Nutr. Food Res. 2015, 59, 1905-1917. [CrossRef] [PubMed]

167. Xiao, H.B.; Lu, X.Y.; Sun, Z.L.; Zhang, H.B. Kaempferol regulates OPN-CD44 pathway to inhibit the atherogenesis of apolipoprotein E deficient mice. Toxicol. Appl. Pharmacol. 2011, 257, 405-411. [CrossRef]

168. Che, J.; Liang, B.; Zhang, Y.; Wang, Y.; Tang, J.; Shi, G. Kaempferol alleviates ox-LDL-induced apoptosis by up-regulation of autophagy via inhibiting PI3K/Akt/mTOR pathway in human endothelial cells. Cardiovasc. Pathol. 2017, 31, 57-62. [CrossRef]

169. Kleemann, R.; Verschuren, L.; Morrison, M.; Zadelaar, S.; van Erk, M.J.; Wielinga, P.Y.; Kooistra, T. Anti-inflammatory, anti-proliferative and anti-atherosclerotic effects of quercetin in human in vitro and in vivo models. Atherosclerosis 2011, 218, 44-52. [CrossRef] 
170. Bhaskar, S.; Helen, A. Quercetin modulates toll-like receptor-mediated protein kinase signaling pathways in oxLDL-challenged human PBMCs and regulates TLR-activated atherosclerotic inflammation in hypercholesterolemic rats. Mol. Cell. Biochem. 2016, 423, 53-65. [CrossRef]

171. Calabriso, N.; Scoditti, E.; Massaro, M.; Pellegrino, M.; Storelli, C.; Ingrosso, I.; Giovinazzo, G.; Carluccio, M.A. Multiple anti-inflammatory and anti-atherosclerotic properties of red wine polyphenolic extracts: Differential role of hydroxycinnamic acids, flavonols and stilbenes on endothelial inflammatory gene expression. Eur. J. Nutr. 2016, 55, 477-489. [CrossRef]

172. Vera, M.; Torramade-Moix, S.; Martin-Rodriguez, S.; Cases, A.; Cruzado, J.M.; Rivera, J.; Escolar, G.; Palomo, M.; Diaz-Ricart, M. Antioxidant and Anti-Inflammatory Strategies Based on the Potentiation of Glutathione Peroxidase Activity Prevent Endothelial Dysfunction in Chronic Kidney Disease. Cell. Phys. Biochem. Int. J. Exp. Cell. Physiol. Biochem. Pharmacol. 2018, 51, 1287-1300. [CrossRef]

173. Qureshi, A.A.; Tan, X.; Reis, J.C.; Badr, M.Z.; Papasian, C.J.; Morrison, D.C.; Qureshi, N. Suppression of nitric oxide induction and pro-inflammatory cytokines by novel proteasome inhibitors in various experimental models. Lipids Health Dis. 2011, 10, 177. [CrossRef] [PubMed]

174. Lu, X.L.; Zhao, C.H.; Yao, X.L.; Zhang, H. Quercetin attenuates high fructose feeding-induced atherosclerosis by suppressing inflammation and apoptosis via ROS-regulated PI3K/AKT signaling pathway. Biomed. Pharmacother. 2017, 85, 658-671. [CrossRef] [PubMed]

175. Li, B.; Yang, M.; Liu, J.W.; Yin, G.T. Protective mechanism of quercetin on acute myocardial infarction in rats. Genet. Mol. Res. GMR 2016, 15, 15017117. [CrossRef]

176. Zahedi, M.; Ghiasvand, R.; Feizi, A.; Asgari, G.; Darvish, L. Does Quercetin Improve Cardiovascular Risk factors and Inflammatory Biomarkers in Women with Type 2 Diabetes: A Double-blind Randomized Controlled Clinical Trial. Int. J. Prev. Med. 2013, 4, 777-785. [PubMed]

177. Chekalina, N.; Burmak, Y.; Petrov, Y.; Borisova, Z.; Manusha, Y.; Kazakov, Y.; Kaidashev, I. Quercetin reduces the transcriptional activity of NF-kB in stable coronary artery disease. Indian Heart J. 2018, 70, 593-597. [CrossRef] [PubMed]

178. Dabeek, W.M.; Marra, M.V. Dietary Quercetin and Kaempferol: Bioavailability and Potential Cardiovascular-Related Bioactivity in Humans. Nutrients 2019, 11, 2288. [CrossRef] [PubMed]

179. Boesch-Saadatmandi, C.; Loboda, A.; Wagner, A.E.; Stachurska, A.; Jozkowicz, A.; Dulak, J.; Doring, F.; Wolffram, S.; Rimbach, G. Effect of quercetin and its metabolites isorhamnetin and quercetin-3-glucuronide on inflammatory gene expression: Role of miR-155. J. Nutr. Biochem. 2011, 22, 293-299. [CrossRef] [PubMed]

180. Boesch-Saadatmandi, C.; Wagner, A.E.; Wolffram, S.; Rimbach, G. Effect of quercetin on inflammatory gene expression in mice liver in vivo-Role of redox factor 1, miRNA-122 and miRNA-125b. Pharmacol. Res. 2012, 65, 523-530. [CrossRef]

181. Wang, M.; Firrman, J.; Liu, L.; Yam, K. A Review on Flavonoid Apigenin: Dietary Intake, ADME, Antimicrobial Effects, and Interactions with Human Gut Microbiota. BioMed Res. Int. 2019, 2019, 7010467. [CrossRef]

182. Tang, D.; Chen, K.; Huang, L.; Li, J. Pharmacokinetic properties and drug interactions of apigenin, a natural flavone. Expert Opin. Drug Metab. Toxicol. 2017, 13, 323-330. [CrossRef] [PubMed]

183. Zhang, K.; Song, W.; Li, D.; Jin, X. Apigenin in the regulation of cholesterol metabolism and protection of blood vessels. Exp. Ther. Med. 2017, 13, 1719-1724. [CrossRef] [PubMed]

184. Jung, U.J.; Cho, Y.Y.; Choi, M.S. Apigenin Ameliorates Dyslipidemia, Hepatic Steatosis and Insulin Resistance by Modulating Metabolic and Transcriptional Profiles in the Liver of High-Fat Diet-Induced Obese Mice. Nutrients 2016, 8, 305. [CrossRef] [PubMed]

185. Qin, W.; Ren, B.; Wang, S.; Liang, S.; He, B.; Shi, X.; Wang, L.; Liang, J.; Wu, F. Apigenin and naringenin ameliorate PKCbetaII-associated endothelial dysfunction via regulating ROS/caspase-3 and NO pathway in endothelial cells exposed to high glucose. Vasc. Pharmacol. 2016, 85, 39-49. [CrossRef] [PubMed]

186. Chen, C.C.; Ke, W.H.; Ceng, L.H.; Hsieh, C.W.; Wung, B.S. Calcium- and phosphatidylinositol 3-kinase/Akt-dependent activation of endothelial nitric oxide synthase by apigenin. Life Scie. 2010, 87, 743-749. [CrossRef]

187. Pothineni, N.V.K.; Karathanasis, S.K.; Ding, Z.; Arulandu, A.; Varughese, K.I.; Mehta, J.L. LOX-1 in Atherosclerosis and Myocardial Ischemia: Biology, Genetics, and Modulation. J. Am. Coll. Cardiol. 2017, 69, 2759-2768. [CrossRef] 
188. Wang, J.; Liao, Y.; Fan, J.; Ye, T.; Sun, X.; Dong, S. Apigenin inhibits the expression of IL-6, IL-8, and ICAM-1 in DEHP-stimulated human umbilical vein endothelial cells and in vivo. Inflammation 2012, 35, 1466-1476. [CrossRef]

189. Ren, B.; Qin, W.; Wu, F.; Wang, S.; Pan, C.; Wang, L.; Zeng, B.; Ma, S.; Liang, J. Apigenin and naringenin regulate glucose and lipid metabolism, and ameliorate vascular dysfunction in type 2 diabetic rats. Eur. J. Pharmacol. 2016, 773, 13-23. [CrossRef]

190. Mueller, M.; Hobiger, S.; Jungbauer, A. Anti-inflammatory activity of extracts from fruits, herbs and spices. Food Chem. 2010, 122, 987-996. [CrossRef]

191. Comalada, M.; Ballester, I.; Bailon, E.; Sierra, S.; Xaus, J.; Galvez, J.; de Medina, F.S.; Zarzuelo, A. Inhibition of pro-inflammatory markers in primary bone marrow-derived mouse macrophages by naturally occurring flavonoids: Analysis of the structure-activity relationship. Biochem. Pharmacol. 2006, 72, 1010-1021. [CrossRef]

192. Ren, K.; Jiang, T.; Zhou, H.F.; Liang, Y.; Zhao, G.J. Apigenin Retards Atherogenesis by Promoting ABCA1-Mediated Cholesterol Efflux and Suppressing Inflammation. Cell. Phys. Biochem. Int. J. Exp. Cell. Physiol. Biochem. Pharmacol. 2018, 47, 2170-2184. [CrossRef] [PubMed]

193. Yamagata, K.; Miyashita, A.; Matsufuji, H.; Chino, M. Dietary flavonoid apigenin inhibits high glucose and tumor necrosis factor alpha-induced adhesion molecule expression in human endothelial cells. J. Nutr. Biochem. 2010, 21, 116-124. [CrossRef] [PubMed]

194. Luo, Y.; Shang, P.; Li, D. Luteolin: A Flavonoid that Has Multiple Cardio-Protective Effects and Its Molecular Mechanisms. Front. Pharmacol. 2017, 8, 692. [CrossRef]

195. Hostetler, G.L.; Ralston, R.A.; Schwartz, S.J. Flavones: Food Sources, Bioavailability, Metabolism, and Bioactivity. Adv. Nutr. 2017, 8, 423-435. [CrossRef]

196. Rangboo, V.; Noroozi, M.; Zavoshy, R.; Rezadoost, S.A.; Mohammadpoorasl, A. The Effect of Artichoke Leaf Extract on Alanine Aminotransferase and Aspartate Aminotransferase in the Patients with Nonalcoholic Steatohepatitis. Int. J. Hepatol. 2016, 2016, 4030476. [CrossRef] [PubMed]

197. Sahebkar, A.; Pirro, M.; Banach, M.; Mikhailidis, D.P.; Atkin, S.L.; Cicero, A.F.G. Lipid-lowering activity of artichoke extracts: A systematic review and meta-analysis. Crit. Rev. Food Sci. Nutr. 2018, 58, 2549-2556. [CrossRef]

198. Xia, F.; Wang, C.; Jin, Y.; Liu, Q.; Meng, Q.; Liu, K.; Sun, H. Luteolin protects HUVECs from TNF-alpha-induced oxidative stress and inflammation via its effects on the Nox4/ROS-NF-kappaB and MAPK pathways. J. Atheroscler. Thromb. 2014, 21, 768-783. [CrossRef]

199. Xiao, C.; Xia, M.L.; Wang, J.; Zhou, X.R.; Lou, Y.Y.; Tang, L.H.; Zhang, F.J.; Yang, J.T.; Qian, L.B. Luteolin Attenuates Cardiac Ischemia/Reperfusion Injury in Diabetic Rats by Modulating Nrf2 Antioxidative Function. Oxid. Med. Cell. Longev. 2019, 2019, 2719252. [CrossRef]

200. Jia, Z.; Nallasamy, P.; Liu, D.; Shah, H.; Li, J.Z.; Chitrakar, R.; Si, H.; McCormick, J.; Zhu, H.; Zhen, W.; et al. Luteolin protects against vascular inflammation in mice and TNF-alpha-induced monocyte adhesion to endothelial cells via suppressing IKappaBalpha/NF-kappaB signaling pathway. J. Nutr. Biochem. 2015, 26, 293-302. [CrossRef]

201. Zhang, L.; Wang, X.; Zhang, L.; Virgous, C.; Si, H. Combination of curcumin and luteolin synergistically inhibits TNF-alpha-induced vascular inflammation in human vascular cells and mice. J. Nutr. Biochem. 2019, 73, 108222. [CrossRef]

202. Kim, H.J.; Lee, W.; Yun, J.M. Luteolin inhibits hyperglycemia-induced proinflammatory cytokine production and its epigenetic mechanism in human monocytes. Phytother. Res. PTR 2014, 28, 1383-1391. [CrossRef] [PubMed]

203. Zaragoza, C.; Villaescusa, L.; Monserrat, J.; Zaragoza, F.; Alvarez-Mon, M. Potential Therapeutic Anti-Inflammatory and Immunomodulatory Effects of Dihydroflavones, Flavones, and Flavonols. Molecules 2020, 25, 1017. [CrossRef] [PubMed]

204. Hong, X.; Zhao, X.; Wang, G.; Zhang, Z.; Pei, H.; Liu, Z. Luteolin Treatment Protects against Renal Ischemia-Reperfusion Injury in Rats. Mediat. Inflamm. 2017, 2017, 9783893. [CrossRef] [PubMed]

205. Ding, X.; Zheng, L.; Yang, B.; Wang, X.; Ying, Y. Luteolin Attenuates Atherosclerosis Via Modulating Signal Transducer And Activator Of Transcription 3-Mediated Inflammatory Response. Drug Des. Dev. Ther. 2019, 13, 3899-3911. [CrossRef] [PubMed] 
206. Wang, P.; Sun, J.; Lv, S.; Xie, T.; Wang, X. Apigenin Alleviates Myocardial Reperfusion Injury in Rats by Downregulating miR-15b. Med. Sci. Monit. Int. Med. J. Exp. Clin. Res. 2019, 25, 2764-2776. [CrossRef] [PubMed]

207. Bian, C.; Xu, T.; Zhu, H.; Pan, D.; Liu, Y.; Luo, Y.; Wu, P.; Li, D. Luteolin Inhibits Ischemia/Reperfusion-Induced Myocardial Injury in Rats via Downregulation of microRNA-208b-3p. PLoS ONE 2015, 10, e0144877. [CrossRef]

208. Arango, D.; Diosa-Toro, M.; Rojas-Hernandez, L.S.; Cooperstone, J.L.; Schwartz, S.J.; Mo, X.; Jiang, J.; Schmittgen, T.D.; Doseff, A.I. Dietary apigenin reduces LPS-induced expression of miR-155 restoring immune balance during inflammation. Mol. Nutr. Food Res. 2015, 59, 763-772. [CrossRef]

209. Zhang, Z.; Xu, P.; Yu, H.; Shi, L. Luteolin protects PC-12 cells from H2O2-induced injury by up-regulation of microRNA-21. Biomed. Pharmacother. 2019, 112, 108698. [CrossRef]

210. Ning, B.B.; Zhang, Y.; Wu, D.D.; Cui, J.G.; Liu, L.; Wang, P.W.; Wang, W.J.; Zhu, W.L.; Chen, Y.; Zhang, T. Luteolin-7-diglucuronide attenuates isoproterenol-induced myocardial injury and fibrosis in mice. Acta Pharmacol. Sin. 2017, 38, 331-341. [CrossRef]

211. Kara, S.; Gencer, B.; Karaca, T.; Tufan, H.A.; Arikan, S.; Ersan, I.; Karaboga, I.; Hanci, V. Protective effect of hesperetin and naringenin against apoptosis in ischemia/reperfusion-induced retinal injury in rats. Sci. World J. 2014, 2014, 797824. [CrossRef]

212. Kanaze, F.I.; Bounartzi, M.I.; Georgarakis, M.; Niopas, I. Pharmacokinetics of the citrus flavanone aglycones hesperetin and naringenin after single oral administration in human subjects. Eur. J. Clin. Nutr. 2007, 61, 472-477. [CrossRef]

213. Joshi, R.; Kulkarni, Y.A.; Wairkar, S. Pharmacokinetic, pharmacodynamic and formulations aspects of Naringenin: An update. Life Sci. 2018, 215, 43-56. [CrossRef] [PubMed]

214. Miceli, N.; Mondello, M.R.; Monforte, M.T.; Sdrafkakis, V.; Dugo, P.; Crupi, M.L.; Taviano, M.F.; De Pasquale, R.; Trovato, A. Hypolipidemic effects of Citrus bergamia Risso et Poiteau juice in rats fed a hypercholesterolemic diet. J. Agric. Food Chem. 2007, 55, 10671-10677. [CrossRef] [PubMed]

215. Mulvihill, E.E.; Assini, J.M.; Sutherland, B.G.; DiMattia, A.S.; Khami, M.; Koppes, J.B.; Sawyez, C.G.; Whitman, S.C.; Huff, M.W. Naringenin decreases progression of atherosclerosis by improving dyslipidemia in high-fat-fed low-density lipoprotein receptor-null mice. Arterioscler. Thromb. Vasc. Biol. 2010, 30, 742-748. [CrossRef] [PubMed]

216. Borradaile, N.M.; de Dreu, L.E.; Barrett, P.H.; Behrsin, C.D.; Huff, M.W. Hepatocyte apoB-containing lipoprotein secretion is decreased by the grapefruit flavonoid, naringenin, via inhibition of MTP-mediated microsomal triglyceride accumulation. Biochemistry 2003, 42, 1283-1291. [CrossRef] [PubMed]

217. Lee, C.H.; Jeong, T.S.; Choi, Y.K.; Hyun, B.H.; Oh, G.T.; Kim, E.H.; Kim, J.R.; Han, J.I.; Bok, S.H. Anti-atherogenic effect of citrus flavonoids, naringin and naringenin, associated with hepatic ACAT and aortic VCAM-1 and MCP-1 in high cholesterol-fed rabbits. Biochem. Biophys. Res. Commun. 2001, 284, 681-688. [CrossRef]

218. Jung, U.J.; Kim, H.F.; Lee, J.S.; Lee, J.F.; Lee, M.K.; Lee, M.F.; Kim, H.O.; Kim, H.F.; Park, E.J.; Park, E.F.; et al. Naringin supplementation lowers plasma lipids and enhances erythrocyte antioxidant enzyme activities in hypercholesterolemic subjects. Clin. Nutr. 2003, 22, 561-568. [CrossRef]

219. Perna, S.; Spadaccini, D.; Botteri, L.; Girometta, C.; Riva, A.; Allegrini, P.; Petrangolini, G.; Infantino, V.; Rondanelli, M. Efficacy of bergamot: From anti-inflammatory and anti-oxidative mechanisms to clinical applications as preventive agent for cardiovascular morbidity, skin diseases, and mood alterations. Food Sci. Nutr. 2019, 7, 369-384. [CrossRef]

220. Rizza, S.; Muniyappa, R.; Iantorno, M.; Kim, J.A.; Chen, H.; Pullikotil, P.; Senese, N.; Tesauro, M.; Lauro, D.; Cardillo, C.; et al. Citrus polyphenol hesperidin stimulates production of nitric oxide in endothelial cells while improving endothelial function and reducing inflammatory markers in patients with metabolic syndrome. J. Clin. Endocrinol. Metab. 2011, 96, E782-E792. [CrossRef]

221. Yamamoto, M.; Jokura, H.; Hashizume, K.; Ominami, H.; Shibuya, Y.; Suzuki, A.; Hase, T.; Shimotoyodome, A. Hesperidin metabolite hesperetin-7-O-glucuronide, but not hesperetin-3'-O-glucuronide, exerts hypotensive, vasodilatory, and anti-inflammatory activities. Food Funct. 2013, 4, 1346-1351. [CrossRef] 
222. Rendeiro, C.; Dong, H.; Saunders, C.; Harkness, L.; Blaze, M.; Hou, Y.; Belanger, R.L.; Altieri, V.; Nunez, M.A.; Jackson, K.G.; et al. Flavanone-rich citrus beverages counteract the transient decline in postprandial endothelial function in humans: A randomised, controlled, double-masked, cross-over intervention study. Br. J. Nutr. 2016, 116, 1999-2010. [CrossRef] [PubMed]

223. Borgatti, M.; Mancini, I.; Bianchi, N.; Guerrini, A.; Lampronti, I.; Rossi, D.; Sacchetti, G.; Gambari, R. Bergamot (Citrus bergamia Risso) fruit extracts and identified components alter expression of interleukin 8 gene in cystic fibrosis bronchial epithelial cell lines. BMC Biochem. 2011, 12, 15. [CrossRef] [PubMed]

224. Xie, J.; Zhang, X.; Zhang, L. Negative regulation of inflammation by SIRT1. Pharmacol. Res. 2013, 67, 60-67. [CrossRef]

225. Testai, L.; Piragine, E.; Piano, I.; Flori, L.; Da Pozzo, E.; Miragliotta, V.; Pirone, A.; Citi, V.; Di Cesare Mannelli, L.; Brogi, S.; et al. The Citrus Flavonoid Naringenin Protects the Myocardium from Ageing-Dependent Dysfunction: Potential Role of SIRT1. Oxid. Med. Cell. Longev. 2020, 2020, 4650207. [CrossRef]

226. Miwa, Y.; Mitsuzumi, H.; Sunayama, T.; Yamada, M.; Okada, K.; Kubota, M.; Chaen, H.; Mishima, Y.; Kibata, M. Glucosyl hesperidin lowers serum triglyceride level in hypertriglyceridemic subjects through the improvement of very low-density lipoprotein metabolic abnormality. J. Nutr. Sci. Vitaminol. 2005, 51, 460-470. [CrossRef]

227. Demonty, I.; Lin, Y.; Zebregs, Y.E.; Vermeer, M.A.; van der Knaap, H.C.; Jakel, M.; Trautwein, E.A. The citrus flavonoids hesperidin and naringin do not affect serum cholesterol in moderately hypercholesterolemic men and women. J. Nutr. 2010, 140, 1615-1620. [CrossRef] [PubMed]

228. Assini, J.M.; Mulvihill, E.E.; Huff, M.W. Citrus flavonoids and lipid metabolism. Curr. Opin. Lipidol. 2013, 24, 34-40. [CrossRef] [PubMed]

229. Hsu, C.L.; Fang, S.C.; Yen, G.C. Anti-inflammatory effects of phenolic compounds isolated from the flowers of Nymphaea mexicana Zucc. Food Funct. 2013, 4, 1216-1222. [CrossRef]

230. Raza, S.S.; Khan, M.M.; Ahmad, A.; Ashafaq, M.; Islam, F.; Wagner, A.P.; Safhi, M.M.; Islam, F. Neuroprotective effect of naringenin is mediated through suppression of NF-kappaB signaling pathway in experimental stroke. Neuroscience 2013, 230, 157-171. [CrossRef]

231. Fuior, E.V.; Deleanu, M.; Constantinescu, C.A.; Rebleanu, D.; Voicu, G.; Simionescu, M.; Calin, M. Functional Role of VCAM-1 Targeted Flavonoid-Loaded Lipid Nanoemulsions in Reducing Endothelium Inflammation. Pharmaceutics 2019, 11, 391. [CrossRef]

232. Liang, J.N.; Zou, X.; Fang, X.H.; Xu, J.D.; Xiao, Z.; Zhu, J.N.; Li, H.; Yang, J.; Zeng, N.; Yuan, S.J.; et al. The Smad3-miR-29b/miR-29c axis mediates the protective effect of macrophage migration inhibitory factor against cardiac fibrosis. (BBA)-Mol. Basis Dis. 2019, 1865, 2441-2450. [CrossRef] [PubMed]

233. Murakami, A. Dose-dependent functionality and toxicity of green tea polyphenols in experimental rodents. Arch. Biochem. Biophys. 2014, 557, 3-10. [CrossRef] [PubMed]

234. Cai, Z.Y.; Li, X.M.; Liang, J.P.; Xiang, L.P.; Wang, K.R.; Shi, Y.L.; Yang, R.; Shi, M.; Ye, J.H.; Lu, J.L.; et al. Bioavailability of Tea Catechins and Its Improvement. Molecules 2018, 23, 2346. [CrossRef] [PubMed]

235. Onakpoya, I.; Spencer, E.; Heneghan, C.; Thompson, M. The effect of green tea on blood pressure and lipid profile: A systematic review and meta-analysis of randomized clinical trials. Nutr. Metab. Cardiovasc. Dis. NMCD 2014, 24, 823-836. [CrossRef] [PubMed]

236. Kim, A.; Chiu, A.; Barone, M.K.; Avino, D.; Wang, F.; Coleman, C.I.; Phung, O.J. Green tea catechins decrease total and low-density lipoprotein cholesterol: A systematic review and meta-analysis. J. Am. Diet. Assoc. 2011, 111, 1720-1729. [CrossRef] [PubMed]

237. Zheng, X.X.; Xu, Y.L.; Li, S.H.; Liu, X.X.; Hui, R.; Huang, X.H. Green tea intake lowers fasting serum total and LDL cholesterol in adults: A meta-analysis of 14 randomized controlled trials. Am. J. Clin. Nutr. 2011, 94, 601-610. [CrossRef]

238. Koo, S.I.; Noh, S.K. Green tea as inhibitor of the intestinal absorption of lipids: Potential mechanism for its lipid-lowering effect. J. Nutr. Biochem. 2007, 18, 179-183. [CrossRef]

239. Abe, I.; Seki, T.; Umehara, K.; Miyase, T.; Noguchi, H.; Sakakibara, J.; Ono, T. Green tea polyphenols: Novel and potent inhibitors of squalene epoxidase. Biochem. Biophys. Res. Commun. 2000, 268, 767-771. [CrossRef]

240. Naveed, M.; BiBi, J.; Kamboh, A.A.; Suheryani, I.; Kakar, I.; Fazlani, S.A.; FangFang, X.; Kalhoro, S.A.; Yunjuan, L.; Kakar, M.U.; et al. Pharmacological values and therapeutic properties of black tea (Camellia sinensis): A comprehensive overview. Biomed. Pharmacother. 2018, 100, 521-531. [CrossRef] 
241. Santos, H.O.; Macedo, R.C.O. Cocoa-induced (Theobroma cacao) effects on cardiovascular system: HDL modulation pathways. Clin. Nutr. ESPEN 2018, 27, 10-15. [CrossRef]

242. Snoussi, C.; Ducroc, R.; Hamdaoui, M.H.; Dhaouadi, K.; Abaidi, H.; Cluzeaud, F.; Nazaret, C.; Le Gall, M.; Bado, A. Green tea decoction improves glucose tolerance and reduces weight gain of rats fed normal and high-fat diet. J. Nutr. Biochem. 2014, 25, 557-564. [CrossRef] [PubMed]

243. Shrestha, S.; Ehlers, S.J.; Lee, J.Y.; Fernandez, M.L.; Koo, S.I. Dietary green tea extract lowers plasma and hepatic triglycerides and decreases the expression of sterol regulatory element-binding protein-1c mRNA and its responsive genes in fructose-fed, ovariectomized rats. J. Nutr. 2009, 139, 640-645. [CrossRef] [PubMed]

244. Pang, J.; Zhang, Z.; Zheng, T.Z.; Bassig, B.A.; Mao, C.; Liu, X.; Zhu, Y.; Shi, K.; Ge, J.; Yang, Y.J.; et al. Green tea consumption and risk of cardiovascular and ischemic related diseases: A meta-analysis. Int. J. Cardiol. 2016, 202, 967-974. [CrossRef] [PubMed]

245. Mangels, D.R.; Mohler, E.R., 3rd. Catechins as Potential Mediators of Cardiovascular Health. Arterioscler. Thromb. Vasc. Biol. 2017, 37, 757-763. [CrossRef] [PubMed]

246. Liu, S.; Sun, Z.; Chu, P.; Li, H.; Ahsan, A.; Zhou, Z.; Zhang, Z.; Sun, B.; Wu, J.; Xi, Y.; et al. EGCG protects against homocysteine-induced human umbilical vein endothelial cells apoptosis by modulating mitochondrial-dependent apoptotic signaling and PI3K/Akt/eNOS signaling pathways. Apoptosis 2017, 22, 672-680. [CrossRef]

247. Wu, C.C.; Hsu, M.C.; Hsieh, C.W.; Lin, J.B.; Lai, P.H.; Wung, B.S. Upregulation of heme oxygenase-1 by Epigallocatechin-3-gallate via the phosphatidylinositol 3-kinase/Akt and ERK pathways. Life Sci. 2006, 78, 2889-2897. [CrossRef]

248. Suzuki-Sugihara, N.; Kishimoto, Y.; Saita, E.; Taguchi, C.; Kobayashi, M.; Ichitani, M.; Ukawa, Y.; Sagesaka, Y.M.; Suzuki, E.; Kondo, K. Green tea catechins prevent low-density lipoprotein oxidation via their accumulation in low-density lipoprotein particles in humans. Nutr. Res. 2016, 36, 16-23. [CrossRef]

249. Tas, S.; Sarandol, E.; Ziyanok, S.; Aslan, K.; Dirican, M. Effects of green tea on serum paraoxonase/arylesterase activities in streptozotocin-induced diabetic rats. Nutr. Res. 2005, 25, 1061-1074. [CrossRef]

250. Ludwig, A.; Lorenz, M.; Grimbo, N.; Steinle, F.; Meiners, S.; Bartsch, C.; Stangl, K.; Baumann, G.; Stangl, V. The tea flavonoid epigallocatechin-3-gallate reduces cytokine-induced VCAM-1 expression and monocyte adhesion to endothelial cells. Biochem. Biophys. Res. Commun. 2004, 316, 659-665. [CrossRef]

251. Arola-Arnal, A.; Blade, C. Proanthocyanidins modulate microRNA expression in human HepG2 cells. PLOS ONE 2011, 6, e25982. [CrossRef]

252. Baselga-Escudero, L.; Blade, C.; Ribas-Latre, A.; Casanova, E.; Suarez, M.; Torres, J.L.; Salvado, M.J.; Arola, L.; Arola-Arnal, A. Resveratrol and EGCG bind directly and distinctively to miR-33a and miR-122 and modulate divergently their levels in hepatic cells. Nucleic Acids Res. 2014, 42, 882-892. [CrossRef] [PubMed]

253. Wang, H.; Bian, S.; Yang, C.S. Green tea polyphenol EGCG suppresses lung cancer cell growth through upregulating miR-210 expression caused by stabilizing HIF-1alpha. Carcinogenesis 2011, 32, 1881-1889. [CrossRef]

254. Kaelin, W.G., Jr.; Ratcliffe, P.J. Oxygen sensing by metazoans: The central role of the HIF hydroxylase pathway. Mol. Cell 2008, 30, 393-402. [CrossRef] [PubMed]

255. Jaiswal, N.; Akhtar, J.; Singh, S.P.; Badruddeen; Ahsan, F. An Overview on Genistein and its Various Formulations. Drug Res. 2019, 69, 305-313. [CrossRef] [PubMed]

256. Beavers, D.P.; Beavers, K.M.; Miller, M.; Stamey, J.; Messina, M.J. Exposure to isoflavone-containing soy products and endothelial function: A Bayesian meta-analysis of randomized controlled trials. Nutr. Metab. Cardiovasc. Dis. NMCD 2012, 22, 182-191. [CrossRef]

257. Yu, D.; Shu, X.O.; Li, H.; Yang, G.; Cai, Q.; Xiang, Y.B.; Ji, B.T.; Franke, A.A.; Gao, Y.T.; Zheng, W.; et al. Dietary isoflavones, urinary isoflavonoids, and risk of ischemic stroke in women. Am. J. Clin. Nutr. 2015, 102, 680-686. [CrossRef]

258. Si, H.; Liu, D. Genistein, a soy phytoestrogen, upregulates the expression of human endothelial nitric oxide synthase and lowers blood pressure in spontaneously hypertensive rats. J. Nutr. 2008, 138, 297-304. [CrossRef]

259. Zhang, H.P.; Zhao, J.H.; Yu, H.X.; Guo, D.X. Genistein ameliorated endothelial nitric oxidase synthase uncoupling by stimulating sirtuin-1 pathway in ox-LDL-injured HUVECs. Environ. Toxicol. Pharmacol. 2016, 42, 118-124. [CrossRef] 
260. Ras, R.T.; Streppel, M.T.; Draijer, R.; Zock, P.L. Flow-mediated dilation and cardiovascular risk prediction: A systematic review with meta-analysis. Int. J. Cardiol. 2013, 168, 344-351. [CrossRef]

261. Hazim, S.; Curtis, P.J.; Schar, M.Y.; Ostertag, L.M.; Kay, C.D.; Minihane, A.M.; Cassidy, A. Acute benefits of the microbial-derived isoflavone metabolite equol on arterial stiffness in men prospectively recruited according to equol producer phenotype: A double-blind randomized controlled trial. Am. J. Clin. Nutr. 2016, 103, 694-702. [CrossRef]

262. Park, M.H.; Ju, J.W.; Kim, M.; Han, J.S. The protective effect of daidzein on high glucose-induced oxidative stress in human umbilical vein endothelial cells. Z. für Naturforschung C J. Biosci. 2016, 71, 21-28. [CrossRef] [PubMed]

263. Setchell, K.D.; Clerici, C.; Lephart, E.D.; Cole, S.J.; Heenan, C.; Castellani, D.; Wolfe, B.E.; Nechemias-Zimmer, L.; Brown, N.M.; Lund, T.D.; et al. S-equol, a potent ligand for estrogen receptor beta, is the exclusive enantiomeric form of the soy isoflavone metabolite produced by human intestinal bacterial flora. Am. J. Clin. Nutr. 2005, 81, 1072-1079. [CrossRef] [PubMed]

264. Rowlands, D.J.; Chapple, S.; Siow, R.C.; Mann, G.E. Equol-stimulated mitochondrial reactive oxygen species activate endothelial nitric oxide synthase and redox signaling in endothelial cells: Roles for F-actin and GPR30. Hypertension 2011, 57, 833-840. [CrossRef] [PubMed]

265. Joy, S.; Siow, R.C.; Rowlands, D.J.; Becker, M.; Wyatt, A.W.; Aaronson, P.I.; Coen, C.W.; Kallo, I.; Jacob, R.; Mann, G.E. The isoflavone Equol mediates rapid vascular relaxation: Ca2+-independent activation of endothelial nitric-oxide synthase/Hsp90 involving ERK1/2 and Akt phosphorylation in human endothelial cells. J. Biol. Chem. 2006, 281, 27335-27345. [CrossRef]

266. Babu, P.V.; Si, H.; Fu, Z.; Zhen, W.; Liu, D. Genistein prevents hyperglycemia-induced monocyte adhesion to human aortic endothelial cells through preservation of the cAMP signaling pathway and ameliorates vascular inflammation in obese diabetic mice. J. Nutr. 2012, 142, 724-730. [CrossRef]

267. Han, S.; Wu, H.; Li, W.; Gao, P. Protective effects of genistein in homocysteine-induced endothelial cell inflammatory injury. Mol. Cell. Biochem. 2015, 403, 43-49. [CrossRef]

268. Xu, L.; Liu, J.T.; Li, K.; Wang, S.Y.; Xu, S. Genistein inhibits Ang II-induced CRP and MMP-9 generations via the ER-p38/ERK1/2-PPARgamma-NF-kappaB signaling pathway in rat vascular smooth muscle cells. Life Sci. 2019, 216, 140-146. [CrossRef]

269. Zhang, H.; Zhao, Z.; Pang, X.; Yang, J.; Yu, H.; Zhang, Y.; Zhou, H.; Zhao, J. Genistein Protects Against Ox-LDL-Induced Inflammation Through MicroRNA-155/SOCS1-Mediated Repression of NF-kB Signaling Pathway in HUVECs. Inflammation 2017, 40, 1450-1459. [CrossRef]

270. Gan, M.; Zheng, T.; Shen, L.; Tan, Y.; Fan, Y.; Shuai, S.; Bai, L.; Li, X.; Wang, J.; Zhang, S.; et al. Genistein reverses isoproterenol-induced cardiac hypertrophy by regulating miR-451/TIMP2. Biomed. Pharmacother. 2019, 112, 108618. [CrossRef]

271. Krga, I.; Milenkovic, D. Anthocyanins: From Sources and Bioavailability to Cardiovascular-Health Benefits and Molecular Mechanisms of Action. J. Agric. Food Chem. 2019, 67, 1771-1783. [CrossRef]

272. Eker, M.E.; Aaby, K.; Budic-Leto, I.; Brncic, S.R.; El, S.N.; Karakaya, S.; Simsek, S.; Manach, C.; Wiczkowski, W.; Pascual-Teresa, S. A Review of Factors Affecting Anthocyanin Bioavailability: Possible Implications for the Inter-Individual Variability. Foods 2019, 9, 2. [CrossRef] [PubMed]

273. Hollands, W.J.; Armah, C.N.; Doleman, J.F.; Perez-Moral, N.; Winterbone, M.S.; Kroon, P.A. 4-Week consumption of anthocyanin-rich blood orange juice does not affect LDL-cholesterol or other biomarkers of CVD risk and glycaemia compared with standard orange juice: A randomised controlled trial. Br. J. Nutr. 2018, 119, 415-421. [CrossRef] [PubMed]

274. Niculescu, L.S.; Sanda, G.M.; Simionescu, N.; Sima, A.V. Bilberries exert an anti-atherosclerotic effect in lipid-loaded macrophages. Cent. Eur. J. Biol. 2014, 9, 268-276. [CrossRef]

275. Farrell, N.; Norris, G.; Lee, S.G.; Chun, O.K.; Blesso, C.N. Anthocyanin-rich black elderberry extract improves markers of HDL function and reduces aortic cholesterol in hyperlipidemic mice. Food Funct. 2015, 6, 1278-1287. [CrossRef] [PubMed]

276. Wallace, T.C.; Slavin, M.; Frankenfeld, C.L. Systematic Review of Anthocyanins and Markers of Cardiovascular Disease. Nutrients 2016, 8, 32. [CrossRef] [PubMed]

277. Sorrenti, V.; Mazza, F.; Campisi, A.; Di Giacomo, C.; Acquaviva, R.; Vanella, L.; Galvano, F. Heme oxygenase induction by cyanidin-3-O-beta-glucoside in cultured human endothelial cells. Mol. Nutr. Food Res. 2007, 51, 580-586. [CrossRef] 
278. Xu, J.W.; Ikeda, K.; Yamori, Y. Upregulation of endothelial nitric oxide synthase by cyanidin-3-glucoside, a typical anthocyanin pigment. Hypertension 2004, 44, 217-222. [CrossRef]

279. Kennedy, M.A.; Barrera, G.C.; Nakamura, K.; Baldan, A.; Tarr, P.; Fishbein, M.C.; Frank, J.; Francone, O.L.; Edwards, P.A. ABCG1 has a critical role in mediating cholesterol efflux to HDL and preventing cellular lipid accumulation. Cell Metab. 2005, 1, 121-131. [CrossRef]

280. Terasaka, N.; Yu, S.; Yvan-Charvet, L.; Wang, N.; Mzhavia, N.; Langlois, R.; Pagler, T.; Li, R.; Welch, C.L.; Goldberg, I.J.; et al. ABCG1 and HDL protect against endothelial dysfunction in mice fed a high-cholesterol diet. J. Clin. Investig. 2008, 118, 3701-3713. [CrossRef]

281. Huang, W.; Zhu, Y.; Li, C.; Sui, Z.; Min, W. Effect of Blueberry Anthocyanins Malvidin and Glycosides on the Antioxidant Properties in Endothelial Cells. Oxid. Med. Cell. Longev. 2016, 2016, 1591803. [CrossRef]

282. Paixao, J.; Dinis, T.C.; Almeida, L.M. Malvidin-3-glucoside protects endothelial cells up-regulating endothelial NO synthase and inhibiting peroxynitrite-induced NF-kB activation. Chem.-Biol. Interact. 2012, 199, $192-200$. [CrossRef] [PubMed]

283. Huang, T.W.; Chang, C.L.; Kao, E.S.; Lin, J.H. Effect of Hibiscus sabdariffa extract on high fat diet-induced obesity and liver damage in hamsters. Food Nutr. Res. 2015, 59, 29018. [CrossRef] [PubMed]

284. Davinelli, S.; Bertoglio, J.C.; Zarrelli, A.; Pina, R.; Scapagnini, G. A Randomized Clinical Trial Evaluating the Efficacy of an Anthocyanin-Maqui Berry Extract (Delphinol(R)) on Oxidative Stress Biomarkers. J. Am. Coll. Nutr. 2015, 34 (Suppl. S1), 28-33. [CrossRef] [PubMed]

285. Jennings, A.; Welch, A.A.; Fairweather-Tait, S.J.; Kay, C.; Minihane, A.M.; Chowienczyk, P.; Jiang, B.; Cecelja, M.; Spector, T.; Macgregor, A.; et al. Higher anthocyanin intake is associated with lower arterial stiffness and central blood pressure in women. Am. J. Clin. Nutr. 2012, 96, 781-788. [CrossRef]

286. Chen, C.Y.; Yi, L.; Jin, X.; Zhang, T.; Fu, Y.J.; Zhu, J.D.; Mi, M.T.; Zhang, Q.Y.; Ling, W.H.; Yu, B. Inhibitory effect of delphinidin on monocyte-endothelial cell adhesion induced by oxidized low-density lipoprotein via ROS/p38MAPK/NF-kappaB pathway. Cell Biochem. Biophys. 2011, 61, 337-348. [CrossRef]

287. Lee, Y.; Lee, J.Y. Blackcurrant (Ribes nigrum) Extract Exerts an Anti-Inflammatory Action by Modulating Macrophage Phenotypes. Nutrients 2019, 11, 975. [CrossRef] [PubMed]

288. Rodriguez-Mateos, A.; Istas, G.; Boschek, L.; Feliciano, R.P.; Mills, C.E.; Boby, C.; Gomez-Alonso, S.; Milenkovic, D.; Heiss, C. Circulating Anthocyanin Metabolites Mediate Vascular Benefits of Blueberries: Insights From Randomized Controlled Trials, Metabolomics, and Nutrigenomics. J. Gerontol. Ser. A 2019, 74, 967-976. [CrossRef] [PubMed]

289. Marques, C.; Fernandes, I.; Norberto, S.; Sa, C.; Teixeira, D.; de Freitas, V.; Mateus, N.; Calhau, C.; Faria, A. Pharmacokinetics of blackberry anthocyanins consumed with or without ethanol: A randomized and crossover trial. Mol. Nutr. Food Res. 2016, 60, 2319-2330. [CrossRef] [PubMed]

290. Singletary, K. Ginger: An Overview of Health Benefits. Nutr. Today 2010, 45, 171-183. [CrossRef]

291. Arablou, T.; Aryaeian, N.; Valizadeh, M.; Sharifi, F.; Hosseini, A.; Djalali, M. The effect of ginger consumption on glycemic status, lipid profile and some inflammatory markers in patients with type 2 diabetes mellitus. Int. J. Food Sci. Nutr. 2014, 65, 515-520. [CrossRef]

292. Santos Braga, S. Ginger: Panacea or Consumer's Hype? Appl. Sci. 2019, 9, 1570. [CrossRef]

293. Gao, H.; Guan, T.; Li, C.; Zuo, G.; Yamahara, J.; Wang, J.; Li, Y. Treatment with ginger ameliorates fructose-induced Fatty liver and hypertriglyceridemia in rats: Modulation of the hepatic carbohydrate response element-binding protein-mediated pathway. Evid.-Based Complement. Altern. Med. eCAM 2012, 2012, 570948. [CrossRef] [PubMed]

294. Carnuta, M.G.; Deleanu, M.; Barbalata, T.; Toma, L.; Raileanu, M.; Sima, A.V.; Stancu, C.S. Zingiber officinale extract administration diminishes steroyl-CoA desaturase gene expression and activity in hyperlipidemic hamster liver by reducing the oxidative and endoplasmic reticulum stress. Phytomedicine 2018, 48, 62-69. [CrossRef] [PubMed]

295. Lei, L.; Liu, Y.; Wang, X.; Jiao, R.; Ma, K.Y.; Li, Y.M.; Wang, L.; Man, S.W.; Sang, S.; Huang, Y.; et al. Plasma cholesterol-lowering activity of gingerol- and shogaol-enriched extract is mediated by increasing sterol excretion. J. Agric. Food Chem. 2014, 62, 10515-10521. [CrossRef] [PubMed]

296. Misawa, K.; Hashizume, K.; Yamamoto, M.; Minegishi, Y.; Hase, T.; Shimotoyodome, A. Ginger extract prevents high-fat diet-induced obesity in mice via activation of the peroxisome proliferator-activated receptor delta pathway. J. Nutr. Biochem. 2015, 26, 1058-1067. [CrossRef] 
297. Semwal, R.B.; Semwal, D.K.; Combrinck, S.; Viljoen, A.M. Gingerols and shogaols: Important nutraceutical principles from ginger. Phytochemistry 2015, 117, 554-568. [CrossRef]

298. Toma, L.; Raileanu, M.; Deleanu, M.; Stancu, C.S.; Sima, A.V. Novel molecular mechanisms by which ginger extract reduces the inflammatory stress in TNF $\alpha$-Activated human endothelial cells; decrease of Ninjurin-1, TNFR1 and NADPH oxidase subunits expression. J. Funct. Foods 2018, 48, 654-664. [CrossRef]

299. Wang, Y.K.; Hong, Y.J.; Yao, Y.H.; Huang, X.M.; Liu, X.B.; Zhang, C.Y.; Zhang, L.; Xu, X.L. 6-Shogaol Protects against Oxidized LDL-Induced Endothelial Injruries by Inhibiting Oxidized LDL-Evoked LOX-1 Signaling. Evid.-Based Complement. Altern. Med. eCAM 2013, 2013, 503521. [CrossRef]

300. Lee, T.Y.; Lee, K.C.; Chen, S.Y.; Chang, H.H. 6-Gingerol inhibits ROS and iNOS through the suppression of PKC-alpha and NF-kappaB pathways in lipopolysaccharide-stimulated mouse macrophages. Biochem. Biophys. Res. Commun. 2009, 382, 134-139. [CrossRef]

301. Ho, S.C.; Chang, Y.H. Comparison of Inhibitory Capacities of 6-, 8- and 10-Gingerols/Shogaols on the Canonical NLRP3 Inflammasome-Mediated IL-1beta Secretion. Molecules 2018, 23, 466. [CrossRef]

302. Wang, S.; Tian, M.; Yang, R.; Jing, Y.; Chen, W.; Wang, J.; Zheng, X.; Wang, F. 6-Gingerol Ameliorates Behavioral Changes and Atherosclerotic Lesions in ApoE(-/-) Mice Exposed to Chronic Mild Stress. Cardiovasc. Toxicol. 2018, 18, 420-430. [CrossRef]

303. Li, J.; Wang, S.; Yao, L.; Ma, P.; Chen, Z.; Han, T.L.; Yuan, C.; Zhang, J.; Jiang, L.; Liu, L.; et al. 6-gingerol ameliorates age-related hepatic steatosis: Association with regulating lipogenesis, fatty acid oxidation, oxidative stress and mitochondrial dysfunction. Toxicol. Appl. Pharmacol. 2019, 362, 125-135. [CrossRef] [PubMed]

304. Kim, S.; Lee, M.S.; Jung, S.; Son, H.Y.; Park, S.; Kang, B.; Kim, S.Y.; Kim, I.H.; Kim, C.T.; Kim, Y. Ginger Extract Ameliorates Obesity and Inflammation via Regulating MicroRNA-21/132 Expression and AMPK Activation in White Adipose Tissue. Nutrients 2018, 10, 1567. [CrossRef]

305. Nelson, K.M.; Dahlin, J.L.; Bisson, J.; Graham, J.; Pauli, G.F.; Walters, M.A. The Essential Medicinal Chemistry of Curcumin. J. Med. Chem. 2017, 60, 1620-1637. [CrossRef] [PubMed]

306. Baell, J.; Walters, M.A. Chemistry: Chemical con artists foil drug discovery. Nature 2014, 513, 481-483. [CrossRef] [PubMed]

(C) 2020 by the authors. Licensee MDPI, Basel, Switzerland. This article is an open access article distributed under the terms and conditions of the Creative Commons Attribution (CC BY) license (http://creativecommons.org/licenses/by/4.0/). 